\title{
Uma Ferramenta de Apoio à Utilização de Statecharts para Especificação do Comportamento de Sistemas de Tempo-Real Complexos
}

\author{
Renata Pontin de Mattos Fortes
}

Orientação: Prof. Dr. Paulo Cesar Masiero

Dissertação apresentada ao Instituto de Ciências Matemáticas de São Carlos USP como parte dos requisitos para obtenção do título de Mestre em Ciências de Computação e Matemática Computacional. 
Aos meus pais que sempre me apoiaram em meus estudos.

Ao Fábio pelo carinho e compreensão.

Aos meus filhos Gustavo e Laura pelas alegrias do dia-a-dia. 


\section{Agradecimentos}

Ao Professor Dr. Paulo Cesar Masiero pela orientação e apoio durante o desenvolvimento deste trabalho.

Às Professoras Dra. Marielza J. Favaro e Dra. M. Carolina Monard pela confiança que sempre depositaram no meu esforço.

Às amigas Agma, Graça, Sandra e Solange, pelo constante apoio e ao Dario a Silvia por todo incentivo.

Ao colega João E. S. Batista, pelas valiosas sugestões, discussões e ajuda durante o desenvolvimento do trabalho.

Às secretarias de Pós-Graduação e do SCE pela eficiência e dedicação. 


\section{RESUMO}

Uma das características dos Sistemas de Tempo-Real é a sua reação imediata a estímulos (eventos) ocorridos no mundo real. Os métodos para especificação e projeto de STRs sugerem o uso de técnicas para especificação desse comportamento reativo dos STRs.

Nesta dissertação faz-se uma revisão bibliográfica de vários métodos para especificação de STRs, verificando-se quais são as técnicas usadas para especificação do aspecto comportamental. Uma dessas técnicas, STATECHARTS, foi escolhida para apoio por Computador. O trabalho descreve uma ferramenta desenvolvida para esse fim.

São discutidos também os requisitos que levaram à construção da ferramenta e mostrada sua arquitetura. Exemplifica-se o uso da ferramenta em um caso abrangente, enfatizando-se as características principais dos Statecharts.

\footnotetext{
ABSTRACT

One of the special features of Real Time Systems is its immediate reaction to real world stimuli. The methods for specification and design of RTSs propose the use of techniques for this reactive behavior specification.

A comprehensive bibliographic review about RTSs specification methods is done in this thesis. As a result the techniques used in these methods for behavior specification have been assessed and one of them, the STATECHARTS, has been chosen to be supported through a tool developed to this end.

The tool requirements and its arquitecture have also been discussed. The tool's usability has been shown, emphasizing its main features and applying it to a typical case.
} 


\section{Conteúdo}

1 INTRODUÇÃO 1

1.1 Objetivos do Trabalho . . . . . . . . . . . . 1

1.2 Organização da dissertação . . . . . . . . . . . 2

2 FUNDAMENTOS PARA O DESENVOLVIMENTO DE STR 4

2.1 Considerações Iniciais $\ldots \ldots \ldots \ldots \ldots \ldots \ldots$

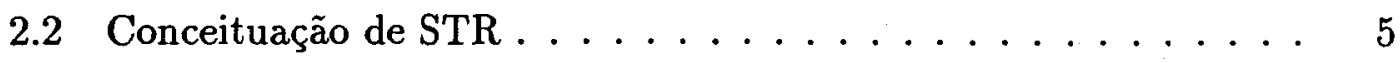

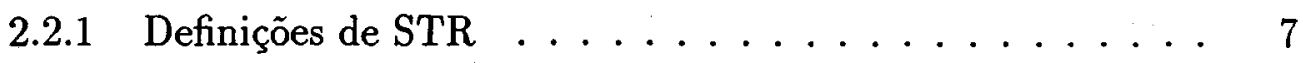

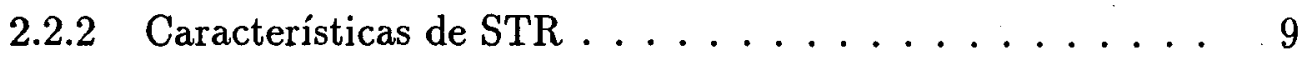

2.2.3 Domínios de Aplicação de STR . . . . . . . . . . 10

2.2.4 Principais Componentes do software de STR . . . . . . 11

$2.2 .5 \quad$ Tipos de STR . . . . . . . . . . . . . 13

2.3 Métodos e Técnicas para Desenvolvimento de STR . . . . . . 15

2.3.1 Revisão Bibliográfica dos Métodos e Técnicas . . . . . . 17

2.3.2 Ferramentas de Apoio por Computador . . . . . . . . 31

2.3.3 Análise dos Métodos e Técnicas . . . . . . . . . . 33

2.4 Conclusões $\ldots \ldots \ldots \ldots \ldots \ldots \ldots \ldots \ldots \ldots \ldots \ldots$ 


\section{A FERRAMENTA DESENVOLVIDA: UM SIMULADOR DE STATECHARTS}

3.1 Considerações Iniciais . . . . . . . . . . . . . . . . . 39

3.2 A Técnica de Especificação de Comportamento de STR: STATECHARTS .................... 40

3.3 Aspectos selecionados do Projeto da Ferramenta . . . . . . . . . 51

3.4 Arquitetura da Ferramenta Implementada . . . . . . . . . . 62

3.5 Decisões de Projeto . . . . . . . . . . . . . . . 73

3.6 Aspectos da Implementação da Ferramenta . . . . . . . . . 75

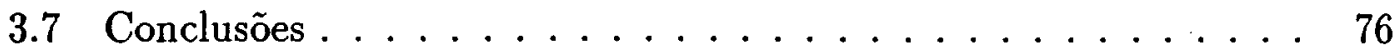

4 UM EXEMPLO DE USO DA FERRAMENTA

4.1 Considerações Iniciais . . . . . . . . . . . . . . . . 77

4.2 A Interface da Ferramenta . . . . . . . . . . . . 77

4.3 Exemplo de Especificação em STATECHARTS . . . . . . . . . . 83

4.4 Uma Demonstração de Utilização da Ferramenta . . . . . . . . . . 89

4.5 Conclusões $\ldots \ldots \ldots \ldots \ldots \ldots \ldots$

5 CONCLUSÕES 101

5.1 Considerações Iniciais $\ldots \ldots \ldots \ldots \ldots$

5.2 Avaliação da Ferramenta . . . . . . . . . . . . . . 102

5.3 Sugestões para futuras pesquisas $\ldots \ldots \ldots \ldots \ldots$

Bibliografia

A Gramática da Linguagem de Especificação de Statecharts (LES)108

B Tipos de dados das Estruturas Internas da Especificação em 


\section{Capítulo 1}

\section{INTRODUÇÃO}

\subsection{Objetivos do Trabalho}

O interesse por métodos e técnicas para auxiliar o desenvolvimento de Sistemas de Tempo-Real ${ }^{1}$ tem crescido acentuadamente nas últimas duas décadas, paralelamente ao avanço da tecnologia de hardware.

Esse interesse crescente deve-se principalmente ao fato de que o desenvolvimento de STR é necessário no âmbito tanto de empresas que desenvolvem e comercializam o STR como produto final, quanto das que se utilizam de STRs como suporte para o desenvolvimento de um outro produto que necessita de controle no decorrer do seu processo de desenvolvimento ou utilização.

As primeiras empresas citadas necessitam de um método que auxilie na otimização dos esforços empregados no desenvolvimento de cada novo produto, ou seja, de cada novo STR. Esse método deve ser tal que forneça subsídios para que haja reaproveitamento das soluções testadas na prática, a cada novo requisito.

O segundo tipo de empresa citado, que utiliza STR como uma ferramenta, freqüentemente se vê diante do problema de ter que alterá-lo. As alterações refletem as mudanças originadas de modificações na especificação do produto, durante o desenvolvimento do produto ou após sua liberação para comercialização. Isso requer que o STR e sua documentação estejam em perfeita sintonia com o estado do produto, de forma a otimizar e tornar segura as manutenções.

\footnotetext{
${ }^{1}$ Para a redação e leitura ao longo deste trabalho, o termo "Sistema de Tempo-Real" será denotado também pela sigla STR.
} 
$\mathrm{O}$ aspecto de segurança na manutenção assume proporções maiores em STR. Isso porque, muitas vezes, os processos de fabricação ou utilização envolvidos requerem algum controle perigoso ou operam com medidas que exigem precisão acima dos limites do ser humano. Como exemplo, podem ser citadas empresas metalúrgicas que possuem um produto final (por exemplo, uma fábrica de redução de alumínio), cujo processo de desenvolvimento (ou de produção) requer um controle perigoso ao ser humano (por exemplo, lidar com alta temperatura); sistemas de aviação, etc.

Este trabalho tem como objetivo principal o estudo das técnicas utilizadas para especificar o comportamento de STRs e o desenvolvimento de uma ferramenta de apoio à especificação e simulação de uma dessas técnicas, a técnica STATECHARTS (Estadogramas), que é um tipo especial de diagrama de estado.

Para a escolha da técnica tratada neste trabalho, foram estudados 12 (doze) métodos para desenvolvimento de STRs, juntamente com suas técnicas particulares. Estes foram os métodos mais freqüentemente citados na literatura. Também foram analisadas as suas características principais. Verificou-se que a maior parte dos métodos utiliza o conceito de estados e transições como técnica básica para modelar o comportamento dinâmico dos sistemas.

O objetivo inicial da ferramenta foi o de permitir a visualização do comportamento dinâmico dos Statecharts, uma vez que isso é relativamente difícil de ser feito sem o apoio de um meio automatizado, principalmente no caso de sistemas complexos.

Dessa forma, além de diminuir o grau de complexidade relativo à representação do comportamento de STR, a ferramenta torna-se um meio para assegurar que a representação proposta pelos analistas e projetistas de tais sistemas é um modelo preciso do sistema sob investigação.

Isso é de grande interesse para os analistas, tanto quanto para os usuários, pois é mais econômico detectarem-se os problemas de um modelo enquanto este estiver sendo elaborado, do que quando já estiver sendo implementado, ou quando o sistema estiver em uso.

\subsection{Organização da dissertação}

Após este capítulo introduzindo este trabalho, o capitulo 2 apresenta uma revisão da bibliografia relevante disponível sobre métodos e técnicas para Análise e Projeto de STRs. A revisão é completada com a apresentação de alguns 
conceitos básicos e fundamentos utilizados nesse tipo de sistemas.

No segundo capítulo são analisados doze métodos, que juntamente com suas técnicas, oferecem um panorama das preocupações mais comuns e importantes durante o processo de desenvolvimento e manutenção de STRs. A avaliação do aspecto dinâmico (ou comportamental) dos sistemas, que os métodos propõem, foi o alvo principal para o levantamento bibliográfico realizado.

Baseando-se nos argumentos encontrados na literatura relativos às técnicas de representação comportamental dos STR, a técnica STATECHARTS foi selecionada, por sua flexibilidade, para que fosse implementado um sistema (ferramenta) de apoio à sua utilização.

No capítulo 3 são apresentados alguns aspectos selecionados do projeto da ferramenta e a arquitetura geral que a descreve. A técnica STATECHARTS para representação da dinâmica dos sistemas é então descrita de maneira a formular os requisitos para o desenvolvimento da ferramenta.

O capítulo 4 ilustra, com um exemplo, a utilização da ferramenta. São feitas as diversas transformações internas por que passam os dados, a partir da especificação fornecida em forma textual.

No capítulo 5 encontram-se as conclusões finais sobre o projeto desenvolvido e uma avaliação da ferramenta resultante, bem como sugestões para novas pesquisas e extensões à ferramenta. 


\section{Capítulo 2}

\section{FUNDAMENTOS PARA O DESENVOLVIMENTO DE STR}

\subsection{Considerações Iniciais}

A quantidade de métodos e técnicas para o desenvolvimento de STR tem sido ampliada devido a fatores tais como:

- nenhum dos métodos e técnicas é suficientemente consagrado, ou

- nenhum método ou técnica satisfaz todos os requisitos requeridos para tais sistemas, ou

- os STRs são muito particulares a cada aplicação a que se destinam.

Portanto, muitos analistas e projetistas sentem algumas dificuldades na aplicação de métodos e técnicas para o desenvolvimento de STR.

Neste capítulo, num primeiro esforço para investigar essas dificuldades, serão introduzidos os conceitos gerais de STRs. Para isso, algumas definições de STRs existentes na literatura são reproduzidas e, a seguir, são analisados os pontos genéricos desse tipo de sistema.

Ao final do capítulo é apresentado um conjunto de métodos e técnicas de desenvolvimento de STR, bem como uma análise de suas características mais importantes. 


\subsection{Conceituação de STR}

Segundo Mellichamp, em [Mell83], a Computação de Tempo-Real é um daqueles termos genéricos que possui diferentes significados para diferentes tipos de pessoas.

No entanto, existe um consenso de que o termo implica a utilização de um computador em conjunção com algum "processo" (ou processos) externo.

O conceito de processo é usado num sentido bastante amplo e a princípio sempre envolve operações sequenciais, como as de uma ferramenta de laboratório, ou operações paralelas continuas, como as de um processo químico, ou alguma combinação de ambas. Estas operações, èm geral, possuem entradas a manipular ou controlar e geram saídas, que por sua vez podem ser monitoradas. Pode-se descrever processo como sendo esquematicamente :

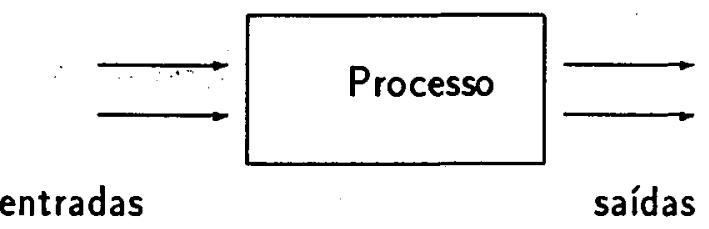

Os objetivos da interconexão entre computador e processo são:

- obter informações do processo (monitorar sua operação através de medidas de variáveis importantes)

- poder manipular o processo (direta ou indiretamente) de alguma maneira (controlar o modo de operação do processo, baseado nas informações previamente obtidas).

Apesar da enorme variedade de propriedades (escala, configuração, propósito, etc.) embutidas em todos os processos, desde um simples instrumento de laboratório até o de uma complexa refinaria de petróleo, um STR pode ser visto esquematicamente como: 


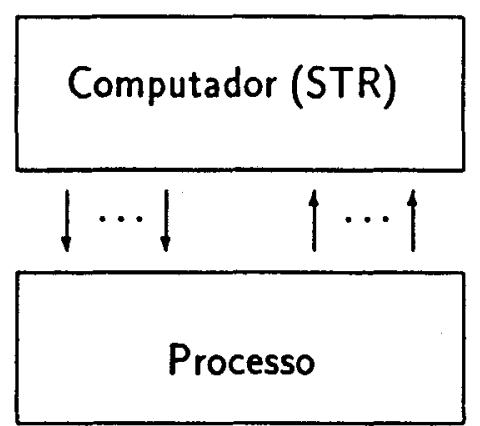

A interconexão (ou "conexão", para descrever a ligação física), representada pelas flechas, indica o fluxo de informação entre o computador e o processo.

Todos os processos operam dentro de suas escalas de tempo próprias. Para se conseguir a interconexão entre o computador e o processo, as operações envolvendo o computador devem ser baseadas nas operações do processo, levandose em conta seus tempos.

Dessa forma, deve-se projetar e programar o computador para que ele possa conservar o aspecto "tempo-real", independentemente de suas operações internas.

O tempo-real, que na realidade é o familiar sistema de medidas de horas, minutos, segundos, frações de segundos, etc., é o padrão de referência em que o computador inicia ações e registra resultados relativos ao processo externo conectado.

O conceito de tempo-real também se refere à habilidade do computador responder suficientemente rápido a estímulos provenientes do processo de acordo com as necessidades deste. Outra característica importante é o meio físico de conexão entre computador e processos. Para essa interface existem os equipamentos de medidas, transdução, conversão e amostragem, que transformam a maioria dos dados do processo, incluindo a variedade de tipos de dados analógicos, para uma forma legivel aos computadores digitais. 


\subsubsection{Definiçōes de STR}

Algumas definições reproduzidas a seguir mostram o amadurecimento dos termos, nestas duas últimas décadas, das definições relativas a STRs :

"Processamento em tempo-real é o processamento de dados que percebe os dados controlados externamente, que não são prontamente reproduziveis, e tem a capacidade de responder exercendo um controle direto efetivo para produzir um resultado físico." [Saff75]

Esta definição de Saffer, é datada como das primeiras. Segundo o autor, as duas características acima não precisam estar presentes no mesmo sistema para que ele seja classificado como um STR.

A caracteristica principal dos STR é tanto o aspecto das entradas ser de controle externo ao computador quanto o aspecto de controle que o computador exerce sobre o processo, que quando existe, é direto. Um exemplo de controle direto, citado pelo autor, é a atuação imediata de um alarme em resposta a alguma irregularidade no sistema que está sendo monitorado.

"O Sistema de Tempo-Real tanto reage quanto afeta o ambiente em que está operando". [Allw81]

Por conveniência, Allworth divide o STR em duas partes: o Sistema Controlado e o Sistema Controlador. O primeiro sistema consiste do hardware das máquinas que comporão a parte do STR que se comunica com o ambiente externo. $\mathrm{O}$ segundo sistema consiste do software, juntamente com seu hardware de processamento associado, isto é, o computador.

O autor destaca que uma descrição de STR deve considerar o fato de que é um sistema de controle. Além disso, o projeto do sistema Controlado é muito dependente do STR como um todo, enquanto a atividade de projetar o sistema Controlador pode ser generalizada.

É importante mencionar que, segundo Allworth, em [Allw81], o evento para o STR pode ser, por exemplo, qualquer ocorrência no sistema Controlado ou Controlador que resulta numa mudança no estado do sistema.

Em sua tese de Doutorado, White, em [Whit87], classifica os sistemas computadorizados em geral por: 
- Tipo de Interface Homem-Máquina (IHM)

- Domínio

- Orientação principal

- Severidade nos requisitos de Tempo

- Hardware

A classificação por Domínio indica o tipo de aplicação a que se destina o sistema resultante. Segundo essa classificação, os sistemas podem ser baseados em Transações ou podem ser Reativos.

Os sistemas baseados em Transações são aqueles que transformam dados e suas funções são norteadas por essas transformações. Já um sistema Reativo, segundo Harel, em [Hare87a], é caracterizado por ser dirigido-a-evento, continuamente tendo que reagir a estímulos externos e internos. Como exemplos de sistemas Reativos, são citados: sistemas de telefonia, automóveis, redes de comunicação, Sistemas Operacionais, sistemas de aviação e de mísseis e a IHM de muitos tipos de software.

Quanto à Orientação principal, embora a maioria dos sistemas possua ambos: dados e controles, existe geralmente uma predominância de um deles em seu funcionamento. Os sistemas baseados em Transações são principalmente orientados a dados e possuem bases de dados ou arquivos de grande porte, enquanto os sistemas Reativos são principalmente orientados a controle e devem responder a, e controlar, eventos externos.

Tipos de restrição de tempo são: não de tempo-real, de tempo-real e de tempo-real rígido. Sistemas de Tempo-Real são sistemas que devem responder rapidamente aos eventos ambientais, ou devem periodicamente atualizar dados dentro de um certo tempo.

Os sistemas que operam num ambiente de tempo-real rígido (também conhecidos por sistemas embutidos) devem continuamente responder sob restrições críticas de tempo e, caso isto não ocorra, os resultados podem ser catastróficos.

De maneira simples, podemos dizer, baseados em nossa experiência profissional, que os Sistemas de Tempo-Real, como a própria denominação já o diz, são SISTEMAS, cuja principal característica é a de ocorrer na realidade, isto é, no mundo real, interagindo com o ambiente externo, e no tempo real, com seu dimensionamento preciso e sua característica de não voltar atrás. 


\subsubsection{Características de STR}

Um STR possui, tipicamente, as seguintes características, segundo Bennett, em [Benn90]:

- múltiplas entradas: eventos discretos ocorrendo a qualquer momento, ou valores de dados que mudam continuamente, ou valores de dados discretos.

- múltiplas saídas: eventos discretos, ou valores de dados que mudam continuamente, ou valores de dados discretos.

- temporização: as açôes tem que ser realizadas dentro de uma escala de tempo ditada pelo ambiente ou em sincronismo com o ambiente. Formalmente os requisitos dos STRs podem ser expressos por :

- a seqüência de computação é determinada pela passagem de tempo ou pelos eventos externos ao computador

- os resultados de cálculos particulares pode depender do valor de alguma variável "tempo" no instante de execução dos cálculos

- a operação correta do software depende do tempo gasto para a realização da computação.

- estado do sistema: as ações executadas sobre as entradas podem mudar de acordo com:

- o estado interno do programa, ou

- o estado do ambiente

- $\mathrm{e}$ as entradas podem mudar o estado interno do sistema.

A partir desta caracterização, Bennett apresentou a figura 2.1, mostrando um possível modelo da Máquina de Estados Finitos que representa um STR.

Quirck, em [Quir85], também aponta duas características principais que devem ser consideradas em qualquer descrição de STR :

- Todo STR é um sistema de estímulo-resposta (causa-efeito) onde as restrições de tempo existem paralelamente às relações de estímulo-resposta.

- O STR é um sistema que muitas vezes consiste de uma combinação de eventos, onde vários deles podem ocorrer em qualquer ordem. 


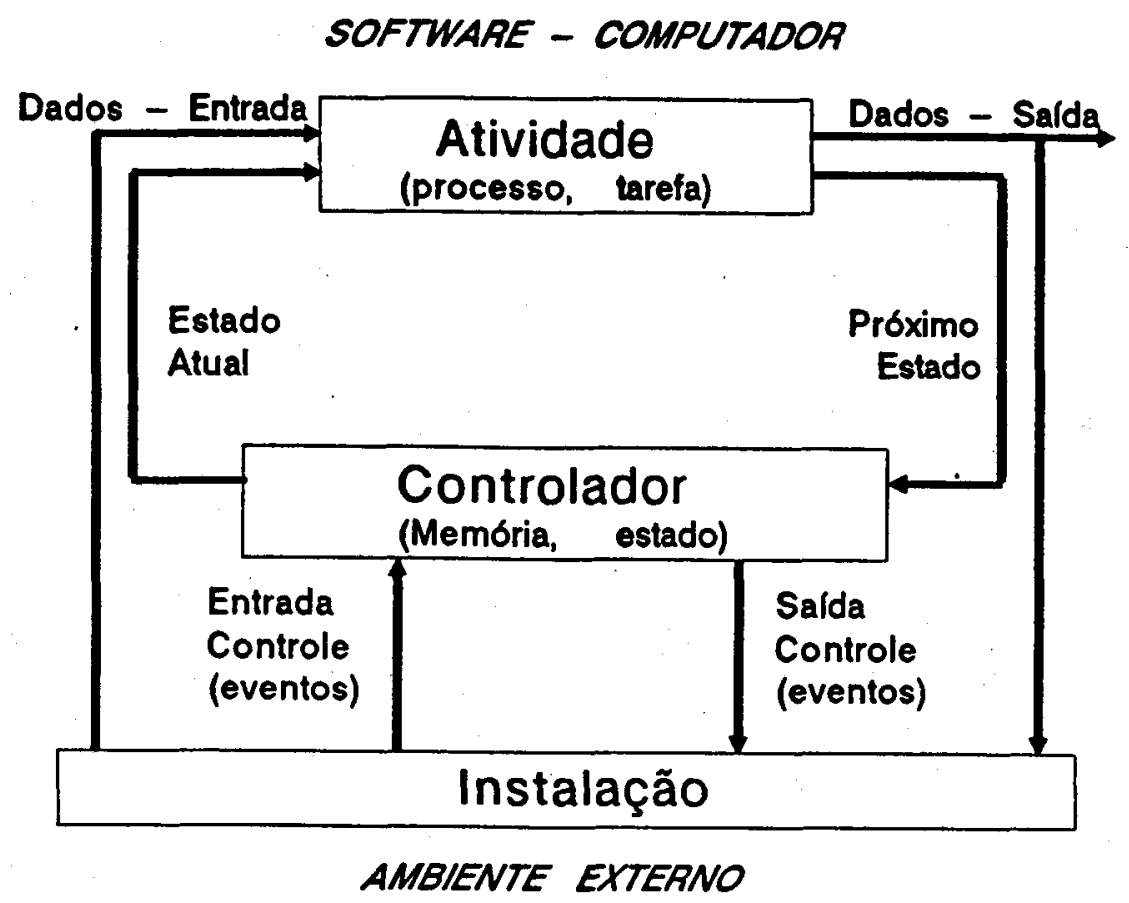

Figura 2.1: Máquina de Estados Finitos do STR

\subsubsection{Domínios de Aplicação de STR}

O conteúdo e o determinismo da informação são os fatores importantes na determinação da natureza da aplicação, isto é, o Domínio da Aplicação, segundo Pressman, em [Pres87].

O conteúdo da informação diz respeito ao significado e à forma das informações recebidas e produzidas pela aplicação.

$O$ determinismo da informação se refere à previsibilidade da ordem e hora de chegada dos dados de entrada. Um programa de análise de Engenharia aceita dados que possuem uma ordem pré-definida, executa o algorítmo de análise sem interrupção, e produz os dados resultantes em um relatório ou em algum outro formato estabelecido. Tais aplicações são determinísticas.

Por outro lado, existem sistemas que aceitam entradas de conteúdo variado e hora arbitrária; executam algorítmos que podem ser interrompidos por condições externas; e produzem saídas em função do ambiente e da hora. Estas aplicações são não determinísticas.

Como os STRs são sistemas que possuem software que lida com even- 
tos do mundo real conforme eles ocorrem no chamado tempo real, então STR são sistemas cujos domínios são não determinísticos.

Devido ao fato de Allworth, em [Allw81], colocar os STR sob o ponto de vista de sistema Controlado e sistema Controlador, o Domínio de Aplicações pode também ser visto separadamente.

Para o sistema Controlado, a configuração e o comportamento de seus elementos variam com o propósito do sistema. Por exemplo, em um ambiente de processamento de dados, esses elementos podem ser terminais, acionadores de discos (disk drivers) ou impressoras; em um ambiente de telecomunicações, podem ser multiplexadores, controladores de linha (line drivers) e teleimpressoras; ou ainda, em um ambiente de controle de processos, podem ser válvulas, relés ou alimentadores.

Observa-se que, geralmente, além desses elementos não funcionarem de forma completamente independentes uns dos outros, o projeto do sistema Controlado, que se compõe deles, é dependente do Sistema Controlador ao qual o sistema se refere. O sistema Controlador, constituido do elemento de software do sistema, pode ser projetado mais genericamente.

O fato de um STR estar trabalhando como um elemento de controle, se torna evidente quando se consideram as áreas de aplicação dos STR.

\subsubsection{Principais Componentes do software de STR}

Pressman, em [Pres87], cita as principais componentes do software, que a maioria dos STR possui:

- Aquisição de dados, que coleta e formata informações oriundas do ambiente externo.

- Análise, que transforma a informação conforme requerido pela aplicação.

- Saída ou Controle, que responde ao ambiente externo.

- Monitoração, que coordena todas as outras componentes para que a resposta em tempo-real possa ser satisfeita.

Em geral, cabe à componente de Monitoração o cumprimento da exatidão dos quesitos de desempenho requeridos pelo software. Esta componente 


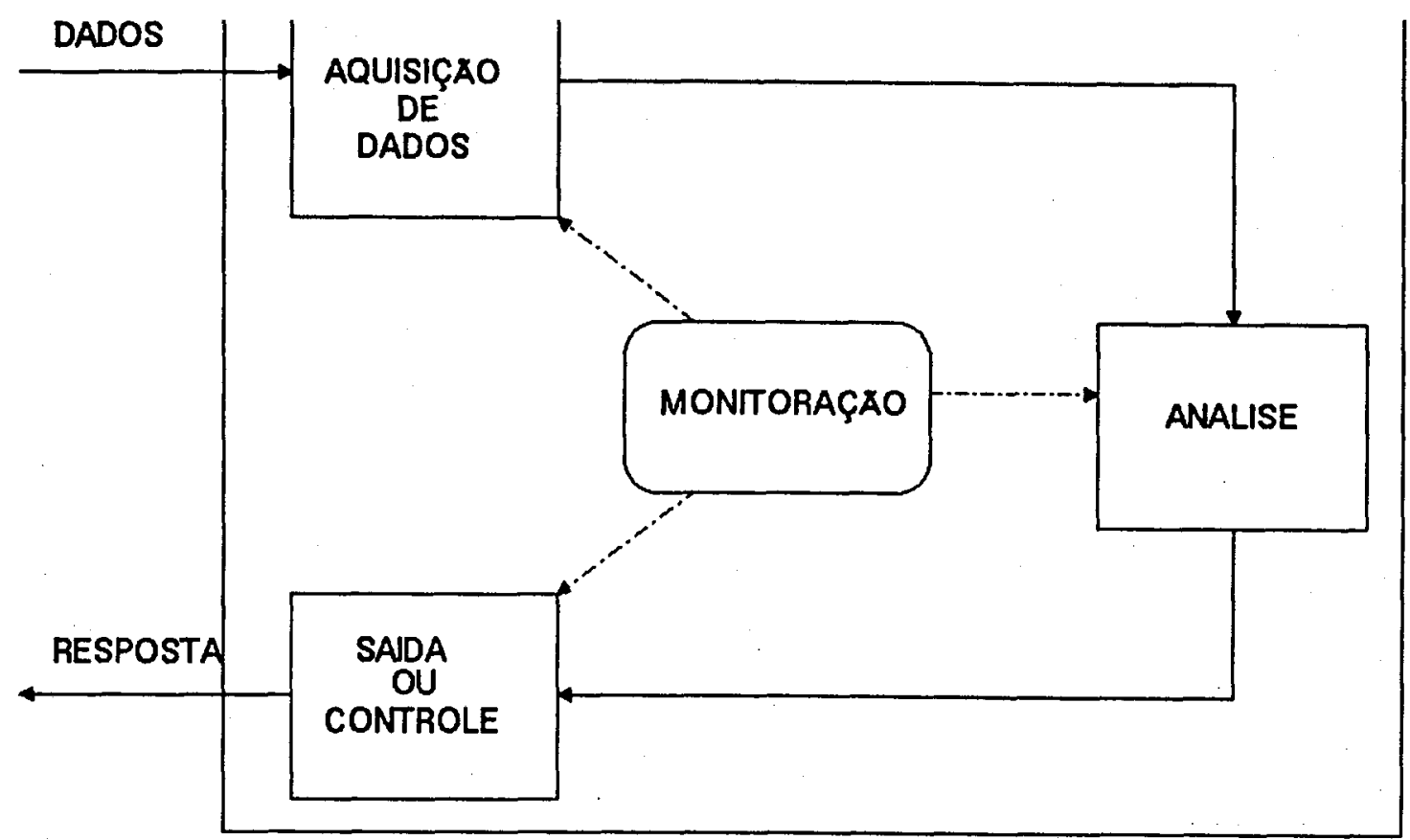

Figura 2.2: Principais Componentes de software de STR

possui a função de Supervisor ou Controlador das demais, cuidando do comportamento que se espera do STR. A figura 2.2 representa as comunicações entre essas componentes.

As características dos programas de STRs, enumeradas abaixo, são relacionadas por Quirck, em [Quir85]:

1. A seqüência e hora das entradas são determinados pelo mundo real e não pelo programador. Portanto, o programa precisa estar preparado para o inesperado e as demandas feitas pelo sistema podem ser conflitantes.

2. As demandas do sistema podem ocorrer em paralelo ao invés de seqüencialmente. Isto significa que o padrão de processamento de um sistema de tempo-real é tipicamente paralelo, com concorrência real ou virtual e, além disso, existem aspectos de sincronização que devem ser considerados.

3. Os STRs devem cumprir prazos (limites de tempo) para satisfazer restrições de tempo físico real. A simples exatidão funcional não é suficiente. 


\subsubsection{Tipos de STR}

Segundo Bennett, em [Benn90], os STRs podem ser de dois tipos :

1. Restrição de tempo rígido $\rightarrow$ onde a computação deve ser feita dentro de um tempo máximo especificado, em cada ocasião.

2. Restrição de tempo brando $\rightarrow$ os sistemas devem ter um tempo médio de execução medido num intervalo de tempo definido de forma a não ultrapassar um máximo especificado.

O primeiro tipo de STR descrito acima possui uma exigência muito mais severa sobre o desempenho dos sistemas. Também denominados por sistemas embutidos, o software desse tipo de STR deve ser extremamente confiável. Grandes somas de dinheiro, equipamentos valiosos e, freqüentemente, vidas humanas, dependem da operação correta e confiável do software destes sistemas.

Os sistemas embutidos geralmente são internos a um outro sistema com o qual têm que interagir. Zave, em [Zave82], cita que o conceito geral que une os sistemas do tipo "embutidos" é o controle de processos, onde tais sistemas desempenham o papel de ter que responder continuamente a um ambiente externo desprovido de qualquer inteligência.

Mellichamp, em [Mell83], divide os sistemas de Computação em duas classes principais: Processamento Interativo ("on-line") e Processamento por Lotes ("batch"), e acredita que o percentual de sistemas de cada uma dessas classes é o seguinte:

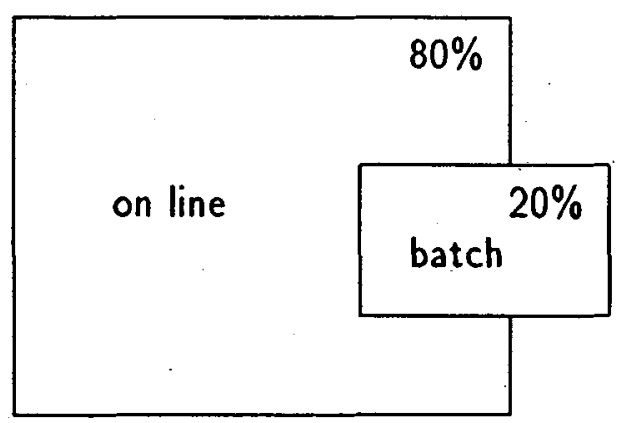


A partir dessa constatação, têm crescido os esforços para se obter maior produtividade na construção de sistemas "on-line".

Mellichamp também esclarece um ponto confuso, de certas pessoas que querem utilizar o termo "tempo-real" quando falam "on-line", e, para tanto, baseando-se na configuração do hardware, ele apresenta uma classificação para os sistemas "on-line" em:

\section{Computação baseada no tempo ou em relógio (clock)}

O computador utiliza um dispositivo (ou dispositivos) para chavear suas operações para o tempo do mundo-real, isto é, o computador está habilitado a manter uma medida precisa do tempo físico ou medir a passagem de um certo intervalo de tempo, em termos das unidades de tempo usual (segundos, minutos, etc.)

\section{Computação baseada em sensores}

O computador utiliza uma interface, isto é, dispositivos externos (sensores digitais e/ou analógicos generalizados), para medir as condições ou estados de um processo físico. O computador pode somente monitorar o processo, sem controlá-lo, ou o computador pode manipular certas entradas do processo. No primeiro caso, o relacionamento é dito "passivo", e no segundo, existe um relacionamento dito "ativo" com o processo.

\section{Computação interativa}

O computador está conectado a dispositivos externos, sejam eles processos, terminais individuais ou outros computadores. Neste caso, se o computador se comunica ativamente com as unidades externas, a resposta do computador pode precisar estar dentro de certas restrições de tempo.

Os exemplos mostrados abaixo ilustram a distinção existente entre as três classes de sistemas "on-line" descritas acima:

1. Um sistema de computação de tempo-compartilhado (time-shared) envolvendo múltiplos terminais, todos conectados a um só computador. 
2. Um computador conectado a um segundo computador com o qual ele se comunica de tempos em tempos.

3. Um sistema de reservas de passagens aéreas constituído de vários terminais conectados a um computador localizado centralmente.

4. Um instrumento de laboratório, que é monitorado e controlado por um computador.

5. Um alarme contra assalto computadorizado, que monitora todas as portas e janelas de uma casa e acende as luzes, aciona alarmes, e disca para a polícia quando um intruso é detectado.

6. Um computador, que monitora a passagem de tempo via seu próprio relógio de tempo-real e relaciona suas atividades computacionais àquele tempo.

Os exemplos (1), (2) e (3) são considerados de computação interativa e se referam ao tipo de STR com restrição de tempo brando, segundo a classificação de Bennett. Já os exemplos (4) e (5) são baseados em sensores, enquanto o exemplo (6) apresenta computação baseada em relógio. Estes três últimos exemplos são do tipo STR com restrição de tempo rígido.

\subsection{Métodos e Técnicas para Desenvolvimento de STR}

A atividade de desenvolvimento de software, segundo Mendes e Aguiar, em [Mend88], é discutida sob três paradigmas.

O primeiro dos paradigmas considera o desenvolvimento de software como um artesanato, onde o projetista desempenha o papel de artesão e seus programas são obras pessoais sem a preocupação com métodos. Este contexto é o de muitos países que consideram o software como um produto protegido pela lei de direito autoral.

O segundo paradigma utiliza a matemática como modelo para o desenvolvimento de software, onde um programa é um algorítmo escrito numa certa linguagem formalizada. $O$ desenvolvimento de algoritmos é uma atividade básica dos matemáticos quando encarada sob o ponto de vista de solucionar problemas.

O último paradigma trata da atividade de desenvolvimento de software como Engenharia. Portanto a atividade possui um componente empírico, 
onde o software deve ser encarado como um produto a ser construído, sofrendo freqüentes revisões e contribuindo para a experiência do seu construtor.

A visão sob este paradigma de Engenharia é a de buscar métodos e técnicas para se projetar software como um produto a ser construído. Além disso, existe a possibilidade de se obter um produto operacional preliminar de software (um protótipo rápido) nas fases iniciais de desenvolvimento.

Todos os três tipos de paradigmas em parte se aplicam ao desenvolvimento de software para STRs.

Para se saber qual a parcela de contribuição de cada paradigma, devese ter em mente a distinção entre programação em pequena e larga escala. No primeiro tipo de programação o produto realmente pode ser encarado como uma obra pessoal, cujo autor busca sua maior eficiência. Quanto ao tipo de programação em larga escala, como os sistemas de ambiente industrial, que são sistemas grandes e muitas vezes complexos, se torna bastante dificil, ou no mínimo inadequado, encarar o produto de software como uma obra individual.

Sem dúvida, os sistemas grandes recebem a maior preocupação, pois geralmente são desenvolvidos e mantidos por muito tempo (em geral, anos) por equipes de pessoas que necessitam de técnicas de documentação precisa para captar e comunicar o conhecimento sobre os sistemas.

Técnicas específicas têm sido desenvolvidas, desde os anos 70, para particionar os grandes sistemas de forma a facilitar sua análise e manutenção. Conforme os sistemas cresceram em tamanho e complexidade, e a tecnologia se tornou mais acessível, novos métodos foram incorporando capacidades adicionais. Outro ponto importante durante a criação de um produto de software é seu período de vida útil. Nesse ponto, a abordagem de Engenharia influencia novamente, pois adota uma documentação da especificação do produto utilizado, que acompanha a vida útil do produto. Embora um produto de software geralmente não requeira outro processo de fabricação a partir de uma mesma especificação, este documento se torna importante na medida em que o produto de software se torne operacional e requeira manutenção.

O STR, por mais que seja uma obra artesanal, provavelmente evoluirá acompanhando a evolução do mundo real com o qual se comunica, e isso, conseqüentemente, acarretará sua manutenção. Além de se tratar de um produto que interage com o ambiente externo, ao qual está acoplado, o STR geralmente possui mais de um usuário e envolve vários projetistas e pessoas não projetistas em sua manutenção. Sendo assim, um procedimento sistemático, ou seja, um método de desenvolvimento se torna imprescindivel para um trabalho deste porte. 
Dessa forma, a seguir é apresentado o levantamento bibliográfico dos diversos tipos de métodos, técnicas e ferramentas que vêm colaborando para melhorar a qualidade e a produtividade do desenvolvimento e manutenção de STR.

\subsubsection{Revisão Bibliográfica dos Métodos e Técnicas}

Método vem do grego "méthodos". É um caminho para se chegar a um fim; modo de proceder; maneira de agir; um jeito de fazer as coisas; uma forma de projetar.

Um método de desenvolvimento especifica:

- quais decisões têm que ser tomadas

- como as decisões devem ser tomadas

- em que ordem isto deve ser feito

Metodologia, segundo Freeman, em [Free83], é um conjunto de passos predominantemente técnicos, que podem ser seguidos do início ao fim do desenvolvimento de um software.

Algumas vezes considera-se que uma metodologia de desenvolvimento de software se compõe de mais de um método de como proceder determinadas etapas de desenvolvimento. Entretanto, muitos métodos são denominados como metodologias e vice-versa.

Neste trabalho, o termo método é utilizado uniformemente, como um procedimento sistemático empregado para a atividade de se desenvolver software. De nosso trabalho no ambiente profissional, notamos que muitos analistas e projetistas combinam de formas diferentes, os métodos existentes, da forma que mais lhes convém e da forma que os métodos melhor se adequem ao tipo de aplicativo que lhes é confiado elaborar.

Existem métodos criados com o objetivo de dar apoio especificamente a determinadas fases do Ciclo de Vida do desenvolvimento de software, enquanto outros englobam mais de uma destas fases.

Durante a fase de Especificação de Requisitos é que geralmente se descreve o comportamento externo esperado do sistema a ser construído. Em se tratando de STR, esta descrição é muito importante, já que uma de suas características básicas é a comunicação com o mundo externo e isso acarreta a 
alteração do comportamento do sistema, conforme discutido na seção anterior deste trabalho. Esta descrição dos primeiros requisitos mais gerais do sistema e do comportamento do sistema é registrada num documento comumente chamado de Especificação de Requisitos de Software.

Embora a maioria dos software existentes tenham suas especificações escritas em linguagem natural, conforme menciona White, em [Whit87], notase que têm sido bastante estudados e desenvolvidos métodos um pouco mais formais de Especificação de Requisitos de Software. Estes novos métodos são devidos, principalmente, ao esforço para se obter uma precisão maior na forma de especificar sistemas, pois sabe-se que a linguagem natural possui problemas para ser utilizada em especificações por ser inerentemente ambígua e, muitas vezes, inconsistente e incompleta, particularmente para o caso de STRs.

Os métodos relacionados a seguir não foram selecionados simplesmente por estarem ligados ao termo tempo-real, mas sim por possuírem uma característica especial que deve ser tratada em especificações de STR: a técnica para representação do aspecto comportamental do sistema. Devido a isso, não foram listados outros métodos bastante consagrados na literatura e na prática profissional.

Os métodos estudados e revisados foram, em ordem alfabética:

DARTS (Design Approach for Real-Time Systems),

DCDS (Distributed Computer Design System),

HOS (Higher Order Software),

JSD (Jackson System Development),

MASCOT (Modular Approach to Software Construction, Operation and Test), PAISley (Process-Oriented, Applicative, Interpretable Specification Language), PAMELA,

PFM (Pragmatic Formal Method),

SA/RT (Structured Analysis for Real-Time Systems),

SARA (System ARchitects' Apprentice),

SCR/A7E (Software Cost Reduction) e, STATEMATE.

Os métodos, de uma maneira geral, são orientados a acompanhar a maior parte do desenvolvimento de software, quando não o desenvolvimento inteiro. No entanto, algumas etapas desse desenvolvimento, para os diversos métodos, podem ser apoiadas por uma mesma técnica. Com isso, observa-se que, enquanto o método determina como proceder a atividade de desenvolvimento de software, cabe a determinada técnica o procedimento em si, dentro de uma etapa 
do período de desenvolvimento. Este trabalho utiliza "técnica" como sendo um formalismo para a realização de um determinado procedimento.

Entre as várias técnicas propostas, que propiciam uma solução para a problemática de se descrever o aspecto comportamental de sistemas do tipo STR, as principais são:

CCS (Calculus of Communicating Systems),

CSP (Cooperating Sequential Processes),

Lógica Temporal,

MEF (Máquinas de Estados Finitos), e

Redes de Petri.

Estas técnicas são discutidas brevemente a seguir, com o objetivo de auxiliar a leitura posterior dos métodos que as utilizam.

\section{Técnicas para descrição do comportamento de STR}

$-\mathrm{CCS}-$

A técnica CCS (Calculus of Communicating Systems) de Milner, em [Miln80], trata-se de uma linguagem formal de especificação ou de programação, de natureza algébrica, que tem acumulado um grande volume de pesquisas relativas a variações em sua apresentação, semântica formal e comparações detalhadas com outras linguagens.

As principais características de CCS são a de adotar a recursão como estrutura de controle, a de possibilitar aninhamento de concorrência e a de permitir se ter nomes de variáveis para representar sinais e canais de comunicação.

$-\operatorname{CSP}-$

A técnica CSP (Cooperating / Communicating Sequential Processes) de Hoare, em [Hoar78], foi proposto por seu autor como sendo uma linguagem de descrição de programas, que sugere basicamente:

- a idéia de que entrada e saída são as primitivas principais de programação e que,

- a composição paralela dos processos de comunicação sequenciais é um método fundamental de estruturação de programas.

De tal maneira as idéias de Hoare repercutiram entre as pessoas que desenvolvem software, que os conceitos que ele preconizou se tornaram premissas 
na aplicação da Engenharia de Software durante a utilização de vários métodos de desenvolvimento de software do tipo que lide com o projeto de programas distribuídos.

\section{- Lógica Temporal -}

A Lógica Temporal se estabeleceu basicamente como um instrumento para especificação e prova de programas escritos em CSP ou em variantes do Pascal concorrente.

Uma característica importante da Lógica Temporal é que ela lida com os operadores proposicionais "sempre", "da próxima vez", "algumas vezes" e "ainda", segundo Moszkowski, em [Mosz84].

Os autores Mendes e Aguiar, em [Mend88], apontam que a Lógica de Predicados é apropriada para se descrever situações estáticas, enquanto a Lógica Temporal é utilizada para se descrever situações dinâmicas. Desta maneira, a Lógica Temporal se enquadra como uma técnica para descrição de comportamento dos sistemas.

Em Lógica Temporal parte-se do conceito de universo composto de muitos estados e de uma relação de acessibilidade entre esses estados. Assim, têm-se que : $R(s 1, s 2)$ é uma relação que estabelece que o estado s2 é acessível a partir do estado s1. Em cada estado os objetos básicos são os mesmos, mas os seus atributos e relacionamentos podem variar. Essa variação é função do parâmetro tempo. Um exemplo citado por Mendes e Aguiar, em [Mend88], sobre Lógica Temporal é: "Faz frio no Rio". Considera-se que a verdade da proposição varia no tempo, como é o caso se forem considerados os dias como os estados para a proposição feita. Portanto, dependendo do dia a veracidade da proposição vai variar, o que indica que o tempo é um parâmetro implícito, isto é, a proposição vai variar no tempo. Se na proposição acima for incluído o tempo explicitamente, ela se torna uma proposição do Cálculo Proposicional.

- MEF -

Um dos conceitos tradicionais da Teoria da Computação são as Máquinas de Estados Finitos (MEF). É através delas que podem ser descritas as dependências de estados anteriores para a determinação da próxima configuração de estados do universo em estudo.

A MEF, segundo Davis, em [Davi88], é um mecanismo hipotético que pode estar em somente um de um número discreto de condições de estados em um certo momento. Em resposta a uma entrada, essa máquina abstrata, gera uma 
saída e modifica o seu estado, ou seja, certos eventos podem ocasionar mudança no seu estado. A saída e o próximo estado são função do estado atual e da entrada. Um processo pode ser representado por uma coleção de MEFs.

As MEFs fornecem um modo preciso para descrição de processos complexos, além de fornecer meios para se verificar se todas as possiveis transições de estado de um sistema foram representadas.

Esta é a solução alternativa mais difundida entre as pessoas que desenvolvem software para STR e possui muita aceitação por ser de fácil visualização. Existem duas notações mais representativas: os diagramas de transição de estados (DTE) e as tabelas de transição de estados (TTE), estas últimas também conhecidas por matrizes de transição de estados.

Na utilização dos DTEs, um círculo denota um estado, um arco dirigido conectando os estados denota a possibilidade de transição entre os dois estados conectados, e um rótulo acima do arco denota a entrada que dispara a transição. Opcionalmente esta entrada é seguida de uma barra (/) e uma saída produzida pelo sistema em resposta imediata àquela transição ocorrida.

Quando se utilizam TTEs para a descrição das transições de estados nas MEFs, existem dois modelos consagrados, a saber: o modelo de Mealy e o modelo de Moore. Basicamente, os dois modelos possuem uma tabela desenhada com todos os possíveis estados ocupando as várias linhas e todos os possíveis estímulos correspondendo às colunas.

A variação entre um modelo e outro é a seguinte: no modelo de Mealy, o próximo estado e a resposta do sistema à transição ocorrida aparecem em cada intersecção de linha e coluna.

No modelo de Moore, somente os próximos estados aparecem nas intersecções de linha e coluna, e uma coluna separada é desenhada para indicar a resposta do sistema associada a cada mudança de estado.

Portanto, se torna bastante intrínseco à aplicação a opção entre um dos dois modelos de TTE, uma vez que a diferença entre eles pode ser benéfica ou não, dependendo do volume de respostas que o sistema tem que fornecer.

\section{- Redes de Petri -}

As Redes de Petri constituem uma técnica gráfica e precisa para a descrição de dinâmica e comunicação entre elementos. Sua representação gráfica, segundo Peterson, em [Pete77], é composta de dois tipos de nós: círculos (denominados lugares) e segmentos de reta (denominados transições). Formalmente, 
esses elementos são dispostos no diagrama na forma de um grafo bipartido.

As Redes de Petri são orientadas a eventos e, por sua definição, obtémse uma representação fiel de concorrência. Suas pesquisas têm sido acumuladas há mais de vinte anos, o que a faz possuir uma teoria matemática bastante fundamentada. Geralmente são utilizadas para modelar sistemas concorrentes distribuídos, pois possibilitam a descrição de sincronização, concorrência e conflito. Outro fator importante é que as redes podem ser analisadas para deteç̧ão de alcançabilidade e impasse (deadlock).

A maioria dos trabalhos teóricos encontrados sobre Redes de Petri são baseados em definição formal, e o seu modelo gráfico é bastante útil para especificação de processos concorrentes.

A estrutura básica da Rede de Petri, segundo White, em [Whit87], é uma sêxtupla ( $\mathrm{P}, \mathrm{T}, \mathrm{E}, \mathrm{M} 0, \mathrm{~K}, \mathrm{~W})$, onde: $\mathrm{P}$ é um conjunto de lugares (places), $\mathrm{T}$ é um conjunto de transições, $\mathrm{E}$ é o conjunto de arcos dirigidos de um lugar para uma transição, ou de uma transição para um lugar. O conjunto de $\operatorname{arcos} \mathrm{E}$ pode ser considerado como um mapeamento de transições para lugares e pode ser definido como $E=(I, O)$, onde I e $O$ são respectivamente as funções de entrada e saída dos lugares, para as correspondentes transições que são descritas. Para se definir o conjunto M0, tem- se que considerar o conceito de tokens, que por sua vez são marcas associadas aos lugares e são representados por pontos pretos que se movimentam de um lugar para outro, segundo regras específicas. É através do movimento dos tokens que se simula o fluxo de controle numa rede, e a marca inicial de tokens na rede é dada pelo conjunto M0. Dos demais conjuntos, $\mathrm{K}$ denota o número máximo de tokens que um lugar pode possuir e $\mathrm{W}$, o peso de um arco, indicando o número de tokens que deve ser removido de um lugar de entrada da transição representada por aquele arco, ou o número de tokens que deve ser adicionado a um lugar de saída daquela transição.

Com o objetivo de destacar a contribuição das linguagens de programação de tempo-real que têm sido pesquisadas e desenvolvidas para os projetos de STR, segue uma visão resumida do que foi encontrado durante as leituras realizadas para a confeç̧ão deste trabalho.

\section{Linguagens de Programação de Tempo-Real}

A linguagem ESTEREL, conforme seus autores, em [Berr84], é uma linguagem de programação de tempo-real desenvolvida com o objetivo de possuir um modelo formal rigoroso. ADA e OCCAM são ainda outras, citadas também por Berry, em [Berr84]. Estas duas linguagens são controvertidas, pois ADA, segundo 
Pressman, em [Pres87], que foi desenvolvida no Departamento de Defesa dos EUA como uma linguagem padrão para Computação em Tempo-Real, possui uma estrutura rica nos seus recursos mas seus oponentes a consideram muito complexa e extensa. Enquanto OCCAM, que também foi desenvolvida para atender a STRs e processamento distribuído, possui uma concepção mais simples, partindo de um núcleo limitado de construções básicas e deixando a cargo do programador a tarefa de implementar as extensões requeridas pelas suas necessidades.

Linguagens como Pascal concorrente, Modula, PLITS (Programming Language In The Sky), SR (Synchronizing Resources), Mesa, Edison, DP (Distributed Processes) são também citadas como possuidoras de notação e conceitos para programação concorrente, segundo Andrews e Schneider, em [Andr83].

Gypsy, em [Ambl77], foi uma das primeiras linguagens de alto nível orientada ao processamento de comunicação e é uma linguagem para especificação e implementação de programas verificáveis.

Existe também uma modelagem que encerra uma linguagem de especificação de requisitos, denominada Gist. Segundo White, em [Whit87], Gist permite a especificação dos requisitos em termos de declarações e tipos de objetos, operações sobre os objetos, restrições e relações entre os dados. As operações sobre os objetos são especificadas por processos sequenciais cooperativos (CSP), denominados "demons" (demônios). As restrições podem ser estáticas ou dinâmicas. As restrições estáticas incluem as restrições sobre os tipos de objetos, número de objetos e condições requeridas. As restrições dinâmicas incluem as restrições sobre mudança de estado, início e término de restrições, e restrições sobre a ordem dos eventos.

A linguagem de especificação Gist é operacional e sua principal orientação é a de ser um método baseado em conhecimento. Foi desenvolvida por Balzer, Goldman, Wile e Swartout no Information Sciences Institute, com objetivo de fornecer suporte à programação automática. Um exemplo de sua aplicação se encontra em [Balz81].

A linguagem denominada LOTOS (Language of Temporal Ordering Specification) é uma técnica de descrição formal para a especificação de sistemas distribuidos. Segundo Cunha e Moura, em [Cunh89], a linguagem LOTOS possui dois componentes: um estático para a descrição dos tipo de dados manipulados na especificação e um dinâmico para a descrição do comportamento observável do processo através de suas interações e operações. Esse componente dinâmico é uma extensão do cálculo de sistemas de comunicação (CCS), referido anteriormente neste mesmo trabalho. 


\section{Métodos para o desenvolvimento de STR}

\section{- SREM -}

Dentre os primeiros métodos de larga divulgação para análise e projeto de STR, destaca-se o método desenvolvido pela empresa TRW, visando principalmente a atender os requisitos particulares dos sistemas que possuissem características que se relacionassem ao tempo do mundo real.

Este método foi pesquisado com o patrocínio do BMDATC dos Estados Unidos (U. S. Army Ballistic Missile Defense Advanced Technology Center), segundo White, em [Whit87]. Denominado SREM, o método desenvolvido por Alford, em [Alfo77], pode ser considerado como uma evolução do método PSL/PSA (Problem Statement Language/ Problem Statement Analyzer), que foi um método pioneiro no apoio por computador à fase de especificação de requisitos para sistemas não de tempo-real.

Como o método SADT, o método SREM inclui um conjunto de procedimentos que guiam a tarefa do analista durante a fase de especificação de requisitos. A princípio, o método SREM foi concebido com o objetivo de auxiliar no desenvolvimento de sistemas embutidos, segundo Pressman, em [Pres87], e as recentes extensões têm subsidiado o desenvolvimento de sistemas concorrentes distribuídos.

O método SREM utiliza-se de uma linguagem, RSL (Requirements Statement Language), para descrever: elementos, atributos, relacionamentos e estruturas. A partir destas primitivas combinadas com informação narrativa, os detalhes da especificação de requisitos ficam estabelecidos. Existe uma notação gráfica correspondente à linguagem RSL, conhecida por R-net, que é uma extensão das MEF e é definida para cada processador que compõe o sistema a ser modelado, segundo Davis, em [Davi88]. As R-nets podem ser decompostas, mas o conceito de função não pode ser decomposto por corresponder a elementos não decomponiveis denominados "alphas". Devido a esse fato, a este método é atribuida a propriedade de ser orientado a fluxo de função.

Um método que é uma extensão de SREM e já se encontra disponível para os analistas e projetistas é o método SYSREM (System Requirements Engineering Methodology). Este método acrescenta a definição de requisitos do sistema e a alocação dos subsistemas de hardware e de software.

Esses dois métodos contam com o apoio de computador, como será visto na próxima seção. 


\section{- HOS -}

$\mathrm{O}$ método HOS é outro método criado dentro do ambiente próximo ao Departamento de Defesa dos EUA. A especificação em HOS é realizada através da decomposição hierárquica de uma função seguindo regras rígidas de decomposição. Esta decomposição funcional do sistema em módulos é a idéia principal também dos métodos orientados a fluxos de dados: SA/RT, em [Mell85] e [Hatl84], DARTS em [Goma84], SADT, em [Ross77a] e [Ross77b] e MASCOT, em [Simp79].

HOS foi desenvolvido principalmente para dar suporte a sistemas da Aeronáutica americana, orientando-se pela propriedade de confiabilidade dos sistemas. A base matemática de teoria das funções, que o método utiliza, fornece um formalismo para a descrição e para a interface de comunicação entre os sistemas. Seus autores Hamilton e Zeldin, em [Hami76], concordam que sua aplicação, de fato, é quase impossível sem auxílio de ferramentas automatizadas.

Este método não utiliza-se dos conceitos de eventos/estados para modelar o comportamento do sistema, mas se baseia na função de seleção sobre condições que devem ser estabelecidas na definição do sistema.

- SA/RT -

Um dos primeiros métodos que se preocupou com a adição das MEF convencionais para permitir a descrição do controle comportamental dos sistemas, foi o método proposto por Ward, conhecido por SA/RT.

Este método estendeu a Análise Estruturada, que já possuía muitos adeptos entre os projetistas de sistemas não de tempo- real. Sua representação gráfica consiste de uma modificação da notação de Diagrama de Fluxo de Dados (DFD), para descrever informações de tempo e controle. Esta diagramação foi originalmente proposta por. Ward e Mellor, em [Mell85], e mais tarde estendida por Ward, em [Ward86]. Esta última modificação consiste de uma notação gráfica acrescentada de regras de formação e um formalismo para execução baseado em token.

No mesmo período, uma outra modificação do DFD, para descrever informações de controle e temporização, foi proposta por Hatley, em [Hat|84], e também ficou sendo conhecida por SA/RT.

A técnica de métodos estruturados adotada pela empresa Boeing é baseada na notação proposta por Hatley. A notação e as regras de formação para esta extensão também foram incorporadas a ferramentas do tipo CASE (Computer Aided Software Engineering). 
Segundo os autores Bruyn, Jensen, Keskar e Ward, em [Bruy88], atualmente já existe uma massa substancial de experiência na utilização destas duas notações estendidas do DFD, conhecidas por SA/RT. Além do que, muitos analistas e projetistas adeptos das duas extensões citadas, têm obtido sucesso com o uso das combinações de elementos das duas notações estendidas. Esta combinação, proposta por Ward e Keskar, encontra-se discutida em [Bruy88] e foi denominada ESML (Extended Systems Modelling Language).

As inovaçôes introduzidas nessas extensões incluem o conceito de transformações de controle, que basicamente transformam fluxos de eventos de entrada em fluxos de eventos de saída. $\mathrm{O}$ mecanismo através do qual as transformações de controle são executadas, geralmente é um autômato de estados finitos do tipo de Mealył que é conhecido em sua forma gráfica por DTE, conforme já mencionado.

Os fluxos de eventos de entrada devem ser sinais, que podem se originar no mundo externo ao sistema ou nas transformações de dados. Eles indicam a ocorrência de uma condição de dado, ou a ocorrência de outras transformações de controle. Este sinal causará então uma transição de estado, no DTE, de um estado para outro. Os fluxos de eventos de saída podem ser sinais, ativações, desativações ou disparos, os quais podem, por sua vez, terminar em uma transformação de dados, ou em outra transformação de controle. Estes eventos de saída são as ações associadas às transições de estados. Desta forma, uma transição de estado consiste de um sinal de entrada, que causa a transição, e ações de saída. Estas ações incluem ativação e desativação dos processos de um DFD.

Outro ponto importante da extensão de DFD é que, a cada nível de expansão (decomposição), corresponde um processo de controle que monitora ou supervisiona os outros processos funcionalmente descritos para o sistema alvo. Este processo de controle é especificado através de um DTE.

\section{- DARTS -}

Além das extensões ao método orientado a fluxo de dados, citadas acima, uma outra proposta por Gomaa, em [Goma84], é denominada DARTS.

Este método estende o método da Análise Estruturada/Projeto Estruturado, pois acrescenta um mecanismo de decomposição de tarefas, para posteriormente tratar do processamento concorrente das mesmas.

O método DARTS, contemporâneo dos outros dois já citados como extensões à Análise Estruturada, se diferencia pelo fato de ser mais orientado à fase de projeto, mantendo a representação para especificação de requisitos proposta 
pelo DFD convencional. Portanto, na fase de projeto é que o método DARTS adiciona as decisões sobre comunicação e sincronização requeridas pelo sistema.

\section{- PAMELA -}

O método PAMELA, de autoria de Cherry, é também um método que utiliza-se da notação de DFD na fase de análise do sistema. É conhecido por ser um método de projeto orientado a objetos. A modelagem proposta por este método se baseia na decomposição do sistema de forma a fazer a correspondência com objetos, segundo White, em [Whit87].

Um aspecto importante é que o método, para executar a referida decomposição, inicia por representar o sistema como um DFD, conhecido por diagrama de contexto. Esta decomposição é orientada pela identificação das tarefas concorrentes e sincronização de processos, cuja especificação se baseia no formalismo de CSP, de Hoare. A partir disso, prossegue-se o projeto com a utilização de pseudo-código de Ada, onde os fluxos de controle são identificados.

Uma característica particular ao método PAMELA é a modelagem do ambiente externo ao sistema, que é representada por um diagrama de transição baseado em MEF.

\section{- PAISLEY -}

PAISLEY, de Zave, em [Zave82], é outro método que trata da modelagem do ambiente externo durante a fase de especificação.

A especificação é representada pela decomposição do ambiente e do sistema, em processos assíncronos que interagem entre si. Com a identificação desses processos prossegue-se a aplicação do método, definindo-se todos os possíveis estados em que os processos podem estar, as funções pelas quais os processos mudam de estados (funções de sucessor), e as funções de como os processos interagem (funções de troca). Cada processo corresponde a um máquina de estados finitos e além disso, os processos que pertencem ao ambiente não são tratados de forma diferente dos processos do sistema.

A característica especial do método PAISley é a de possuir uma linguagem simples, mas com rigor e formalismo para os conceitos de processos assíncronos e programação funcional. No entanto, existe o aspecto de compreensão do método e, em [Davi87] e em [Whit87], é mencionada a dificuldade inerente ao entendimento da notação adotada pelo método PAISley. Outra característica importante deste método é a de fornecer um modelo operacional para a especificação resultante, através do qual obtém-se uma visão do comportamento 
do sistema especificado.

- JSD -

O método JSD, de Jackson e Cameron, em [Came86], também é uma abordagem orientada à modelagem operacional do sistema, segundo Masiero, em [Masi89]. Neste sentido, o método conduz a uma especificação que pode ser executada, ou interpretada, de forma a imitar o comportamento esperado do sistema.

O método JSD possui suas raizes no método JSP para programação, também de Jackson. JSD se baseia principalmente nas estruturas de dados que o sistema tem que manipular. Portanto, o método é mais conhecido por ser orientado a estrutura de dados, segundo Pressman, em [Pres87]. Utilizando uma abordagem bastante similar à técnica empregada na análise orientada a objetos, o método JSD inicia por identificar as entidades e as ações relacionadas com o sistema. A forma de representação adotada equivale a uma estrutura de árvore e é denominada Diagrama de Estrutura (DE), que após ser transladada para uma forma textual, corresponde aos processos do sistema. A partir disso, o método prossegue para a construção de um modelo inicial do mundo real. Então a especificação é gerada, utilizando uma simbologia própria e esta especificação é denominada diagrama de especificação do sistema (DES), onde então são construídas as Redes de Processos.

Os diagramas do JSD foram estudados por Zave, em [Zave85], propondo-se uma alternativa para sua representação, como máquinas de estados finitos.

\section{- MASCOT -}

O método MASCOT, de Jackson e Simpson, em [Simp79], é um dos mais antigos, pois iniciou suas pesquisas em 1972. Foi o primeiro método para desenvolvimento de sistemas que exigem sincronização. Seus autores mencionam que foi a partir da experiência ganha do projeto e implementação de um STR de grande porte, que surgiu a ênfase na necessidade de modularidade do software em três aspectos separados, mas interdependentes: construção, operação e teste.

Como o método DARTS, o método MASCOT é mais orientado ao projeto, proporcionando inclusive, no estágio de construção do sistema, as facilidades de compilação, ligação e carregamento para os módulos construídos para o sistema.

MASCOT é caracterizado como um método orientado a fluxo de dados, pois utiliza uma representação de fluxo de informação dos processos concor- 
rentes, através da qual fornece a representação da intercomunicação das áreas de dados, para a definição da comunicação interprocessos.

\section{- SCR/A7E -}

O método SCR/A7E de Heninger, em [Heni80], também foi estimulado por um projeto prático, pois foi desenvolvido durante a reconstrução do software da aeronave A7E da marinha americana. Este projeto serviu para praticar os principios da Engenharia de Software incorporados ao método SCR/A7E, e segundo Parikh e Zvegintzov, em [Pari83], se enquadra como um método de manutenção de sistemas, devido ao fato de pröduzir ao final, um documento guia de entendimento do sistema, base para eventuais modificações de sua implementação.

O estilo de separação de conteúdos utilizado no método SCR/A7E, propiciou ao projeto prático, em que foi aplicado, a produção de uma descrição completa da situação do sistema da aeronave, que na época contava com 12.000 linhas de código de programa em linguagem Assembly.

\section{- SARA -}

O primeiro objetivo que incentivou o desenvolvimento do método SARA, por Estrin e Campos, em [Camp77], foi o de encorajar o projeto de sistemas. testáveis. Portanto, um dos princípios que este método incorpora, é a inclusão de um modelo do ambiente externo como uma invariante do projeto.

Possuidor de uma notação gráfica própria e de convenções de uma linguagem de programação própria, o método SARA encaminha o projeto para ser simulado, com o objetivo de fazer sua validação. Além disso, a sua notação de significado próprio, oferece meios para descrição de concorrência entre processos.

Uma característica deste método é a representação do comportamento dos sistemas através do GMB (Graph Model Behavior), modelo gráfico de comportamento. Esta forma de representação se compõe das definições de: gráfico de controle, gráfico de dados e da modelagem da interpretação que define os formatos dos dados.

$\mathrm{O}$ autor Estrin, em [Estr79], menciona que o gráfico de controle proposto em SARA, é equivalente às Redes de Petri.

\section{- PFM -}

$\mathrm{O}$ método PFM, de White, em [Whit87], também conduz à atividade de simulação do sistema e, proporciona para tal, uma modelagem do sistema em 
forma de PFM-nets. As PFM-nets são extensões das Redes de Petri.

O método PFM foi desenvolvido, baseando-se em atributos selecionados por White, para o cumprimento dos requisistos de sistemas embutidos distribuídos. Possui um fundamento teórico baseado em formalismos, sendo que, para a descrição comportamental do sistema, o método PFM utiliza-se da teoria dos intervalos temporais de Allen, em [Alle83], pertinente à técnica de Lógica Temporal anteriormente referida.

Uma das principais preocupações deste método é a de não antecipar questões durante a fase de especificação do sistema, que porventura tenham permanecido vagas ou incompletas, com o objetivo de deixá-las para as decisões de projeto. Para suprir estas "questões a serem determinadas", o conceito de intervalo de tempo é utilizado na especificação, com operadores da lógica temporal estendida do tipo: "eventualmente" ou "de agora em diante".

\section{- STATEMATE -}

STATEMATE é outro método, segundo White, em [Whit87], que possui uma estrutura formalizada para o procedimento do desenvolvimento de sistemas. As técnicas que este método utiliza, que norteiam a especificação dos sistemas, são a de decomposição de funções e a técnica de mapeamento de sequêencias de entradas em seqüências de saída. O termo STATEMATE é também utilizado na literatura para designar o ambiente de apoio às técnicas que compõem o método STATEMATE.

Segundo White, em [Whit87], a qualidade visual do modelo gráfico de estados proposto pelo método, é a melhor entre os existentes. Este modelo gráfico consiste da técnica denominada STATECHARTS.

A premissa básica do método é a necessidade de se especificar e analisar o sistema a partir de três pontos de vista bastante relacionados: estrutural, funcional e comportamental. Para cada um desses pontos de vista o método STATEMATE fornece uma linguagem gráfica de especificação e Harel, em [Hare88a], mostra a estrutura geral do método, ilustrando com um exemplo a especificação de um sistema nas três formas gráficas com os relacionamentos entre elas.

A técnica STATECHARTS é a grande contribuição do método STATEMATE e será mais detalhada no próximo capitulo. 


\subsubsection{Ferramentas de Apoio por Computador}

$O$ que entende-se por ferramenta (tool), na comunidade de pessoas envolvidas com o desenvolvimento de software, é o auxílio automatizado à aplicação de determinada técnica ou método, que subsidie inclusive o próprio entendimento de tal técnica ou método. Além deste fator, existem inúmeros outros, que estimulam cada vez mais a produção de tais ferramentas, como por exemplo: redução nos tempos de desenvolvimento, aumento de produtividade, deteç̧ão de erros em fases anteriores à de implementação e maiores garantias de qualidade do software a ser produzido.

A maior parte dos métodos, quando desenvolvidos originalmente, previam a sua aplicação de forma puramente manual. No entanto, atualmente, muitos deles já possuem partes automatizadas devido a estarem se tornando imprescindíveis para o desenvolvimento de sistemas grandes e complexos, dado o volume de informações que tais sistemas geram. Além disso, a própria aplicação do método está sujeita a erros, pois muitas vezes se torna enfadonho o seu uso, diante do volume de informações que deve ser manipulado.

A seguir são relacionadas algumas ferramentas que compõem as partes automatizadas dos métodos citados na seção anterior.

O REVS (Requirements Engineering Validation System) é um conjunto de ferramentas que analisa os requisitos escritos em RSL, desenvolvidos utilizando-se o método SREM (Software Requirements Engineering Methodology). O REVS foi desenvolvido também pela TRW, em pesquisa promovida pela U.S. Army Ballistic Missile Defense Advanced Technology Center. Esta ferramenta REVS já está em uso desde 1977, originalmente instalada num computador Texas Instruments Advanced Scientific e em um CDC 7600. Posteriormente foi reescrita em Pascal e reinstalada em um VAX. Recentemente, foi reescrita em Ada. A característica inovadora desta ferramenta é a capacidade de gerar um modelo para simulação a partir das especificações escritas em RSL. A ferramenta que acompanha o método SYSREM (System Requirements Engineering Methodology) é conhecida por DCDS (Distributed Computer Design System), segundo Davis, em [Davi88].

O RLP (Requirements Language Processor) é uma parte de um sistema global RPS (Requirements Processing System) desenvolvido pelo laboratório GTE em Waltham, Massachusetts. A motivação para o desenvolvimento do RLP foi similar ao do REVS: máquina de estados finitos (MEF) ser de difícil gerenciamento para as especificações de requisitos de Sistemas de Tempo-Real complexos. Enquanto o REVS usa as R-nets como unidade organizacional para as suas especi- 
ficações, o RLP usa a sequência de estímulo-resposta, segundo Davis. A sequência de estímulo-resposta é essencialmente o esboço de um diálogo de dois-sentidos entre o sistema que está sendo especificado e seu ambiente.

A notação e as regras de formação para o método estendido da Análise Estruturada, elaborado por Ward, em [Ward86], foram agrupadas numa ferramenta do tipo CASE (Computer Aided Software Engineering). Esta ferramenta se encontra disponivel comercialmente e os protótipos do modelo executável são demostrados em um TI Explorer dentro da ferramenta Flavors, num ambiente VAX sobre as ferramentas ADAS CASE, e em OPS5.

A versão de Hatley referida na seção anterior como outra extensão à Análise Estruturada, também foi implementada numa ferramenta do tipo CASE, conforme é citado em [Bruy88].

Atualmente, existem disponiveis três ferramentas de suporte ao método JSD, segundo Cameron, em [Came86]. A ferramenta PDF é um editor gráfico para os diagramas de árvore e listas de operações, e um gerador de código para várias linguagens de programação, a partir destes diagramas. A idéia do pacote é a de que os diagramas se toransformem em código de programas fonte. Esta ferramenta roda em IBM PC, VAX VMS com terminal do tipo VT100 e sob UNIX.

SPEEDBUILDER é uma ferramenta planejada para se constituir de uma série de produtos de suporte ao método JSD. No entanto, somente uma parte se encontra disponivel. Esta parte consta de uma base de dados do modelo da especificação em JSD, e roda em IBM PC.

A outra ferramenta, denominada JSP-Cobol, constitue-se de um préprocessador Cobol, que automatiza a inserção de mecanismos de escalonamento de procedimentos e fornece vários auxílios para teste. Esta ferramenta roda em uma grande variedade de mini-computadores e mainframes.

Para o método HOS, seus autores forneceram, simultaneamente com o próprio método, duas ferramentas automatizadas. Como o método possui uma linguagem de especificação formal, baseada em axiomas, numa primeira etapa, um sistema definido em HOS pode ser analisado automaticamente por sua consistência axiomática pelo Analisador de Projeto.

A segunda ferramenta de apoio ao método HOS é um Analisador Executivo de Estruturação que roda sobre uma base de tempo-real, checando o comportamento do sistema. $\mathrm{O}$ resultado dessas duas ferramentas de apoio ao método é, segundo Hamilton e Zeldin, em [Hami76], de que o software produzido 
pode ser desenvolvido eficientemente com interfaces confiáveis.

O STATEMATE constitue um ambiente composto de pacotes de consultas, testes e simulação, possuindo capacidade para geração de código e protomodelagem.

A ferramenta de ambiente que o STATEMATE implementa tem por objetivo habilitar o usuário a rodar, depurar e analisar as especificações e projetos, resultantes das linguagens gráficas, fornecidas pelo próprio método. Para esse fim, foi construida uma base de dados que subsidia uma execução rigorosa da especificação e a recuperação de informações de vários tipos, a partir das três visões do sistema fornecidas pelo usuário, segundo Harel, em [Hare88a]: a visão estrutural, a visão funcional e a comportamental do sistema.

Duas ferramentas especiais do ambiente STATEMATE são: OLG (Object List Generator), que é uma linguagem para consultar a base de dados e recuperar informação dela, e a SLG (Simulation Control Language), que permite ao usuário emular o ambiente do sistema, executar as especificações com resposta animada, e rastrear erros e problemas em tempo de execução. Além disso, fornece testes dinâmicos, como alcançabilidade, deteç̧ão de impasse (deadlock) e nãodeterminismo.

O ambiente STATEMATE também permite a tradução semi-automática da especificação para Ada, que pode resultar numa versão protótipo do sistema final.

\subsubsection{Análise dos Métodos e Técnicas}

Os vários métodos para STR se diferenciam pelo tipo de relacionamento temporal que utilizam, além dos relacionamentos de funções e de dados que, a princípio, todos eles utilizam. Alguns métodos, como os orientados a fluxo de dados, acabam por estender os métodos já existentes para sistemas não de tempo-real, conforme visto nas seções anteriores.

Os relacionamentos temporais são necessários como base para se modelar a reação, isto é, o comportamento dinâmico de resposta a estímulos externos dos sistemas, e são descritos na maioria dos métodos numa estrutura similar a uma máquina de estados finitos (MEF).

Para que se possa ter uma visão da situação dos métodos diante dos requisitos que eles consideram, a seguir é mostrada uma tabela que foi confec- 
cionada de forma a permitir uma análise comparativa entre os métodos. A tabela foi construída com base numa discussão de Harel, em [Hare88b], quando o autor apresenta a estrutura de STATEMATE.

Segundo Harel, para se especificar e analisar o sistema em desenvolvimento é necessário que se considere o sistema sob três pontos de vista estritamente relacionados: estrutural, funcional e comportamental. Para cada método estudado foram identificadas as técnicas que compõem o método, de acordo com cada um desses três pontos de vista que a seguir são descritos.

A visão estrutural se refere à decomposição hierárquica do sistema em componentes "físicos", conhecidos por módulos do sistema ou subsistemas, e também identifica o fluxo de informações entre esses módulos.

A visão funcional corresponde ao conceito de decomposição funcional do sistema. É o conceito que cuida da identificação da hierarquia das atividades, especifica os fluxos de dados e os sinais de controle que fluem entre as atividades. Assim como ocorre com os diagramas de fluxos de dados, esta visão funcional não especifica as ativações, términos e paralelismo entre as atividades.

A visão comportamental é que se responsabiliza pela especificação de controle, a dinâmica do STR. 


\begin{tabular}{|c|c|c|c|c|}
\hline Método & visão funcional & visão estrutural & $\begin{array}{l}\text { visão comporta- } \\
\text { mental }\end{array}$ & $\begin{array}{l}\text { possui fer- } \\
\text { ramenta }\end{array}$ \\
\hline $\begin{array}{l}\text { SA/RT } \\
/ 84\end{array}$ & $\begin{array}{l}\text { orientado a fluxo de } \\
\text { dados, refinamentos } \\
\text { sucessivos, DFD es- } \\
\text { tendido }\end{array}$ & $\begin{array}{l}\text { implícito } \\
\text { via confecção } \\
\text { do Projeto Es- } \\
\text { truturado }\end{array}$ & $\begin{array}{l}\text { Diagrama de } \\
\text { Transição de Es- } \\
\text { tados }\end{array}$ & $\operatorname{sim}$ \\
\hline $\begin{array}{l}\text { SARA } \\
179\end{array}$ & $\begin{array}{l}\text { refinamentos suces- } \\
\text { sivos ou composição } \\
\text { de abstrações }\end{array}$ & $\begin{array}{l}\text { Modelo Estru- } \\
\text { tural }\end{array}$ & $\begin{array}{l}\text { GMB, equiva- } \\
\text { lentes a Redes de } \\
\text { Petri }\end{array}$ & $\operatorname{sim}$ \\
\hline $\begin{array}{l}\text { DARTS } \\
/ 84\end{array}$ & $\begin{array}{l}\text { orientado a fluxo de } \\
\text { dados, refinamentos } \\
\text { sucessivos, DFD }\end{array}$ & $\begin{array}{l}\text { identifica ção } \\
\text { de tarefas, } \\
\text { TCM e TSM }\end{array}$ & $\begin{array}{l}\text { Diagrama de } \\
\text { Transição de Es- } \\
\text { tados, STM }\end{array}$ & กล̃o \\
\hline $\begin{array}{l}\text { MASCOT } \\
/ 79\end{array}$ & $\begin{array}{l}\text { orientado a fluxo de } \\
\text { dados }\end{array}$ & $\begin{array}{l}\text { identificação } \\
\text { de tarefas, fila } \\
\text { de controle }\end{array}$ & $\begin{array}{l}\text { Matriz de } \\
\text { Transição de Es- } \\
\text { tados, STM }\end{array}$ & $\operatorname{sim}$ \\
\hline $\begin{array}{l}\mathrm{JSD} \\
/ 83\end{array}$ & $\begin{array}{l}\text { orientado a estrutura } \\
\text { de dados, definição } \\
\text { de ações, entidades, } \\
\text { Diagrama Estrutura }\end{array}$ & $\begin{array}{l}\text { Redes de Pro- } \\
\text { cessos }\end{array}$ & $\begin{array}{l}\text { equivalente } \\
\text { aos Diagramas de } \\
\text { Transição de Es- } \\
\text { tados }\end{array}$ & $\operatorname{sim}$ \\
\hline $\begin{array}{l}\text { SCR/A7E } \\
/ 77\end{array}$ & $\begin{array}{l}\text { Modos de operação e } \\
\text { descrição funcional }\end{array}$ & (não oferece) & $\begin{array}{l}\text { Tabela de } \\
\text { Transição de Es- } \\
\text { tados para cada } \\
\text { função }\end{array}$ & กล̃o \\
\hline $\begin{array}{l}\text { STATEMATE } \\
/ 87\end{array}$ & $\begin{array}{l}\text { orientado a fluxo de } \\
\text { dados, } \\
\text { Activity-charts }\end{array}$ & $\begin{array}{l}\text { identificação } \\
\text { de } \\
\text { subsistemas, } \\
\text { Module-charts }\end{array}$ & $\begin{array}{l}\text { Diagramas de } \\
\text { Transição de Es- } \\
\text { tados estendidos } \\
\text { STATECHARTS }\end{array}$ & sim \\
\hline $\begin{array}{l}\text { DCDS } \\
/ 73\end{array}$ & (não oferece) & $\begin{array}{l}\text { definição de } \\
\text { "alphas" } \\
=\text { funções não } \\
\text { decomponíveis }\end{array}$ & $\begin{array}{l}\text { R-nets }=\text { ex- } \\
\text { tensão de MEF, } \\
\text { F-nets = gráfico } \\
\text { estímulo-resposta }\end{array}$ & $\operatorname{sim}$ \\
\hline $\begin{array}{l}\text { HOS } \\
/ 76\end{array}$ & $\begin{array}{l}\text { orientado a funções, } \\
\text { árvore, definição de } \\
\text { tipos abstratos de } \\
\text { dados }\end{array}$ & $\begin{array}{l}\text { não é referi- } \\
\text { do na literatura } \\
\text { (?) }\end{array}$ & $\begin{array}{l}\text { percurso } \\
\text { árvore }\end{array}$ & sim \\
\hline
\end{tabular}




\begin{tabular}{|l|l|l|l|l|}
\hline Método & visão funcional & visão estrutural & $\begin{array}{l}\text { visão comporta- } \\
\text { mental }\end{array}$ & $\begin{array}{l}\text { possui fer- } \\
\text { ramenta }\end{array}$ \\
\hline $\begin{array}{l}\text { PAISley } \\
\text { /82 }\end{array}$ & $\begin{array}{l}\text { refinamentos suces- } \\
\text { sivos orientado a pro- } \\
\text { gramação funcional }\end{array}$ & $\begin{array}{l}\text { não é referi- } \\
\text { do na literatura } \\
(?)\end{array}$ & $\begin{array}{l}\text { ciclo de processos } \\
\text { equivalente MEF }\end{array}$ & sim \\
\hline $\begin{array}{l}\text { PAMELA } \\
\text { /85 }\end{array}$ & $\begin{array}{l}\text { orientado a objetos } \\
\text { similar ao SA/RT }\end{array}$ & $\begin{array}{l}\text { não é referi- } \\
\text { do na literatura } \\
(?)\end{array}$ & $\begin{array}{l}\text { Diagrama de } \\
\text { Transição de Es- } \\
\text { tados }\end{array}$ & $?$ \\
\hline PFM & similar ao SCR/A7E & $\begin{array}{l}\text { Diagramas } \\
\text { de funções cor- } \\
\text { respondentes a } \\
\text { subsistemas ou } \\
\text { módulos }\end{array}$ & $\begin{array}{l}\text { Diagramas de } \\
\text { Transição de Es- } \\
\text { tados, e simulado } \\
\text { por PFM-net }\end{array}$ & modelo \\
\hline \hline
\end{tabular}

\subsection{Conclusões}

As definições de STR estudadas neste capítulo mostraram que existem vários aspectos especiais neste tipo de sistema. Os principais aspectos levantados foram:

- interconexão de um STR a um processo externo ao computador;

- o STR deve processar em tempo-real, na escala de tempo do processo externo;

- a aleatoriedade dos dados de entrada ao STR; caracterizando seu Domínio de Aplicações como não-determinístico;

- alterações no comportamento do STR diante da ocorrência de eventos externos;

- controle direto do processo interconectado;

- o projeto do STR exige a integração das equipes que desenvolvem o seu hardware e o seu software;

- o STR requer máxima confiabilidade;

- a arquitetura do software do STR em geral envolve processos concorrentes.

Além disso, procurou-se caracterizar exatamente o que diferencia um STR de um sistema voltado para o processamento de transações, pois o projeto do STR requer atenção no tratamento dos aspectos especiais relacionados acima. 
Adicionalmente, foram discutidos os sistemas embutidos e os interativos ("on-line"). Esses sistemas também podem ser considerados como STR e caracterizam as diferentes dimensões de tempo que um STR trata. No caso dos sistemas embutidos, o requisito de tempo é bastante rígido, enquanto que para os sistemas interativos existe uma tolerância major. No entanto, além do requisito de tempo, os dois tipos de sistemas possuem fatores comuns que os caracterizam, tais como: a comunicação com o ambiente e a dinâmica das mudanças de seu estado, sofrendo interferência não exclusivamente dos eventos externos como também do seu estado corrente.

Neste capítulo a revisão bibliográfica mostrou também que os métodos e técnicas para o desenvolvimento de STR têm sido objeto de muito estudo, inclusive sob patrocínio de empresas que possuem tais sistemas como parte de seus produtos. Além disso, a variedade de métodos vistos, demonstrou que, por serem métodos muitas vezes desenvolvidos para tratar especificamente de STR, possuem alguma técnica para representação do comportamento do sistema.

É fato visto na bibliografia dos métodos existentes para especificação de sistemas que, em geral, a primeira preocupação, historicamente, foi a de que os métodos fornecessem meios de se descrever os aspectos estruturais e funcionais do sistema a ser desenvolvido, sem se preocuparem com o aspecto comportamental. Esta é uma das razões porque muitos métodos vistos são extensões dos métodos de desenvolvimento de sistemas não de tempo-real.

Outro aspecto evolutivo observado foi a preocupação dos métodos para desenvolvimento de STR em incorporar a modelagem do ambiente externo, durante a fase de análise de requisitos.

Pôde-se notar também que, a utilização da abordagem de transição de estados para a representação de comportamento foi adotada na maioria dos métodos revisados.

São diversas as formas em que aparecem as representações para transições de estados: diagramas, tabelas, matrizes, ou ainda outras variações e extensões dessas formas. 


\section{Capítulo 3}

\section{A FERRAMENTA DESENVOLVIDA: UM SIMULADOR DE STATECHARTS}

\subsection{Considerações Iniciais}

Para os Sistemas de Tempo-Real, geralmente, a distinção entre as técnicas de análise e de projeto se torna obscura. $O$ analista deve considerar questões de projeto, ou a descrição da especificação será apenas uma formalidade, o que em termos de STR significa, muitas vezes, deixar em aberto alguns aspectos importantes para as etapas posteriores de implementação.

Os auxílios de simulação durante o desenvolvimento de STRs ajudam o analista e o projetista a assegurár que:

- as decisões arquiteturais podem ser implementadas,

- o desempenho tem uma boa probabilidade de ser alcançado, e

- a concorrência obterá o efeito desejado.

Desta forma, uma simulação automatizada visa permitir que se averigue com maior agilidade se um STR funciona não somente com relação às funções que deve executar como também à dinâmica que deve ter. 
Em muitos campos de estudo, um fenômeno não é estudado diretamente, mas através de um modelo do fenômeno. Um modelo, no contexto de software de sistemas, é uma representação, freqüentemente em termos matemáticos, das características importantes do objeto ou sistema em estudo. Pela manipulação da representação obtém-se novos conhecimentos sobre o fenômeno modelado e sobre o próprio modelo, sem o custo, incoveniência ou mesmo perigo da manipulação do fenômeno real. Por exemplo, muitos trabalhos com energia atômica têm sido feitos por modelagem, devido ao custo e perigo do manuseio de materiais radioativos.

As ferramentas automatizadas, além de facilitarem a aplicação prática dos métodos, são geralmente úteis para a recuperação de informação, representação de múltiplos pontos de vista, referências cruzadas e simulação dos requisitos de software e de sistemas.

White, em [Whit85], comenta a dificuldade de se desenvolver manualmente uma documentação de requisitos adequada e de se fazer análise de consistência para os sistemas embutidos devido à dimensão dos múltiplos estados desses sistemas, sua natureza dinâmica e distribuida, e sua contínua evolução.

Neste capítulo, são apresentados os aspectos gerais de modelagem da ferramenta, cujo principal objetivo é o de apoiar a utilização da técnica STATECHARTS para especificação do comportamento de STR complexos, através da simulação dos seus diagramas.

Na próxima seção é apresentada a técnica com alguns de seus detalhes mais importantes e nas outras duas seções consecutivas são listados os aspectos relevantes do projeto e implementação da ferramenta.

\subsection{A Técnica de Especificação de Comporta- mento de STR: STATECHARTS}

A partir da conceituação de STRs que este trabalho apresentou no capítulo 2, ficou clara a necessidade da especificação do aspecto comportamental de sistemas do tipo STR.

Conforme visto no levantamento bibliográfico do capítulo anterior, existem várias formas de se representar o comportamento dos sistemas, isto é, o aspecto das reações dos sistemas a eventos externos e a eventos internos. As técnicas utilizadas pelos métodos não são totalmente distintas, pois a maioria 
delas parte do princípio de se estabelecer uma representação gráfica que mostre o universo de estados e possíveis eventos que possam ocorrer no sistema a ser modelado, de forma a permitir que se tenha uma configuração da situação corrente do sistema.

Durante a revisão bibliográfica, constatou-se que todas as técnicas para representação de comportamento vistas possuem as propriedades de:

- serem rigorosas, de forma a evitar as possiveis falhas por parte de quem as utiliza. Quando os sistemas possuem muitos estados e transições que devem ser analisados, as técnicas geralmente fornecem alguma forma de checagem de impasses, estados nunca alcançados e não-determinismo, por exemplo, através de algum algoritmo aplicado à representação feita.

- apresentarem de forma gráfica as inúmeras situações em que os sistemas possivelmente possam estar, para uma rápida visualização e compreensão do sistema.

Observou-se, também, que a maior parte dos métodos utiliza as MEFs, e suas respectivas formas gráficas para a representação da dinâmica dos sistemas, seja Diagramas ou Tabelas de Transição de Estados. Razões para preferências por essa técnica podem ser encontradas no trabalho de Jacob, em [Jaco83].

Em seu artigo Jacob faz uma investigação sobre a utilização de duas técnicas para especificação formal em projetos de Interface Homem-Máquina: DTE (Diagramas de Transição de Estados) e BNF (Backus-Naur Form). Jacob conclui que apesar das duas técnicas serem formalmente equivalentes, as formas diferentes de representação possuem um efeito importante sobre a compreensão das especificações resultantes. A vantagem do DTE sobre a BNF é a de que em sua notação, o conceito dos estados e das regras de transição associadas a eles aparece explicitamente.

A técnica denominada STATECHARTS (mapa de estados ou diagrama de estados ou rota de estados), segundo seu criador Harel, em [Hare87a], é um auxílio à especificação e projeto de sistemas reativos complexos e de grande porte. A técnica é uma extensão da técnica DTE.

STATECHARTS fornece um formalismo visual para representação dos relacionamentos entre todos os estados em que um STR pode se encontrar, o que corresponde à descrição comportamental de STRs. Isso é feito de uma maneira agradável è suficientemente rigorosa por possuir o embasamento teórico das MEFs. 
Segundo Harel, o principal objetivo de STATECHARTS é amenizar a dificuldade de se descrever o comportamento reativo, isto é, a dinâmica dos sistemas reativos, de forma clara e realística, e ao mesmo tempo formal e rigorosa, de maneira a possibilitar também uma simulação detalhada do sistema.

A revisão bibliográfica mostrou também que a maioria da literatura está de acordo que estados e eventos são, a priori, o meio mais natural através do qual se descreve o comportamento dinâmico de um sistema.

Uma componente básica da descrição comportamental dos sistemas é uma transição de estado, que toma a seguinte forma geral:

- Quando o evento "a" ocorre no estado $A$, se a condição $C$ é verdadeira nessa hora, o sistema muda para o estado $\mathrm{B}$.

A representação convencional adotada pelos DTEs para essa formulação é visualizada através do seguinte diagrama :

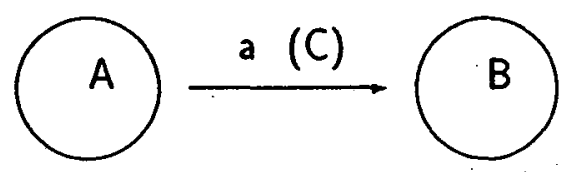

As MEFs e seus correspondentes DTEs são o mecanismo formal para juntar tais componentes básicas de descrição comportamental (transição de estado) num todo, segundo Brady, em [Brad77].

Os DTEs convencionais, conforme visto na seção anterior, são grafos dirigidos, com os nós denotando os estados e setas (rotuladas com os eventos disparadores e as condições de guarda) denotando as transições.

A especificação de um sistema complexo usando diagramas de transição convencionais geralmente esbarra na necessidade de se criar um diagrama muito volumoso, com grande quantidade de estados e transições, o que torna difícil sua visualização e manipulação.

Portanto, uma boa abordagem de estado/evento/transição deveria também cuidar naturalmente de aspectos mais gerais e flexíveis, como mostram, por exemplo, os seguintes requisitos: 
1. "em todos estados de vôo, quando a alavanca amarela é puxada, o assento será lançado para fora"

2. "a mudança de estado na caixa-de-engrenagem é independente do sistema de breque (freios)"

3. "quando o botão de seleção é pressionado, entrar no modo seleção"

4. "Modo-Mostrador consiste de mostrador-hora, mostrador-data e mostradorcronômetro"

O primeiro requisito sugere alguma habilidade de agregar estados num superestado. ortogonalidade.

O segundo introduz a idéia de ter-se independência entre estados, ou

$\mathrm{O}$ terceiro requisito sugere a necessidade de transições mais gerais do que uma simples transição (seta de evento) rotulada, fato que está associado à noção de modos do sistema. A definição de modos de sistemas é encontrada em [Whit87] e diz que modo é um estado do sistema baseado no estado inicial e na história dos eventos que afetam o sistema. Um nome de modo pode ser substituído pelos conjuntos de condições ou pela história dos eventos no sistema. Um exemplo citado por White, em [Whit87], é o de um navio que pode estar operando no modo de comunicação e no modo de navegação ao mesmo tempo.

$\mathrm{O}$ quarto requisito indica o refinamento dos estados.

Como se verá a seguir, os diagramas Statecharts atendem aos quatro requisitos levantados acima. A aplicação da técnica STATECHARTS no exemplo ilustrado na figura 3.1, conduz ao diagrama da figura 3.2, e corresponde à seguinte semântica dos estados:

- Existem três estados: A, B e C

- O evento " $\mathrm{d}$ ", ocorrendo no estado A, transfere o sistema para o estado C, somente se a condição $P$ for verdadeira no instante da ocorrência do evento.

- Uma vez que o sistema muda para o estado B a partir da transição "b" de $\mathrm{A}$ ou $\mathrm{C}$, a técnica permite o agrupamento destes últimos estados num superestado D e substitui as duas setas "b" por uma. 


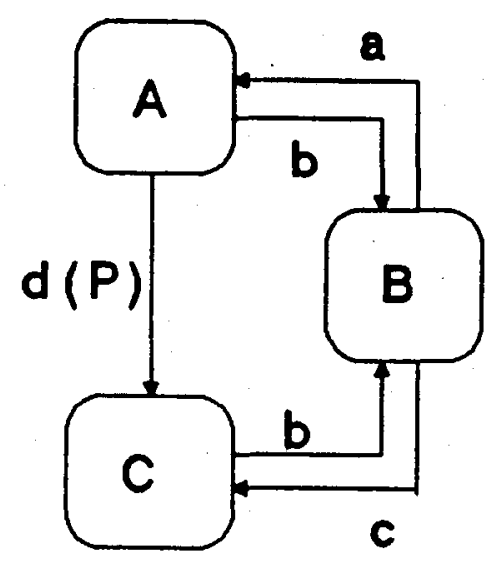

Figura 3.1: Diagrama de Transição de estados (1)

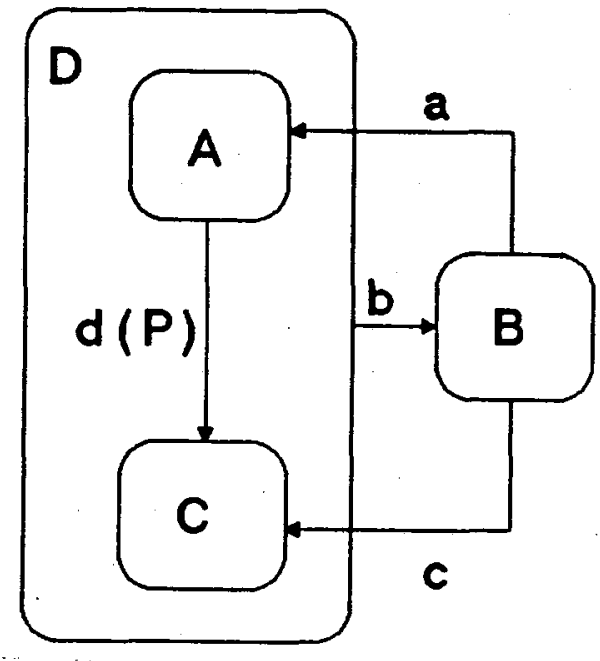

Figura 3.2: Statechart (1)

A semântica de D é então o ou-exclusivo (XOR) de $\mathrm{A}$ e $\mathrm{C}$; isto é, para estar no estado $D$, deve-se estar em $A$ ou em $C$, e não em ambos. Portanto, $D$ é agora uma abstração de A e C, e a seta "b", que se origina em D, capta uma propriedade comum de $\mathrm{A}$ e $\mathrm{C}$, que é a de se originar deles e terminar em $\mathrm{B}$.

A decisão de se manter a transição saindo de um superestado, como é o caso da transição cujo evento disparador é "b", no exemplo, é a de representar as transições que saem de todos os subestados daquele superestado. Este é o mecanismo básico que permite à técnica de mapeamento de estados, adotada em STATECHARTS, economizar no número de setas, em relação à formulação convencional dos DTEs.

No caso de representação de concorrência (ortogonalidade), a notação adotada em STATECHARTS é de linhas tracejadas delimitando os estados con- 


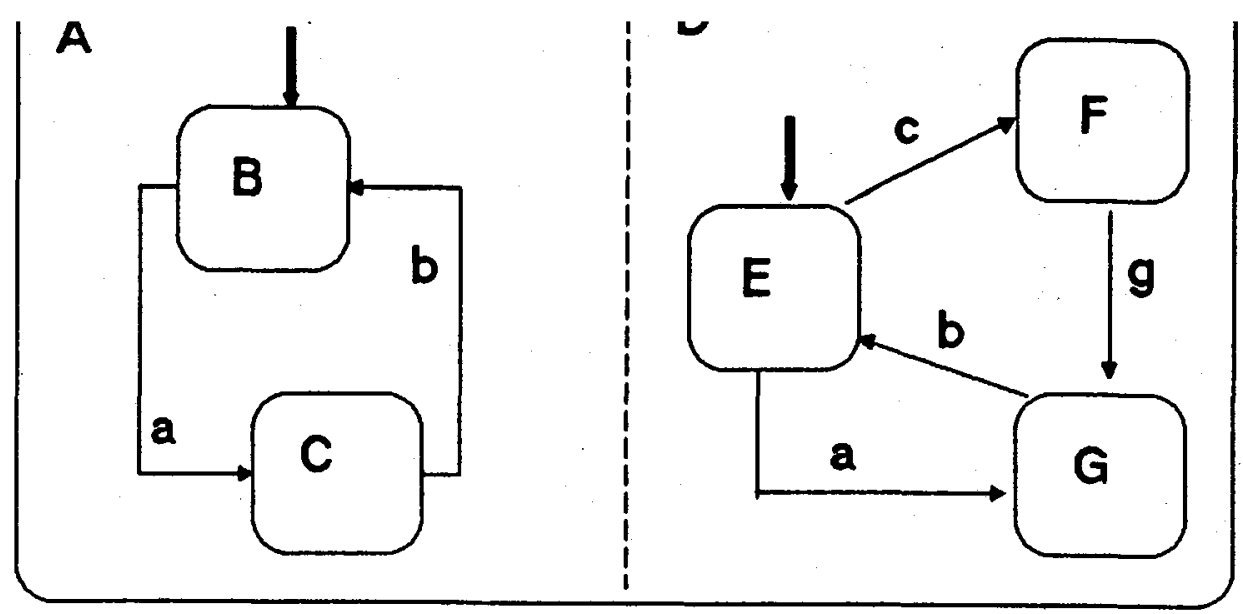

Figura 3.3: Statechart (2)

correntes, conforme mostra a figura 3.3.

A entrada no superestado $F$ indica que o sistema estará num subestado de $\mathrm{A}$ e num subestado de $\mathrm{D}$ simultaneamente.

Assim como nas máquinas de Mealy, eventos de saída podem ser especificados nos Statecharts. A esses eventos são dados os nomes de "ações" e, além de simplesmente indicarem possiveis eventos para o mundo real, podem gerar novos eventos internos que se propagam ("Broadcasting"), afetando outros componentes do diagrama. Por exemplo, se uma transição rotulada por "ev/a" ocorre, então " $\mathrm{a}$ " é imediatamente acionado, podendo causar transições adicionàis, como mostra a figura 3.4 .

Portanto, os diagramas Statecharts possuem um formalismo visual para descrever estados e transições em uma forma modular, habilitando agregação, ortogonalidade e refinamento.

Além das propriedades de modularidade, agregação, ortogonalidade e refinamento, o mapeamento de estados de STATECHARTS permite que se tenha capacidades de "Zoom" para movimentar para dentro ou detalhar os níveis de abstração (zoom- in), e, para movimentar para fora ou resumir os níveis de abstração (zoom-out), que são obtidos da estratificação entre os estados.

Essencialmente, as duas idéias principais da técnica são a abstração de descrições, através da representação de hierarquia dos estados, e a noção de 


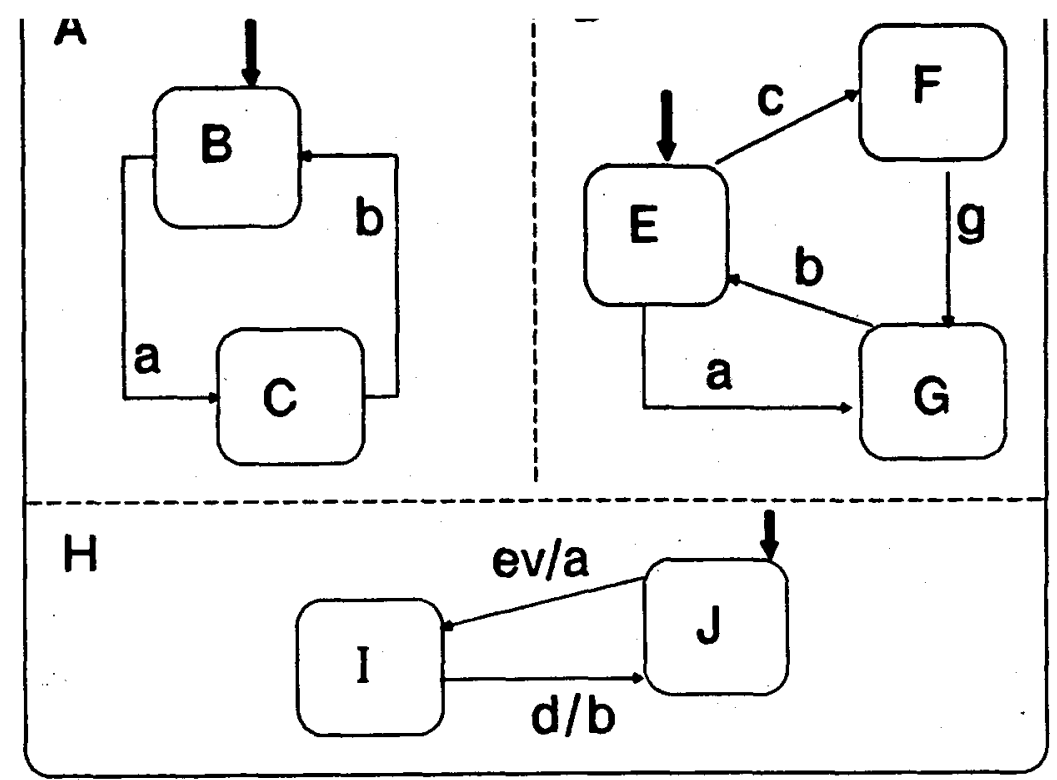

Figura 3.4: Statechart (3)

ortogonalidade, que representa a independência entre os estados. Essas idéias se referem à decomposição dos estados e os dois tipos de decomposição permitidos funcionam da seguinte maneira:

- utilizando-se a decomposição-OU, um estado em um nível de abstração é descrito no próximo nível inferior usando uma outra máquina de estados finitos completa.

- na decomposição-E um estado é dividido em dois ou mais estados ortogonais.

$\mathrm{Na}$ decisão sobre uma representação gráfica para captar profundidade e hierarquia, existe uma desvantagem nos desenhos de árvores ou outros grafos de linhas, pois esses meios não se utilizam da área do gráfico em si, ou seja, as linhas e os pontos não têm nenhuma largura, e assim não é possível tirar-se algum proveito de sua alocação.

Nos Statecharts, os retângulos arredondados são utilizados para denotar os estados em qualquer nível, utilizando o encapsulamento para expressar a relação de hierarquia. As setas, representando as transições, podem se origi- 


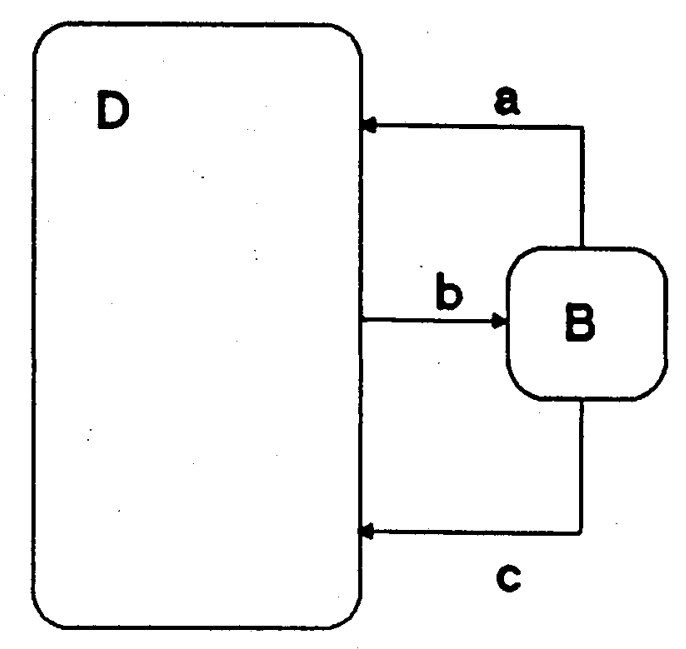

Figura 3.5: Statechart (1) - "zoom-out"

nar e terminar em qualquer nivel. Uma seta é rotulada com um evento (ou sua abreviação) e, opcionalmente, também com uma condição parentizada.

A representação gráfica adotada é baseada num conceito mais geral: o higraph (hierarchical graph ou higrafo em português), apresentado por Harel. Este higrafo combina noções dos círculos de Euler, diagramas de Venn (conjuntos de elementos e as interconxões de estrutura), grafos (elementos e uma relação binária sobre eles) e hipergrafos (conjuntos de elementos e uma relação entre eles). A analogia é de que um grafo pode representar um autômato finito e um higrafo pode representar um Statechart.

Existe também uma possivel generalização do higrafo, segundo Harel, em [Hare88b], que é a de poder ser utilizado para eliminação dos relacionamentos "is-a" nos Diagramas de Entidade-Relacionamento, que são utilizados para descrição dos esquemas de Base de Dados. Isso é possível denotando-se o relacionamento "is-a" por uma relação de subestado. Por exemplo, um gerente poderia ser denotado como um subestado dentro do estado de empregado.

Para a abordagem de mapeamento de estados, STATECHARTS possibilita que a figura 3.2 possa ser vista a partir de um outro ângulo, que exemplifica a técnica de refinamentos sucessivos. Poderia-se ter inicialmente a situação da figura 3.5, e então o estado $\mathrm{D}$ poderia ser refinado para consistir de $\mathrm{A}$ e $\mathrm{C}$, como na figura 3.6. No entanto, nesse refinamento produzido pela figura 3.6 , as setas de entrada "a" e "c" se tornam subespecificadas, pois elas não dizem em qual dos dois estados $\mathrm{A}$ ou $\mathrm{C}$, a transição acarretará uma mudança. A partir da especificação das setas para $\mathrm{A}$ e $\mathrm{C}$ respectivamente, e da adição da transição "d" dentro de $\mathrm{D}$, obtém-se novamente a figura 3.2 . 


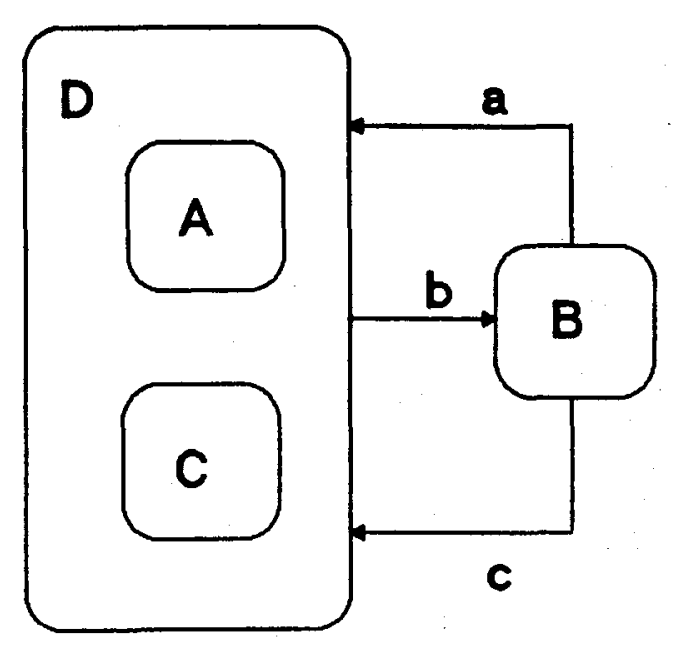

Figura 3.6: Statechart (1) - 1. "zoom-in"

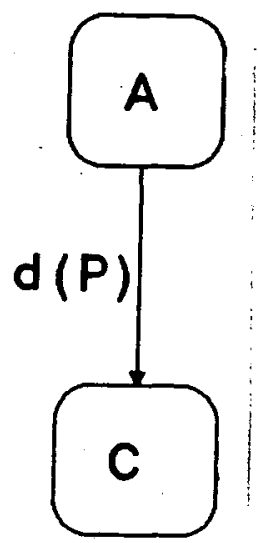

Figura 3.7: Statechart (1) - 2. "zoom-in"

Os conceitos de agregação ou abstração (bottom-up) e refinamento (top-down) dão origem ao relacionamento "ou" entre os subestados de um estado.

As operações de detalhar (zoom-in) e resumir (zoom-out) podem ser ilustradas usando-se esse exemplo. A primeira (zoom-in) é obtida olhando-se "dentro" de D, isto é, detalhando-se D e enxergando simplesmente a figura 3.7; e a segunda (zoom-out) é feita pela eliminação do que está dentro de $\mathrm{D}$ e abstraindo ou resumindo a figura 3.2 para a figura 3.5 .

No caso em que para o mundo "externo", o estado A é o estado de entrada quando a entrada é requerida no grupo de estados A, B, C, o sistema entra em A a menos que outro estado inicial seja especificado, ou seja, pela ausência de especificação de outro estado. A notação para representar essa situação é uma pequena seta cuja origem é apenas um ponto (indicando o estado "default" ou inicial), como pode ser visto na figura 3.8 . 


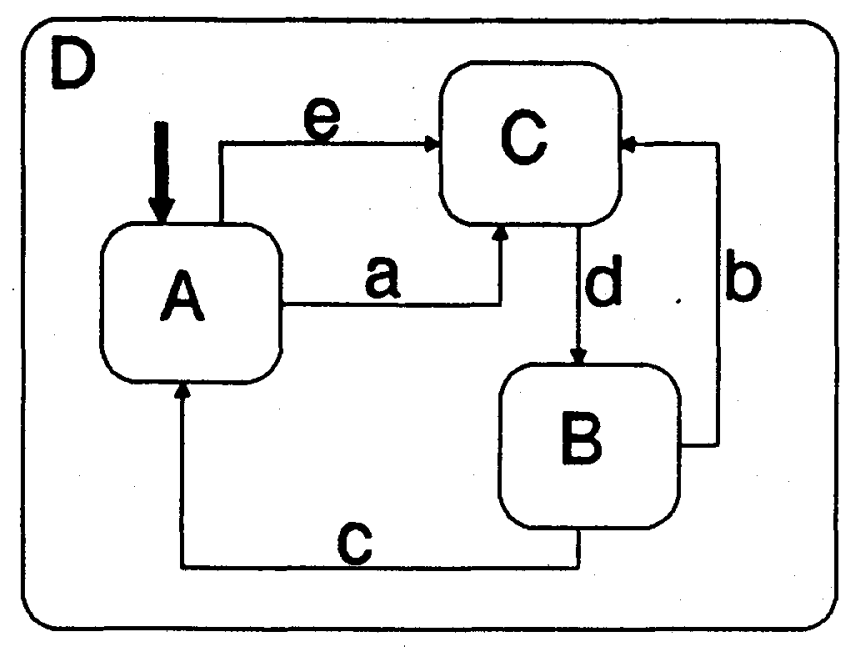

Figura 3.8: Statechart (4)

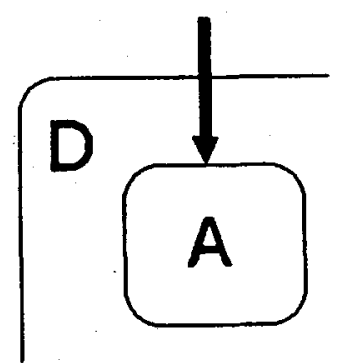

Figura 3.9: Parte do Statechart (4) - Uma notação de default

Para a figura 3.2 poderiam ter sido utilizadas as notaçōes das figuras 3.9 e 3.10 , que representam que $D$ é o estado assumido por ausência de especificação entre D e B, e A é o estado assumido por ausência entre A e C, por exemplo. É claro que, para as operações de detalhar (zoom-in) e de resumir (zoom- out), o último tipo de representação tem vantagens óbvias.

Nota-se que as setas que são assumidas por ausência de especificação (default) são análogas aos estados iniciais dos autômatos de estados finitos.

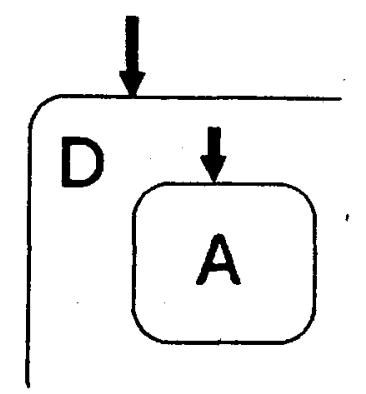

Figura 3.10: Parte do Statechart (4) - Outra notação de default 


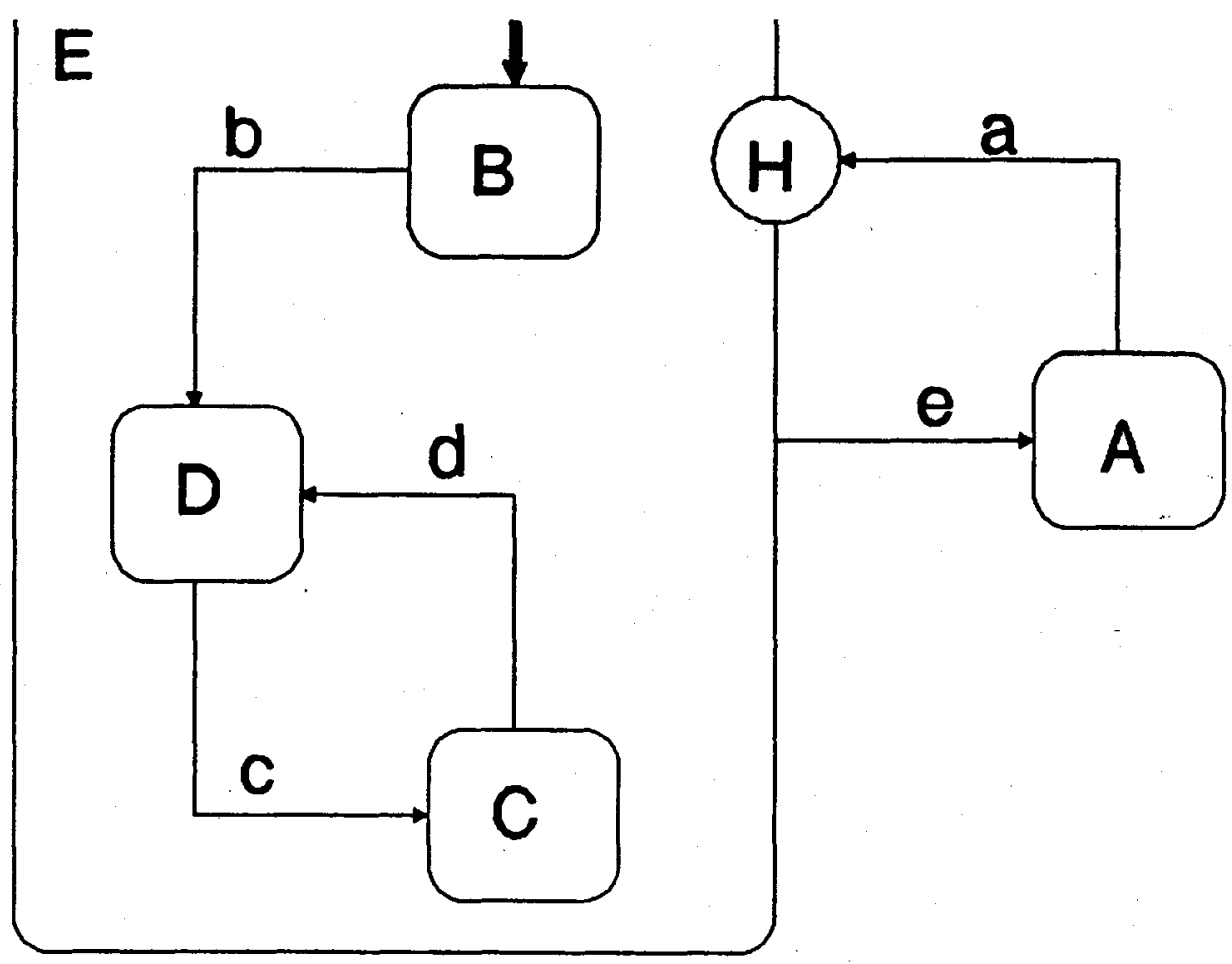

Figura 3.11: Statechart (5) - Notação de História

A característica de História é uma outra notação adicional introduzida por STATECHARTS. A notação é um H ligado a uma transição de um estado (subestado ou superestado) para um superestado. Representa um controle especial relacionado àquele evento descrito na transição. A transição possui então o significado de que, quando seu evento dispara, faz com que o próximo estado para o qual o sistema muda, seja aquele em que o sistema estava da última vez em que aquele superestado foi ativado. Adicionalmente a esta notação, Harel utiliza $\mathbf{H}^{*}$ quando a volta do sistema para a última situação em que esteve nele não se limita somente ao nível do superestado em que a entrada $H$ chega, mas sim, se propaga até os estados básicos do superestado.

O Statecharts da figura 3.11 mostra, como um exemplo da utilização da notação $\mathrm{H}$, a possível situação de que após ocorrida a transição "a", os estados $\mathrm{B}, \mathrm{C}$ ou $\mathrm{D}$ estarão ativados, dependendo da última configuração de ativação do superestado $\mathrm{E}$.

Com todo este aparato visual, o mapeamento de estados adotado em STATECHARTS tem também a vantagem de possuir o formalismo derivado das MEFs. A sintaxe e a semântica da técnica são descritas com mais detalhes por Harel, em [Hare87b] e também por Batista, em [Bati90]. 


\subsection{Aspectos selecionados do Projeto da Fer- ramenta}

Foi visto na seção anterior que os Statecharts representam uma evolução dos DTEs, tendo, entre outras vantagens, facilidades para representar situações paralelas, situações em vários níveis de abstração, etc. Para a especificação dos requisistos que a ferramenta deveria cumprir, foi elaborado um estudo de todas as suas formas para representação dessas facilidades.

Batista, em [Bati90], propõe o desenvolvimento de um Editor-Gráfico de STATECHARTS criando também estruturas de dados correspondentes para o armazenamento do STATECHART, usando Árvores "E-OU" e tabelas. Complementando esse Editor-Gráfico, a ferramenta desenvolvida cria um ambiente que permitirá, posteriormente, a simulação gráfica das especificações em STATECHARTS.

Alguns aspectos que foram mais importantes no desenvolvimento da ferramenta são apresentados a șeguir, na forma de uma descrição simplificada do projeto desenvolvido.

\section{Requisitos da Ferramenta}

Para a elaboração da ferramenta de apoio à Simulação de Especificações em STATECHARTS, a premissa básica foi a de que fornecesse meios para se interpretar a lógica embutida na notação da técnica.

Harel, em [Hare87b], apresenta um apêndice contendo a Sintaxe e a Semântica formal dos Statecharts. Baseando-se nesse artigo, os ítens abaixo são listados; adequados à nomenclatura adotada durante o projeto da ferramenta. Os Statecharts devem possuir os seguintes conjuntos básicos:

1- ESTADOS : Sobre o conjunto de ESTADOS, como requisitos, têm-se as seguintes caracteristicas:

1.1 A função Hierarquia que define a decomposição dos estados em subestados.

1.2 A existência de um único estado raiz do STATECHARTS que não é subestado de nenhum outro estado. 
1.3 A função Tipo que define para cada estado o seu tipo: "AND" ou "OR". Essa função determina que, se um estado é do tipo "OR", a decomposição dos seus subestados significa que quando o sistema estiver nesse estado, ele estará em somente um dos subestado desse estado. Portanto, o tipo "OR" possui a lógica de ou-exclusivo (xor) entre os subestados. Para o estado do tipo "AND" o sistema estará em todos os subestados desse estado, em paralelo.

1.4 Os símbolos de História que definem a memorização de uma determinada configuração de estados do sistema de forma a possibilitar sua restauração.

1.4.1 para que somente um nivel de restauração seja memorizado o símbolo $\mathrm{H}$ é utilizado.

1.4.2 quando a restauração for requerida em todos os níveis a partir de onde se encontra o símbolo de História o símbolo utilizado é $H^{*}$.

1.5 A função default que define um conjunto de estados e símbolos de História de forma a configurar um estado do sistema a partir do estado raiz. Essa função possui as seguintes possibilidades de utilização:

1.5.1 "def" $\rightarrow$ indica que o estado é um estado default do sistema e sua representação gráfica é uma pequena seta, apontando para o estado. Esse símbolo deve estar associado a um único estado, no caso de subestados de um estado do tipo "OR".

1.5.2 "def/H" $\rightarrow$ indica que o estado é um estado default do sistema, respeitando-se a "História" do sistema naquele estado. Sua representação gráfica é uma pequena seta apontando para o estado, juntamente com o símbolo $H$. Sua utilização significa que, se o sistema já possuir uma memorização de algum estado de mesmo nível de Hierarquia, esse estado prevalece sobre o estado onde se encontra o símbolo de default.

1.5.3 "def/ $\mathrm{H}^{*} " \rightarrow$ indica que o estado é um estado default do sistema, respeitando-se a "História" do sistema a partir daquele estado, em todos os níveis de Hierarquia de subestados. Sua representação gráfica é uma pequena seta apontando para o estado, juntamente com o simbolo $\mathrm{H}^{*}$. Sua utilização significa que, caso o sistema já possua uma memorização de algum estado de mesmo nível de Hierarquia, esse estado prevalece sobre o estado onde se encontra o símbolo de default, bem como toda a "História" dos subestados a partir dele.

2 - EXPRESSÕES : O conjunto de EXPRESSÕES é definido como a com- 
binação de operações algébricas sobre números e variáveis além de um operador especial: current.

2.1 0 operador current aplica-se a variáveis, retornando o valor atual da variável e é denotado por "cr(var)".

2.2 Os operadores algébricos são requeridos na formação de expressões.

3 - CONDIÇÕES : O conjunto de CONDIÇÕES PRIMITIVAS define basicamente os valores true e false para serem avaliados durante uma transição no sistema. Essas condiçôes fazem com que os estímulos percebidos pelo sistema sejam neutralizados em função de uma avaliação das condições especificadas na transição.

As condições são combinadas entre si de forma a compor novas condições com os seguintes operadores:

3.1 "in(estado_x $)$ " $\rightarrow$ que retorna true quando o sistema está no estado_x.

3.2 "not_yet(evento_x)" $\rightarrow$ que retorna true quando o sistema avalia que o evento_x ainda não foi disparado.

3.3 "current(condição_x)" $\rightarrow$ que retorna o valor atual da condição_x.

3.4 os operadores relacionais aplicados a expressões:

"=" (igual)

"<>" (diferente)

">" (maior)

"<" (menor)

" $<=$ " (menor ou igual)

">=" (maior ou igual)

3.5 os operadores lógicos aplicados a condições:

"and", "or" , "not"

4 - EVENTOS : O conjunto de EVENTOS PRIMITIVOS define os estímulos que são percebidos pelo sistema e que propiciarão o disparo das transições. Como "eventos primitivos", entende-se intuitivamente como qualquer ocorrência, independente de avaliação, que pode alterar o estado do sistema.

Os eventos podem ser de dois tipos :

4.1 eventos externos, que são acionados sob alguma intervenção externa à Simulação. São tidos como simples identificadores na especificaçã̀o.

4.2 eventos internos, que são disparados pela própria lógica de sua especificação. Ou seja, a especificação do evento deve ser avaliada para que possa intervir na configuração dos estados do sistema. 
Os eventos primitivos podem estar combinados entre si e com os eventos internos relacionados abaixo:

4.3 "true (condição_x)" $\rightarrow$ que determina um estímulo no instante em que a condição_x se tornou verdadeira.

4.4 "false(condição_x)" $\rightarrow$ que determina um estímulo no instante em que a condição_x se tornou falsa.

4.5 "changed(variavel)" $\rightarrow$ que determina um estímulo no instante em que a variável mudou de valor.

4.6 "exit(estado_x)" $\rightarrow$ que determina um estímulo no instante em que o sistema deixou de estar no estado_x.

4.7 "entered(estado_x)" $\rightarrow$ que determina um estímulo no instante em que o sistema passou a estar no estado_x.

Para a composição de eventos como acionadores de transições, os seguintes operadores de eventos são requeridos:

4.8 "or" , "and"

4.9 "evento_x [ condição_y ]" $\rightarrow$ que determina um estímulo no instante em que ocorreu o evento-x, desde que a condição-y seja verdadeira nesse mesmo instante.

Finalmemte, um evento especial bastante utilizado nos exemplos de Harel pode ser enunciado:

4.10 "time_out(n unid_tempo)" $\rightarrow$ que determina um estímulo no instante em que " $\mathrm{n}$ " unidades de tempo (unid_tempo) transcorreram desde o momento em que o sistema passou a estar no estado-origem da transição que possui esse evento.

5 - AÇÕES : O conjunto de AÇÕES é definido como o das reações instantâneas simultâneas às tranisições em que elas são especificadas. As ações aparecem especificadas após o símbolo "/" (barra) e são disparadas pelos eventos que as antecedem.

Uma ação requer o operador de atribuição ":=" nas seguintes formas:

5.1 "condição_primitiva $:=$ condição_ $x$ " $\rightarrow$ onde a ação consiste da atribuição do valor da avaliação da condição_x à condição_primitiva.

5.2 "variável $:=$ expressão_x" $\rightarrow$ onde a ação consiste da atribuição do valor da avaliação da expressão_x à variável. 
Dessa forma pode-se observar que uma ação pode vir a ser um evento para o sistema, uma vez que seu acionamento é instantâneo e simultâneo à transição. Esse efeito é chamado de propagação de eventos (Broadcasting). Para esse efeito deve ser prevista uma distinção entre os eventos ocorridos externamente dos que foram criados por propagação. Harel define as unidades de passo, que são os intervalos entre eventos ocorridos, e os micropassos, que reconfiguram os estados do sistema devido a eventos gerados por ações das transições e que são intervalos contidos nas unidades de passo.

Uma ação especial pode ser enunciada devido à sua utilização nos exemplos apresentados por Harel:

5.3 "clear(estado[*])" $\rightarrow$ equivale a "clear history" e consiste em eliminar a história para a configuração de um estado do sistema (apenas ele ou ele e todos os seus subestados), fazendo com que nas próximas transiçooes chegando a esse estado, mesmo as que possuem o símbolo de história, o sistema vá para os estados defaults.

6 - TRANSIÇÕES : Sobre o conjunto de TRANSIÇÕES a ferramenta possui o requisito de que, dado um conjunto de estados atuais do sistema, se ocorrer um estímulo (eventos) no sistema, ele então passará para um outro conjunto de estados, configurando a resposta ao estímulo recebido.

As transições, que graficamente constituem os arcos no Statecharts, possuem os rótulos que as acompanham da seguinte forma: "evento_x / ação_y". Esse rótulo determina que a transição seja disparada no instante em que recebe o estímulo do evento_x e a ação-y seja executada.

As TRANSIÇÕES podem ser:

6.1 "1 - 1" (um para um) quando afetam estados do tipo OR da seguinte maneira: deixam de estar no estado-origem da transição e passam para o estado-destino da transição.

6.2 " $\mathrm{n}-\mathrm{m}$ " ( $n$ para $m$ ) quando afetam estados do tipo AND. Para esse tipo de transição, os $n$ estados-origem em que o sistema deixa de estar devem ser o de todos os estados ortogonais de onde parte a transição. Equivalentemente os $\mathrm{m}$ estados-destino da transição para os quais o sistema configura, devem ser todos os estados ortogonais a ele.

Para esse requisito, vale ressaltar que as transições descritas afetam as $\mathrm{Hj}$ erarquias dos estados envolvidos.

Um outro requisito importante no conjunto de transições pode ser descrito: 
6.3 As transições são relacionamentos entre estados do tipo OU do sistema especificado. A partir desse fato pode-se ter o caso de transições paralelas, por estarem contidas em subestados do tipo AND. Esse é o caso, por exemplo, quando várias transições, contidas em subestados ortogonais diferentes, possuírem o mesmo rótulo. Portanto, elas devem ser efetivadas simultâneamente.

Enumerados os principais requisitos para o desenvolvimento da ferramenta, a seguir, encontra-se uma relação das decisões tomadas quanto à Análise e Simulação para implementar cada requisisto, pois a ferramenta é composta de um módulo Analisador, que permite a criação de uma base de dados contendo a representação interna do Statechart e um módulo de Simulação (vide seção $3.4)$. 


\begin{tabular}{|c|c|c|c|}
\hline Item & Requisito & ANALISADOR & SIMULADOR \\
\hline$\overline{1.1}$ & Hierarquia & $\begin{array}{l}\text { Reconhecida pelo sim- } \\
\text { bolo SUBESTADOS. }\end{array}$ & $\begin{array}{l}\text { Quando ocorre uma transição } \\
\text { os estados-origem são desati- } \\
\text { vados e os estados-destino são } \\
\text { ativados a partir do Ancestral } \\
\text { comum. O requisito é sem- } \\
\text { pre tratado nos algoritmos da } \\
\text { Árvore dos Estados. }\end{array}$ \\
\hline 1.2 & Raíz & $\begin{array}{l}\text { Verificada a sua unici- } \\
\text { dade. }\end{array}$ & $\begin{array}{l}\mathrm{Na} \text { inicialização por default a } \\
\text { ativação dos estados sempre } \\
\text { começa pelo estado "raiz_tab". }\end{array}$ \\
\hline 1.3 & Tipo & $\begin{array}{l}\text { Reconhecidas as decom- } \\
\text { posições OR e AND } \\
\text { dos estados. Incluído } \\
\text { - atributo "ATOMO" } \\
\text { para os estados que não } \\
\text { possuem decomposição. }\end{array}$ & $\begin{array}{l}\text { Requisito considerado em toda } \\
\text { a Simulação, mais especifica- } \\
\text { mente na desativação e ativação } \\
\text { dos estados relativos à transição } \\
\text { ocorrida. }\end{array}$ \\
\hline 1.4 .1 & $\overline{\mathrm{H}}$ & $\begin{array}{l}\text { Reconhecida transição } \\
\text { por Historia através do } \\
\text { simbolo } \mathrm{H} \text {. }\end{array}$ & $\begin{array}{l}\text { A transição faz com que recu- } \\
\text { pere a configuração de estados } \\
\text { da última vez que esteve ativado } \\
\text { no nível do estado. }\end{array}$ \\
\hline 1.4 .2 & $\mathrm{H}^{*}$ & $\begin{array}{l}\text { Reconhecida transição } \\
\text { por Historia para todos } \\
\text { os niveis através do sim- } \\
\text { bolo } H^{*} \text {. }\end{array}$ & $\begin{array}{l}\text { A transição faz com que recu- } \\
\text { pere a configuração de estados } \\
\text { da última vez que esteve ativado } \\
\text { em todos os níveis a partir do } \\
\text { estado-destino da transição. }\end{array}$ \\
\hline 1.5 .1 & def & $\begin{array}{l}\text { Reconhecido estado de- } \\
\text { fault pelo símbolo DEF. }\end{array}$ & $\begin{array}{l}\text { Inicialização do sistema com os } \\
\text { estados que estão indicados por } \\
\text { default. }\end{array}$ \\
\hline
\end{tabular}




\begin{tabular}{|c|c|c|c|}
\hline Item & Requisito & ANALISADOR & SIMULADOR \\
\hline 1.5 .2 & $\mathrm{def} / \mathrm{H}$ & $\begin{array}{l}\text { Reconhecido estado de- } \\
\text { fault e História através } \\
\text { do símbolo } D E F / H \text {. }\end{array}$ & $\begin{array}{l}\text { Inicialização por default na } \\
\text { primeira vez que o estado é ati- } \\
\text { vado e usando a última con- } \\
\text { figuração de estados de mesmo } \\
\text { nível nas vezes seguintes. Para } \\
\text { os subestados do estado ativado, } \\
\text { inicialização por def. }\end{array}$ \\
\hline 1.5 .3 & $\operatorname{def} / H^{*}$ & $\begin{array}{l}\text { Reconhecido estado de- } \\
\text { fault e História em to- } \\
\text { dos os niveis através do } \\
\text { símbolo } D E F / H^{*} \text {. }\end{array}$ & $\begin{array}{l}\text { Inicialização por default na } \\
\text { primeira vez que o estado é ati- } \\
\text { vado e também para os seus } \\
\text { subestados. Nas vezes se } \\
\text { guintes é utilizada a última con- } \\
\text { figuração dos estados e respec- } \\
\text { tivos subestados. }\end{array}$ \\
\hline 2.1 & $\operatorname{cr}($ var $)$ & $\begin{array}{l}\text { Operador reconhecido } \\
\text { nas Expressões por CR. }\end{array}$ & $\begin{array}{l}\text { Interpretado sempre como de } \\
\text { valor Verdadeiro. }\left({ }^{*}\right)\end{array}$ \\
\hline 2.2 & $\begin{array}{l}\text { Operadores } \\
\text { Algébricos }\end{array}$ & $\begin{array}{l}\text { Os operadores algébri- } \\
\text { cos reconhecidos nas } \\
\text { Expressōes são : }+,- \text {, } \\
l, * \text {. }\end{array}$ & $\begin{array}{l}\text { Avalia dos de acordo com seu sig- } \\
\text { nificado convencional. }\left({ }^{*}\right)\end{array}$ \\
\hline 3.1 & in(estado) & $\begin{array}{l}\text { Reconhecido como ope- } \\
\text { rador de condição pelo } \\
\text { símbolo IN. }\end{array}$ & $\begin{array}{l}\text { Verifica se o estado está ati- } \\
\text { vado, nesse caso retornando } \\
\text { Verdadeiro. }\end{array}$ \\
\hline 3.2 & not_yet(e) & $\begin{array}{l}\text { Reconhecido como ope- } \\
\text { rador de condição pelo } \\
\text { símbolo NOT_YET. }\end{array}$ & $\begin{array}{l}\text { Interpretado sempre como de } \\
\text { valor Verdadeiro. }\left(^{*}\right)\end{array}$ \\
\hline 3.3 & $\operatorname{cr}($ cond $)$ & $\begin{array}{l}\text { Reconhecido como ope- } \\
\text { rador de condição pelo } \\
\text { símbolo CR. }\end{array}$ & $\begin{array}{l}\text { Retorna o valor avaliado da } \\
\text { condição. }\left({ }^{*}\right)\end{array}$ \\
\hline
\end{tabular}




\begin{tabular}{|c|c|c|c|}
\hline Item & Requisito & ANALISADOR & SIMULADOR \\
\hline 3.4 & $\begin{array}{l}\text { Operadores } \mathrm{Re}- \\
\text { lacionais }\end{array}$ & $\begin{array}{l}\text { Todos os operadores re- } \\
\text { lacionais listados são re- } \\
\text { conhecidos nas Condi- } \\
\text { ções. }\end{array}$ & $\begin{array}{l}\text { Avalia dos de acordo com seu sig- } \\
\text { nificado convencional. }\left(^{*}\right)\end{array}$ \\
\hline 3.5 & and, or, not & $\begin{array}{l}\text { Operadores lógicos re- } \\
\text { conhecidos nas Condi- } \\
\text { çōes. }\end{array}$ & $\begin{array}{l}\text { Avalia dos de acordo com seu sig- } \\
\text { nificado convencional. }\left(^{*}\right)\end{array}$ \\
\hline 4.1 & $\begin{array}{l}\text { eventos exter- } \\
\text { nos }\end{array}$ & $\begin{array}{l}\text { Reconhecidos como } \\
\text { Identificadores. }\end{array}$ & $\begin{array}{l}\text { Aceitos como entrada em cada } \\
\text { passo da Simulação, podendo } \\
\text { entrar mais de um. }\end{array}$ \\
\hline 4.2 & $\begin{array}{l}\text { eventos } \\
\text { internos }\end{array}$ & $\begin{array}{l}\text { Reconhecidos como o- } \\
\text { peradores de condições, } \\
\text { de expressões e pal. } \\
\text { chaves. }\end{array}$ & $\begin{array}{l}\text { Avaliados a cada passo da Simu- } \\
\text { lação, logo após o tratamento } \\
\text { dos eventos externos. }\end{array}$ \\
\hline 4.3 & true(c) & $\begin{array}{l}\text { Reconhecido como ope- } \\
\text { rador aplicado à condi- } \\
\text { ção pelo símbolo TR. }\end{array}$ & $\begin{array}{l}\text { Avalia o valor da condição, se for } \\
\text { Verdadeiro, retorna Verdadeiro. }\end{array}$ \\
\hline 4.4 & false(c) & $\begin{array}{l}\text { Reconhecido como o- } \\
\text { perador aplicado à con- } \\
\text { dição pelo símbolo FS. }\end{array}$ & $\begin{array}{l}\text { Avalia o valor da condição, se for } \\
\text { Falso, retorna Verdadeiro. }\end{array}$ \\
\hline 4.5 & changed(v) & $\begin{array}{l}\text { Reconhecido como ope- } \\
\text { rador aplicado à variavel } \\
\text { pelo símbolo } \mathrm{CH} \text {. }\end{array}$ & $\begin{array}{l}\text { Interpretado sempre como Ver- } \\
\text { dadeiro. }\left({ }^{*}\right)\end{array}$ \\
\hline 4.6 & exit(e) & $\begin{array}{l}\text { Reconhecido como ope- } \\
\text { rador aplicado a estado } \\
\text { pelo símbolo EX. }\end{array}$ & $\begin{array}{l}\text { Interpretado sempre como Ver- } \\
\text { dadeiro. }\left({ }^{*}\right)\end{array}$ \\
\hline 4.7 & entered(e) & $\begin{array}{l}\text { Reconhecido como ope- } \\
\text { rador aplicado a estado } \\
\text { pelo símbolo EN. }\end{array}$ & $\begin{array}{l}\text { Interpretado sempre como Ver- } \\
\text { dadeiro. }\left({ }^{*}\right)\end{array}$ \\
\hline
\end{tabular}




\begin{tabular}{|c|c|c|c|}
\hline Item & Requisito & ANALISADOR & SIMULADOR \\
\hline 4.8 & or, and & $\begin{array}{l}\text { Reconhecidos como o- } \\
\text { peradores lógicos de } \\
\text { eventos. }\end{array}$ & $\begin{array}{l}\text { Avalia dos de acordo com seu sig- } \\
\text { nificado convencional. }\end{array}$ \\
\hline 4.9 & ev [cond] & $\begin{array}{l}\text { Reconhecido e construí- } \\
\text { da pilha polonesa a par- } \\
\text { tir da condição delimi- } \\
\text { tada pelos colchetes }\end{array}$ & $\begin{array}{l}\text { Avalia a condição codificada } \\
\text { numa pilha polonesa ao início do } \\
\text { passo da Simulação iniciado pelo } \\
\text { evento externo. }\end{array}$ \\
\hline 4.10 & t_out(n ut) & $\begin{array}{l}\text { Reconhecido o even- } \\
\text { to interno de contro- } \\
\text { le de tempo através de } \\
\text { T_OUT. Gerada a nota- } \\
\text { ção polonesa para sua } \\
\text { expressão de " } n \text { " unida- } \\
\text { des de tempo. }\end{array}$ & $\begin{array}{l}\text { Interpretado sempre como Ver- } \\
\text { dadeiro. }\left({ }^{*}\right)\end{array}$ \\
\hline 5.1 & $c p:=c$ & $\begin{array}{l}\text { Reconhecida a } \\
\text { ação através da palavra } \\
\text { chave AÇÃO, e também } \\
\text { o símbolo de atribuição. }\end{array}$ & $\begin{array}{l}\text { Considerado como um identifi- } \\
\text { cador de Ação, não recebe ne- } \\
\text { nhum tratamento durante a Si- } \\
\text { mulação. }\left({ }^{*}\right)\end{array}$ \\
\hline 5.2 & $v:=\exp$ & $\begin{array}{l}\text { Reconhecida a } \\
\text { ação através da palavra } \\
\text { chave AÇÃO, e também } \\
\text { o símbolo de atribuição. }\end{array}$ & $\begin{array}{l}\text { Considerado como um identifi- } \\
\text { cador de Ação, não recebe ne- } \\
\text { nhum tratamento durante a Si- } \\
\text { mulação. }\left({ }^{*}\right)\end{array}$ \\
\hline 5.3 & clear(est) & $\begin{array}{l}\text { Reconhecido como ação } \\
\text { especial. }\end{array}$ & Ação não executada. $\left({ }^{*}\right)$ \\
\hline
\end{tabular}




\begin{tabular}{|c|c|c|c|}
\hline Item & Requisito & ANALISADOR & SIMULADOR \\
\hline 6.1 & $\begin{array}{l}\text { transição } \\
\text { "1 } 1 \text { " }\end{array}$ & $\begin{array}{l}\text { Reconhecida a transição } \\
\text { através de somente um } \\
\text { estado após a pala- } \\
\text { vra reservada ORIGEM } \\
\text { e somente um estado } \\
\text { após a palavra reservada } \\
\text { DESTINO. }\end{array}$ & $\begin{array}{l}\text { Tratada como relacionamento } \\
\text { entre dois estados de tipo OR. } \\
\text { A transição é validada para cer- } \\
\text { tificar que o estado origem es- } \\
\text { teja ativo e em seguida busca-se } \\
\text { o estado Ancestral comum dos } \\
\text { dois estados relacionados para } \\
\text { aplicar-se a desativação a par- } \\
\text { tir do ancestral comum até a } \\
\text { origem da transição e ativação } \\
\text { dos estados a partir do ancestral } \\
\text { comum até o estado destino. }\end{array}$ \\
\hline 6.2 & $\begin{array}{l}\text { transição } \\
\text { "m } \rightarrow n \text { " }\end{array}$ & $\begin{array}{l}\text { Reconhecida a transição } \\
\text { através de "m" estados } \\
\text { separados por vírgula } \\
\text { após a palavra reser- } \\
\text { vada ORIGEM e de "n" } \\
\text { estados separados por } \\
\text { vírgula após a palavra } \\
\text { DESTINO. }\end{array}$ & $\begin{array}{l}\text { Tratada como relacionamento } \\
\text { entre pelo menos m+n estados. } \\
\text { Esses estados possuem algum } \\
\text { estado ancestral que é do tipo } \\
\text { OR sobre o qual é possível a efe- } \\
\text { tivação da transição. Os "m" } \\
\text { estados origem são do tipo AND } \\
\text { entre si e os " } n \text { " estados destino } \\
\text { também. Além do tratamento } \\
\text { de transição entre estados OR } \\
\text { descrito acima, a transição m-n } \\
\text { requer a construção dos "cami- } \\
\text { nhos independentes" para que se } \\
\text { efetive as transições para os es- } \\
\text { tados destino paralelos. }\end{array}$ \\
\hline 6.3 & $\begin{array}{l}\text { transições } \\
\text { simultâneas }\end{array}$ & $\begin{array}{l}\text { Reconhecidas as transi- } \\
\text { ções de mesmo rótulo } \\
\text { como diferentes enti- } \\
\text { dades. }\end{array}$ & $\begin{array}{l}\text { Tratadas as transições simultâ- } \\
\text { neas, simulando-se a cada passo } \\
\text { que todas tenham sido efe- } \\
\text { tivadas sem apresentar o re- } \\
\text { sultado intermediário entre as } \\
\text { transições. }\end{array}$ \\
\hline
\end{tabular}

Os requisitos marcados com $\left(^{*}\right)$ na coluna relativa ao SIMULADOR indicam que esses operadores, símbolos especiais, etc, não são atualmente tratados. A razão dessa decisão se deve ao fato de que para que eles pudessem ser tratados seria necessário executar as ações associadas a cada transição e isso não foi incluido no escopo deste trabalho, estando previsto para uma segunda versão 
da ferramenta de Simulação.

Para ilustrar a necessidade de execução das ações para que esses operadores especiais tenham sentido, considere-se como exemplo o operador "not_yet (evento_x)" que deve retornar Verdadeiro se o evento_x não se alterou durante a execução de um passo e Falso caso contrário. No início de cada passo de Simulação os eventos não ocorridos têm conteúdo "Falso". Qualquer transição que contivesse essa expressão "not_yet (evento_x)" só poderia ser efetivada caso a execução de alguma ação, por propagação, modificasse o conteúdo do evento_x durante a execução do passo.

\subsection{Arquitetura da Ferramenta Implementada}

A ferramenta é um Sistema para apoio à Simulação de Especificações em STATECHARTS, também abreviada pela sigla SES. Inicialmente, as duas principais atividades da ferramenta SES foram esquematizadas como no Diagrama de Contexto da figura 3.12 .

A primeira atividade de Análise da Especificação corresponde ao tratamento da entrada de dados feito pela ferramenta. A atividade de Simulação da Especificação, que foi o motivo principal da automatização da técnica, corresponde ao tratamento de saída dos dados em função dos eventos recebidos.

A partir da identificação desse contexto, a arquitetura da ferramenta foi concebida como mostra a figura 3.13 .

Nesse ponto foram modelados os dados das especificações em STATECHARTS e então definidos os tipos de dados que a atividade de Análise deveria fornecer à atividade de Simulação, segundo a semântica daqueles diagramas. Nas figuras $3.14,3.15,3.16$ e 3.17 são representados os tipos de dados principais que foram definidos para a Simulação.

No apêndice B se encontram detalhadas as definições de todos os tipos de dados e as respectivas estruturas de dados básicas utilizadas para implementar o modelo descrito nas figuras 3.14 a 3.17. No documento [Fort91a] o Analisador é descrito com mais detalhes, incluindo-se uma listagem de seu programa fonte em "C".

$\mathrm{Na}$ primeira fase de implementação foram então escritas as rotinas de gerenciamento dessa base de dados: recuperação e gravação das estruturas básicas definidas. 


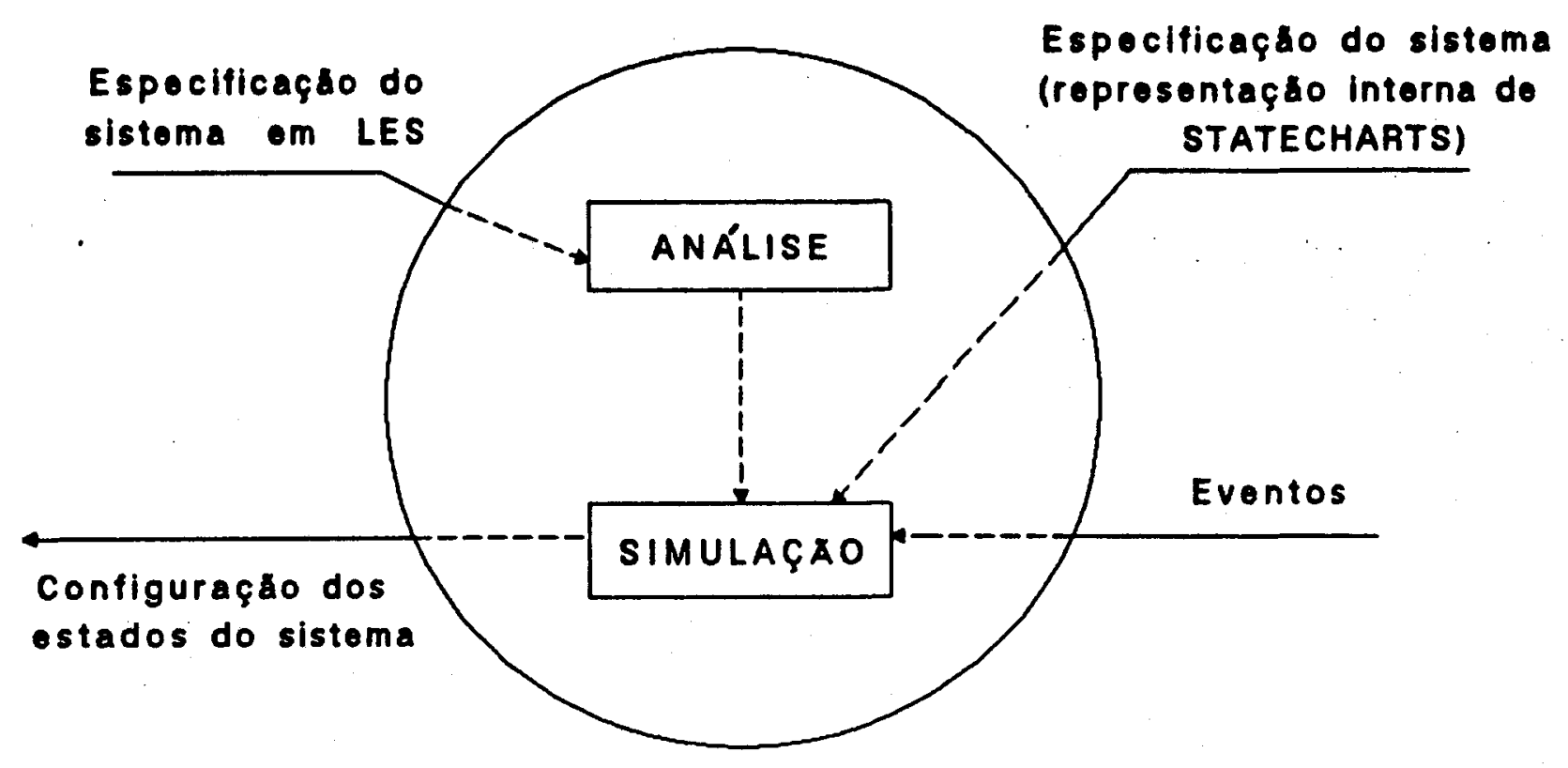

Figura 3.12: Diagrama de Contexto da Ferramenta

A seguir, para a atividade de Análise, foi feita uma descrição mais detalhadas de suas partes. Assim, a Análise de especificações de Statecharts em LES pode ser representada, conforme mostra a figura 3.18, contendo algumas das fases típicas de um compilador. As fases representadas na figura não necessariamente possuem uma correspondência com a execução sequencial das mesmas, mas retratam todos os passos implementados, ainda que de forma entrelaçada.

Pode-se observar na figura 3.18, que dois grupos maiores foram tratados durante a compilação da Especificação em LES. O primeiro grupo, denominado "ANÁLISE", foi decomposto em :

- análise léxica,

- análise sintática e

- análise de contexto

Essas fases são responsáveis pela análise do texto da especificação fonte, criando as tabelas intermediárias de símbolos referentes aos objetos contidos na especificação.

O segundo grupo, denominado "SÍNTESE", a partir das tabelas criadas durante a análise, realiza a geração de código intermediário das estruturas básicas da BASE DE DADOS STATECHARTS, com o objetivo de possibilitar a interpretação dos dados, durante a atividade posterior de Simulação. 


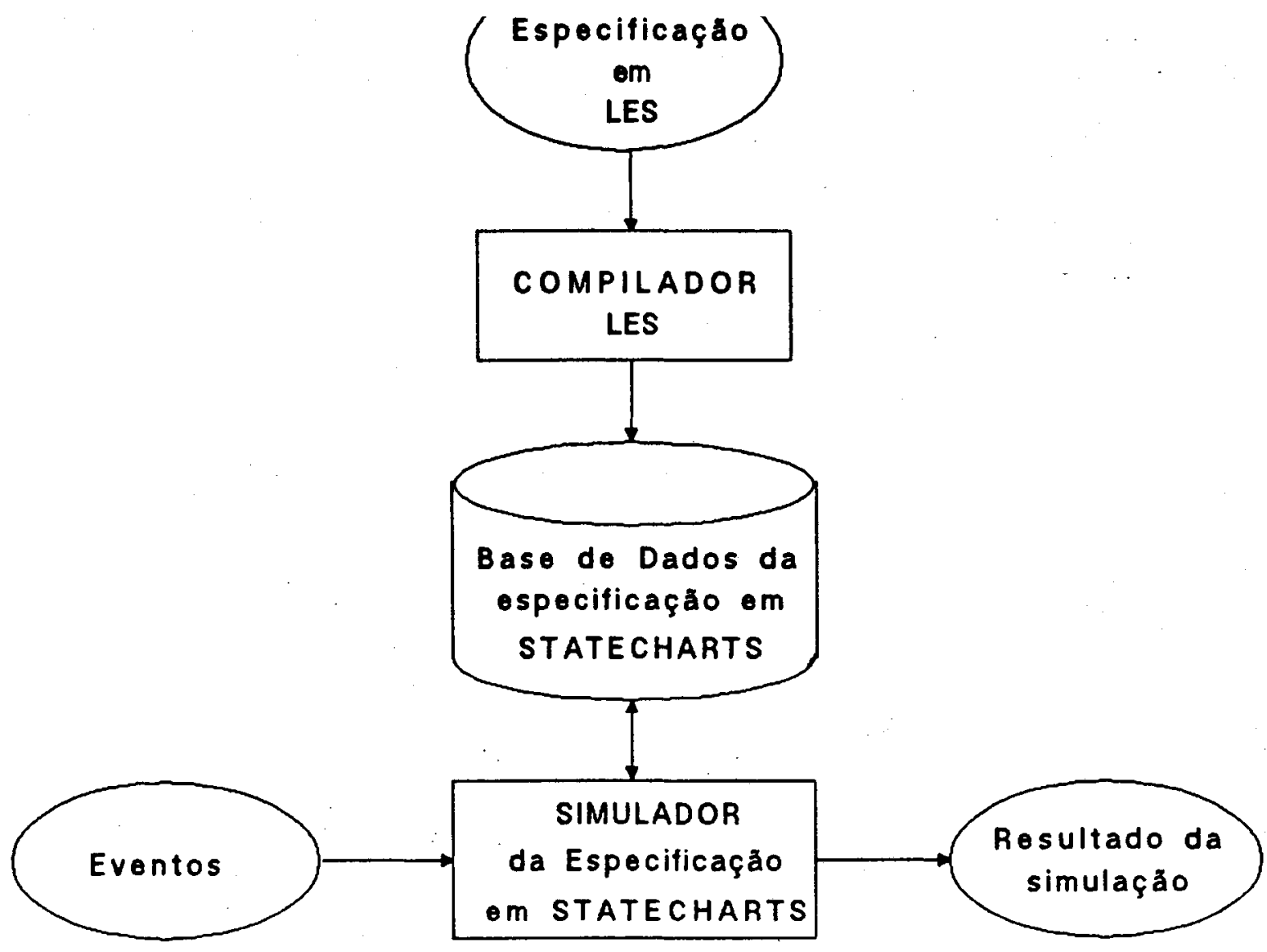

Figura 3.13: Arquitetura da Ferramenta 


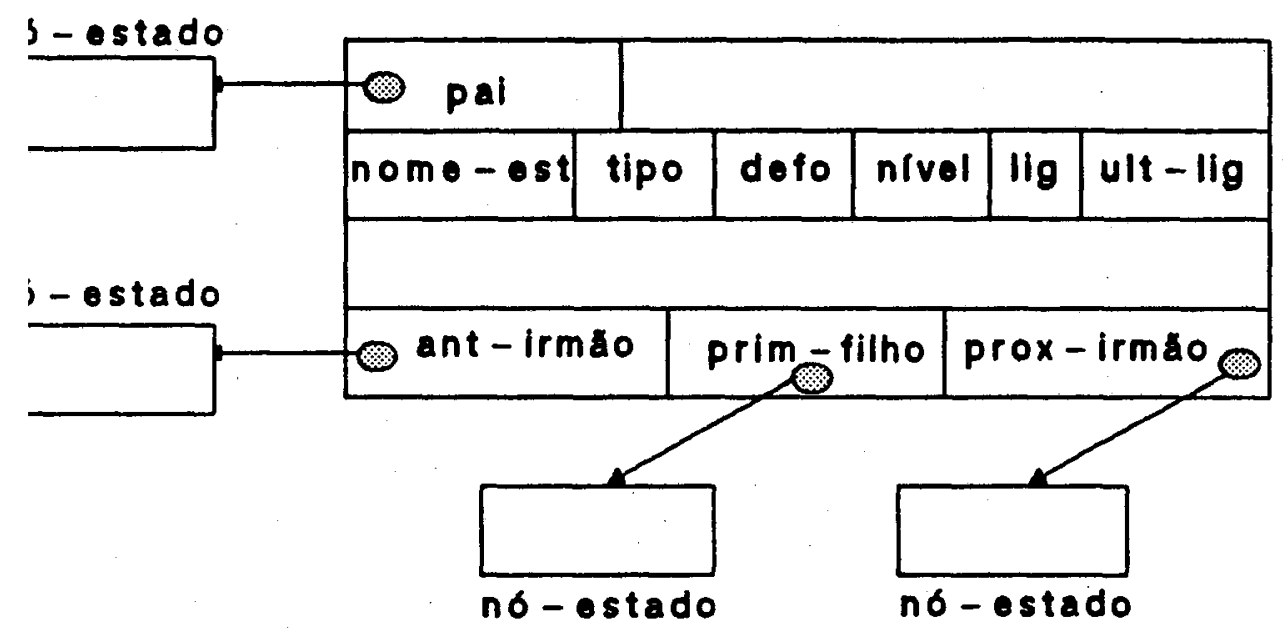

Descrição do No-estado

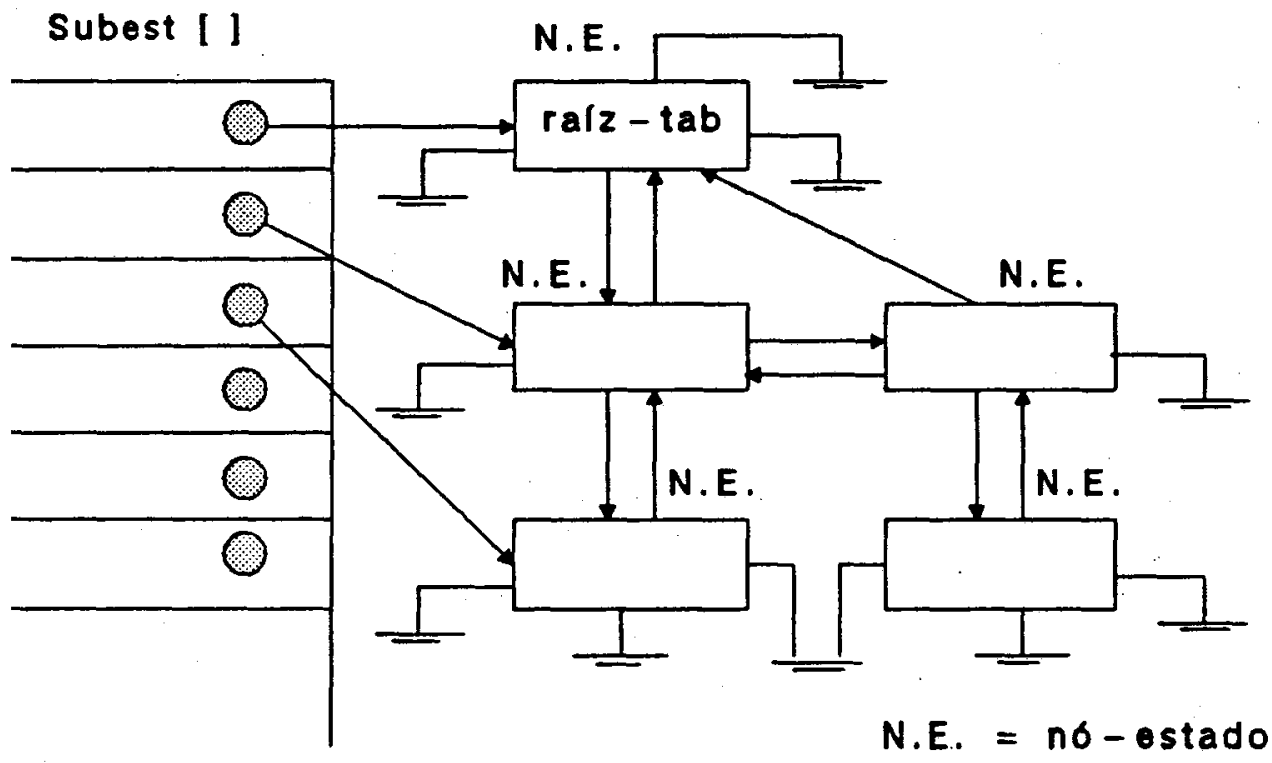

Arvore dos Estados

Obs: (1) cada estrutura NO-ESTADO corresponde a uma bolha no diagrama gráfico.

(2) As demais estruturas de dados se referem a essa ARVORE DE ESTADOS através do indice do vetor Subest [ ].

Figura 3.14: Estruturas de Dados : ESTADOS 


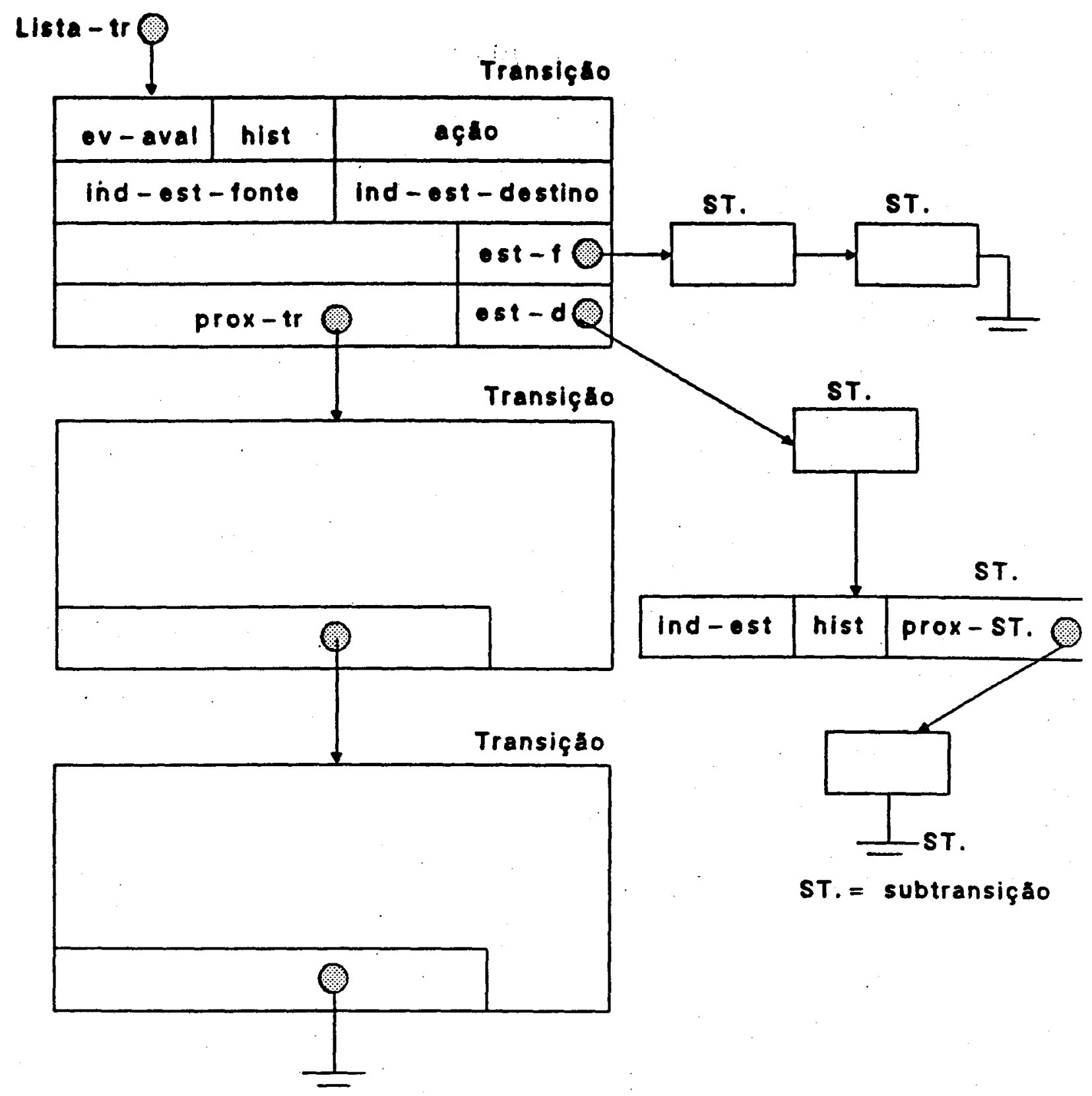

Obs: (1) cada estrutura de TRANSIÇAO corresponde a um "arco" no diagrama gráfico.

(2) No caso em que o "arco" bifurcado, têm-se as "SUBTRANSiçós" que representam os arcos direcionando Subestados paralelos.

(2.1) Quando não existem "Subtransições", est-f/ est-d săo nulos.

(2.2.) Quando existem "Subtransições", o ponteiro est- $f$ / est-d endereça a lista das Subtransiçóes - 0 ind-est-fonte 1 ind-est-destino possuem o valor "paralelo".

Figura 3.15: Estruturas de Dados : TRANSIÇõES 


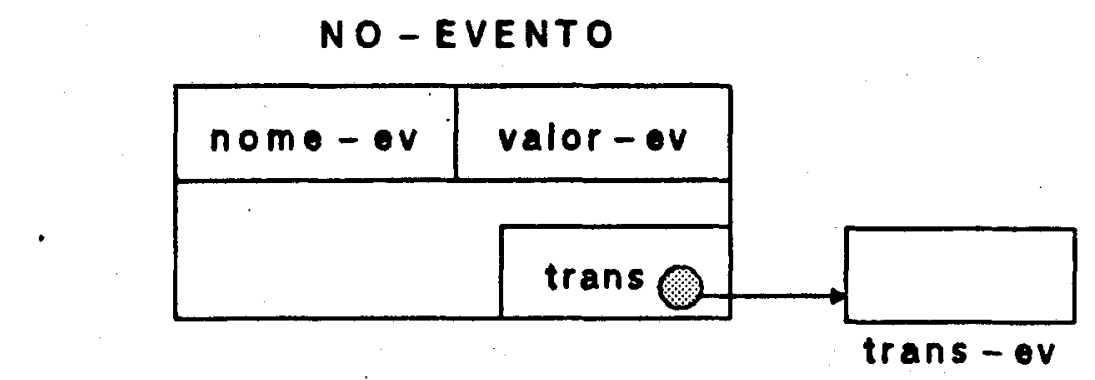

TABELA DOS EVENTOS:

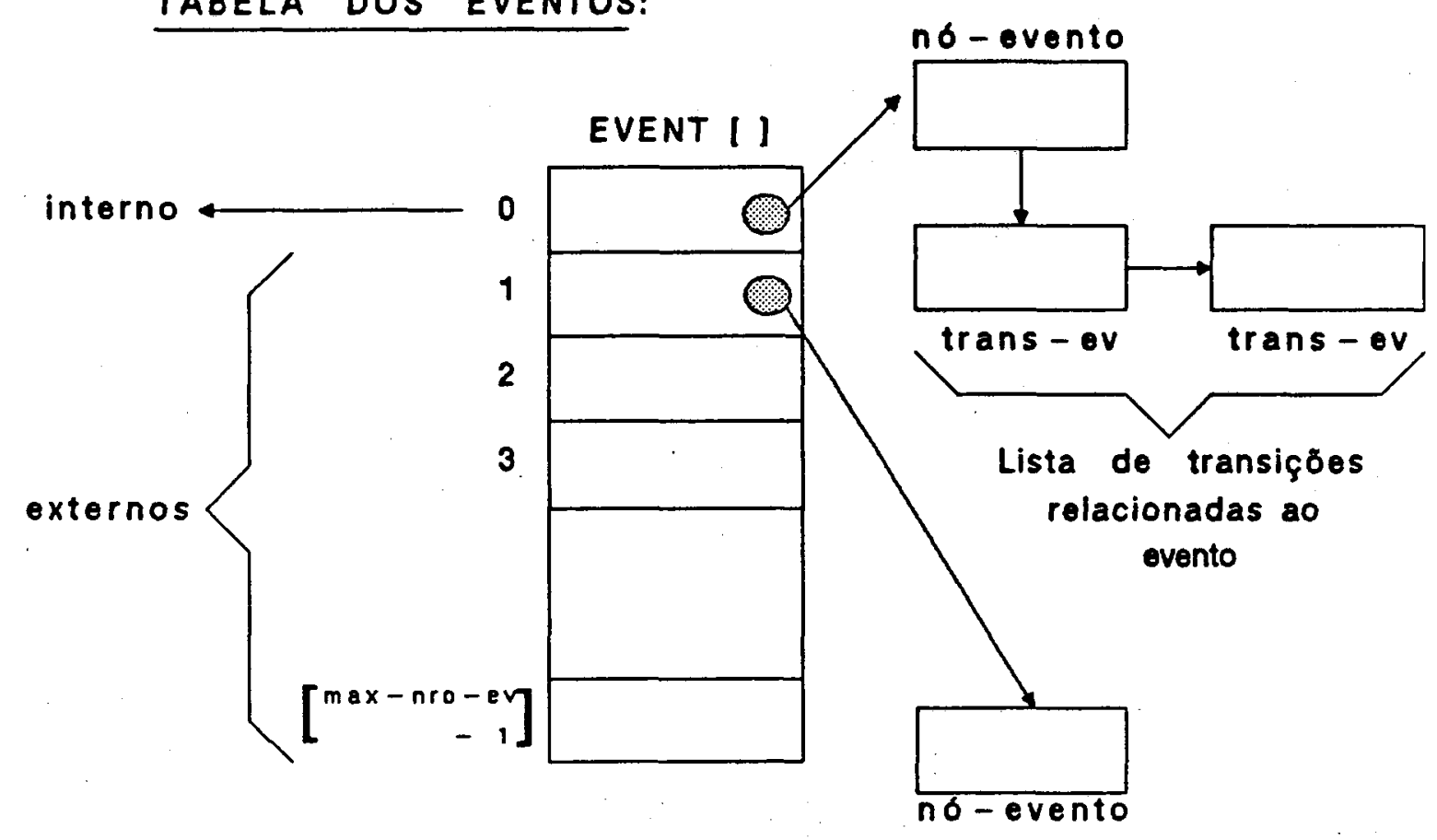

Figura 3.16: Estruturas de Dados : EVENTOS 
(Resumo das ligą̧os ontro EVENTOS - TRANSIÇOES)

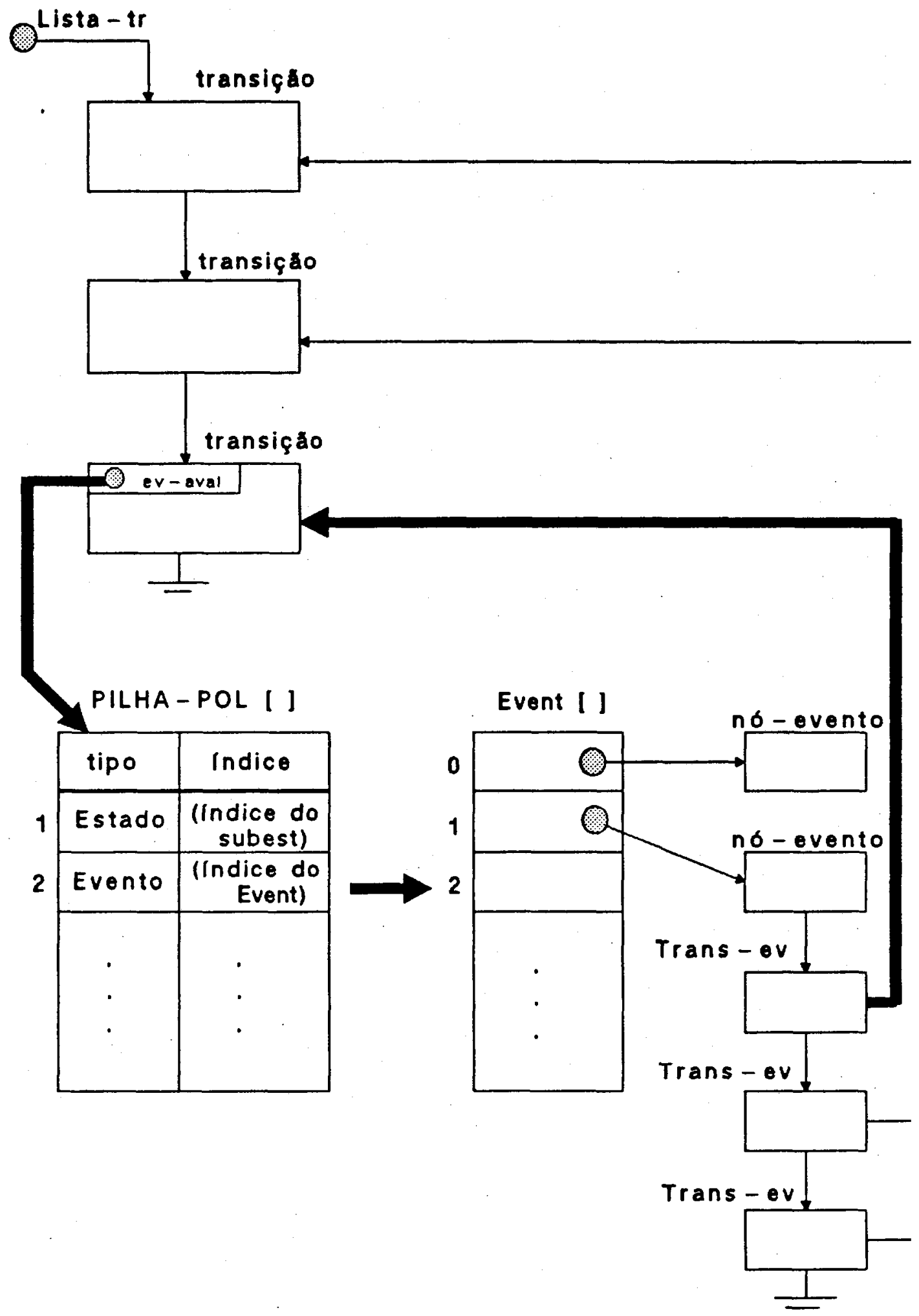

Figura 3.17: Estruturas de Dados : EVENTOS x TRANSIÇÕES 


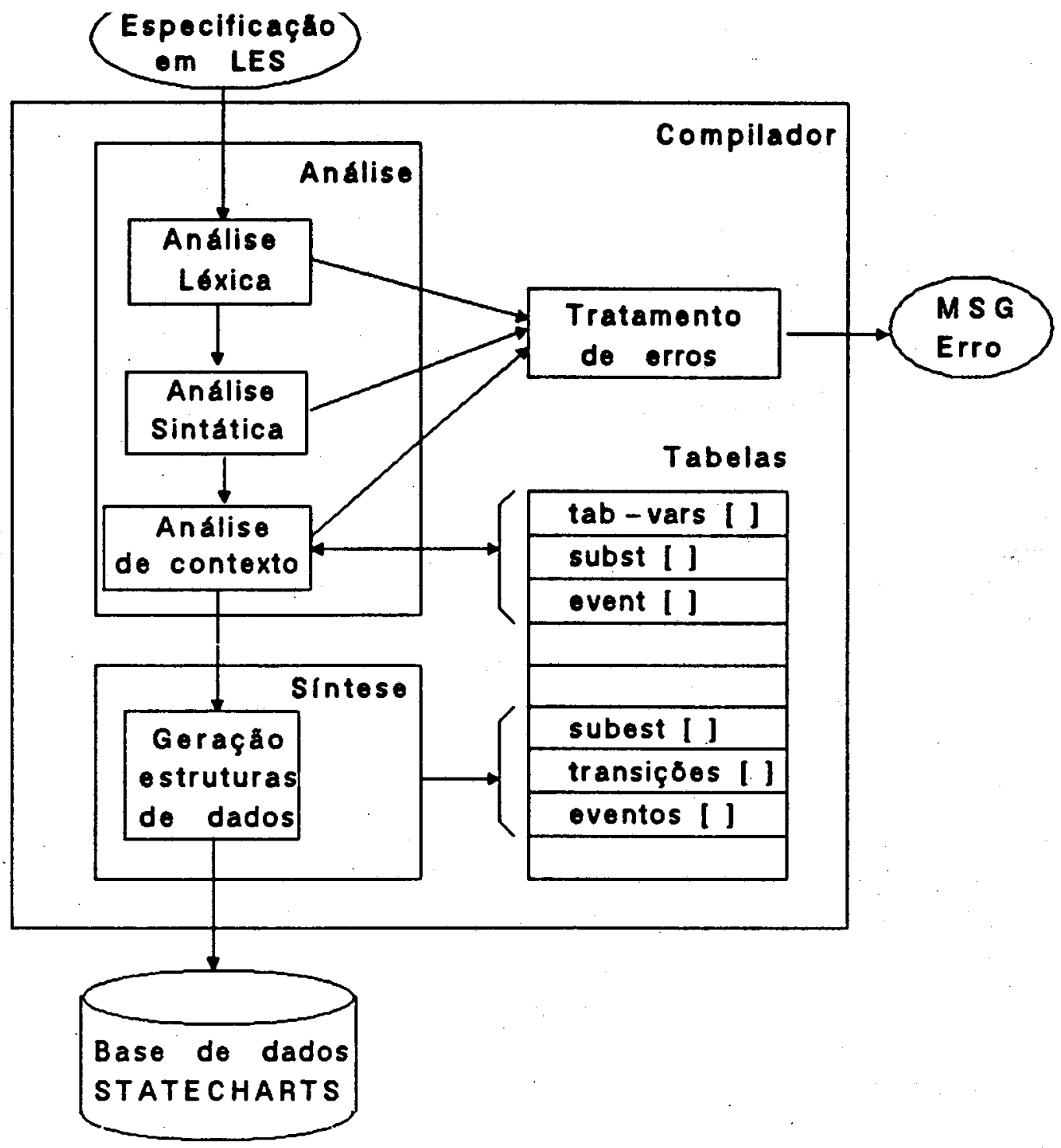

Figura 3.18: Visão Esquemática das Fases implementadas no Compilador para a LES 


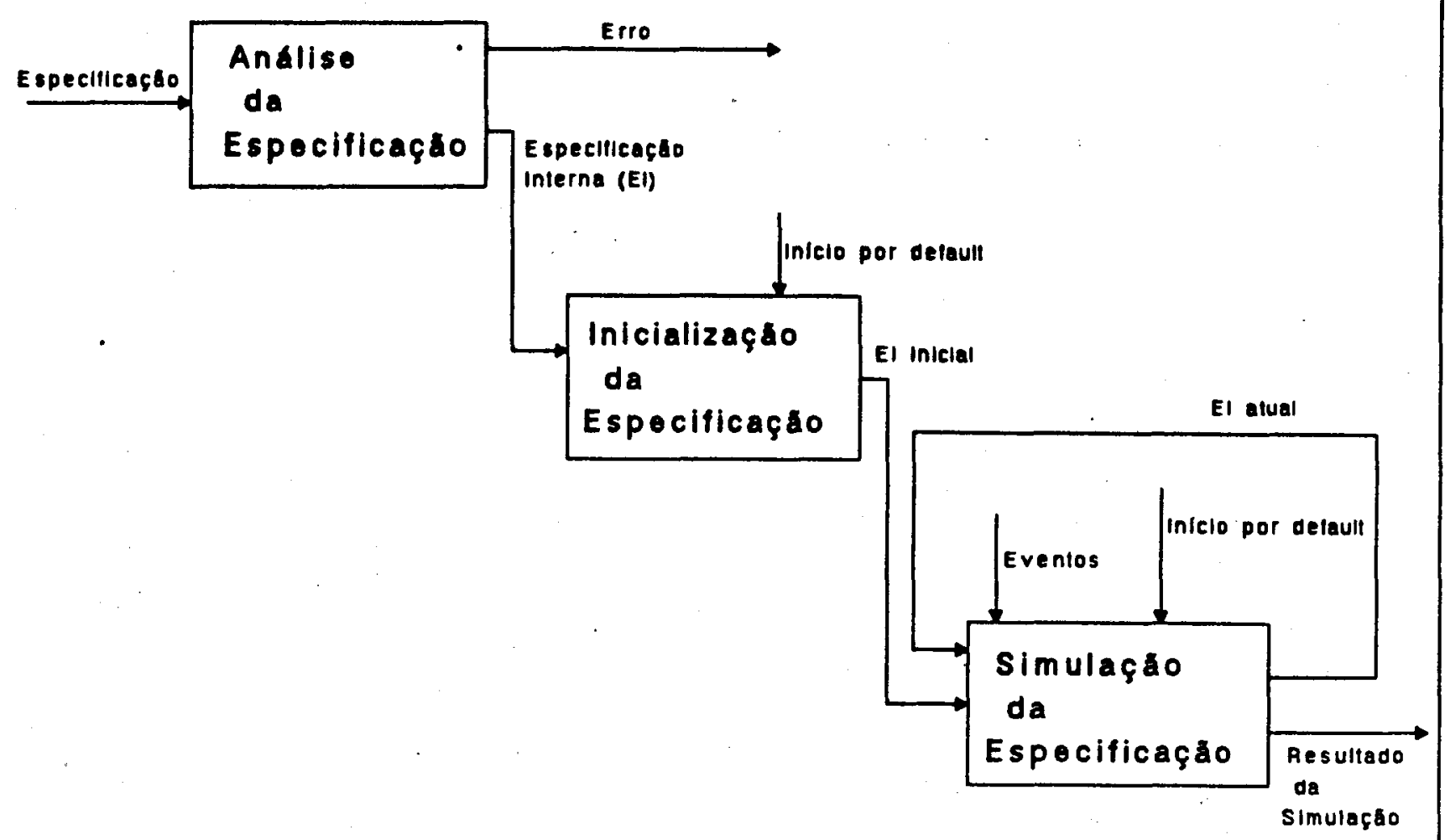

Figura 3.19: Diagrama de Atividades da Ferramenta

A ferramenta SES possui sua modelagem funcional como mostram as figuras 3.19 a 3.21 e suas funçôes principais são:

1 - Análise da Especificação em STATECHARTS -> inicialmente é introduzido no sistema SES uma especificação em STATECHARTS escrito em LES, que por sua vez passa por uma compilaçãa. Essa compilação transforma a especificação introduzida para uma representação interna, a qual foi denominada Especificação Interna. A gramática da linguagem LES (LINGUAGEM DE ESPECIFICAÇÃO DE STATECHARTS) na notação BNF se encontra descrita no Apêndice A.

A Especificação Interna (EI) representa uma instância do modelo de dados para especificações de STATECHARTS. Essa EI corresponde a uma especificação na BASE DE DADOS STATECHARTS, representada na figura 3.13 da arquitetura da ferramenta.

2 - Inicialização da Especificação $\rightarrow$ a especificação deve receber uma inicialização, que representa o estado inicial do sistema. A própria técnica STATECHARTS fornece a notação dos estados "default" do sistema. Esses estados, simulando a configuração corrente do sistema, para o SES, são qualificados como "ligados".

Essa função não necessita ser ativada quando for o caso em que se deseje continuar a partir de uma configưração de estados que já estivesse armazenada 


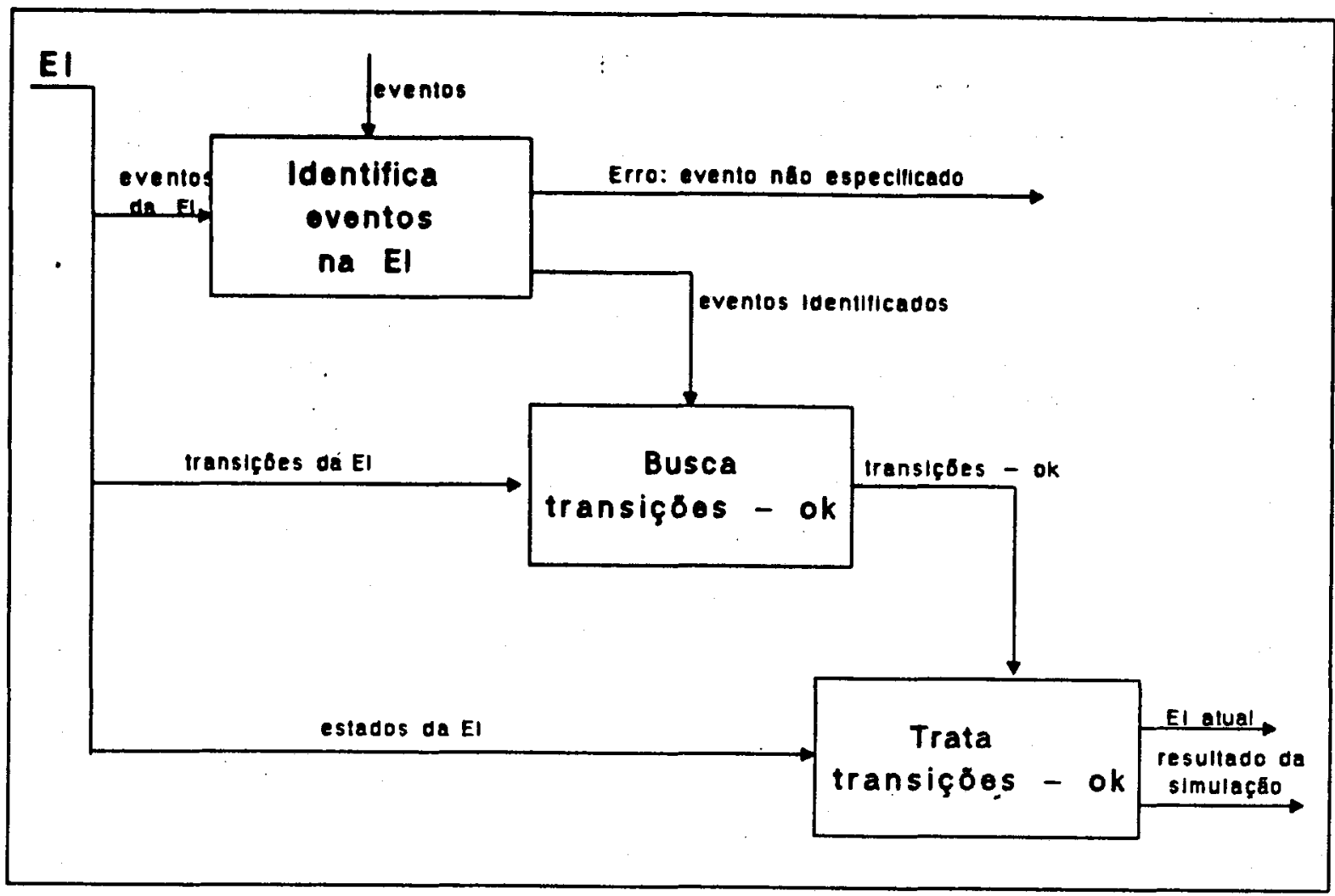

Figura 3.20: Diagrama de Atividades da Simulação

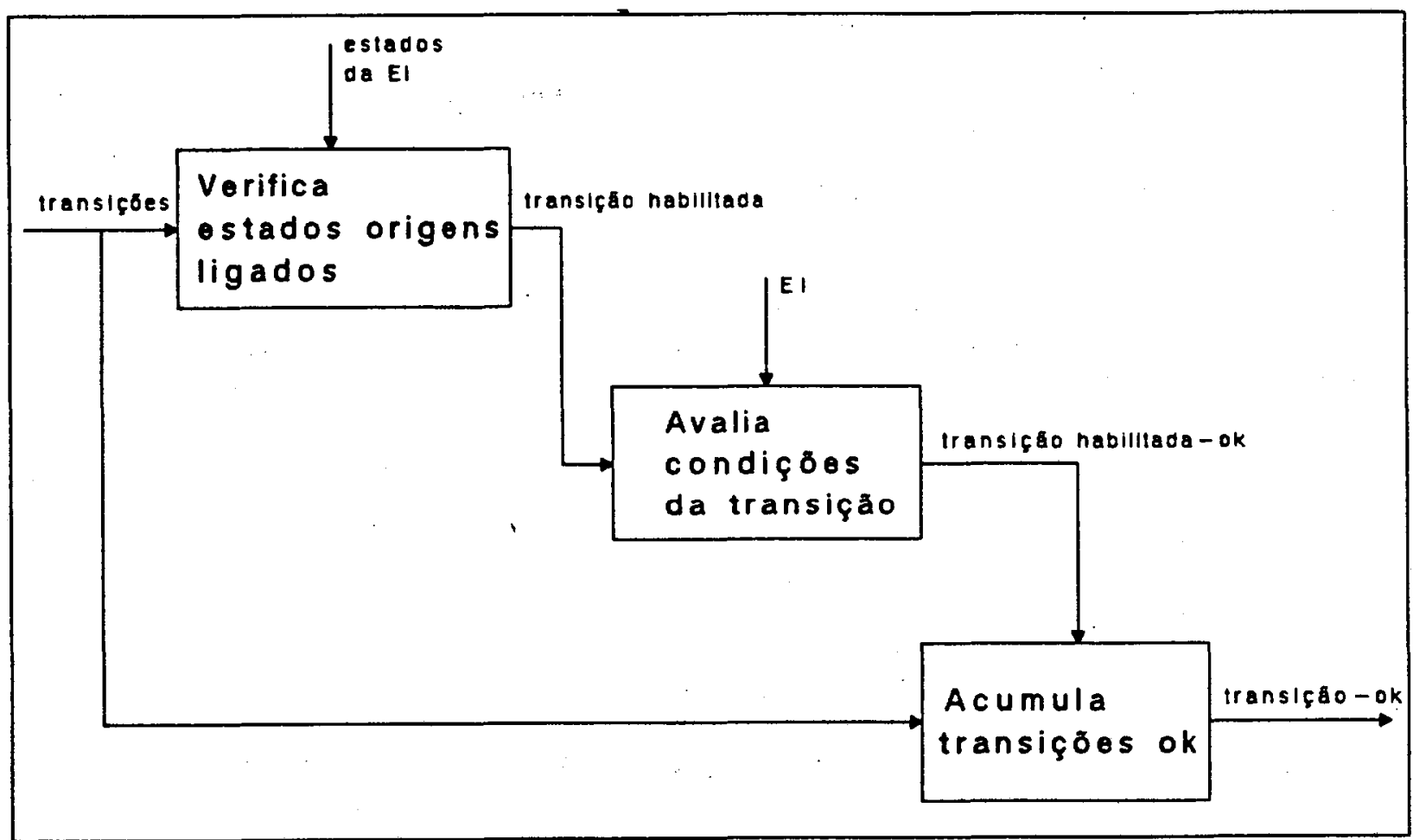

Figura 3.21: Diagrama de Atividades de Busca-Transições-Ok 
em memória secundária.

3 - Simulação $\rightarrow$ função que demonstra o comportamento do sistema especificado, através das trajetórias por que passam os seus estados, relativamente aos eventos recebidos. Cabe a essa função a interpretação da lógica da notação dos Diagramas STATECHARTS e apresentação de seus efeitos relativos aos eventos introduzidos.

Nessa atividade podem-se distinguir quatro principais subfunções, a saber:

3.1 - Recepção de eventos $->$ o sistema permanece em estado de prontidão para receber os eventos de entrada e verificando sua consistência relativa à EI atual. Caso o evento não tenha sido especificado, ele não é tratado.

3.2 - Busca das transições $\mathrm{Ok} \rightarrow$ função que busca na EI as transições, relacionadas ao evento disparado, que podem ocorrer. A transição só pode ocorrer se possuir os seus estados-origem ligados (ou marcados) e se as condições relativas à transição (após avaliação) estiverem satisfeitas no momento de disparo dos eventos. Essa avaliação corresponde a um módulo "interpretador". do código contido na EI.

3.3 - Tratamento das transições habilitadas $\rightarrow$ o sistema deve analisar as transições que serão efetivadas. Esse intervalo em que o sistema não recebe outro evento externo é chamado de unidade de passo. Nessa unidade de passo o sistema reconfigura o seu estado não somente para os eventos externos recebidos como também para os eventos internos que são disparados devido à interpretação da lógica interna de seu enunciado.

A análise das transições a serem efetivadas consiste em verificar a repercussão das transições quando:

- as transições afetarem subestados ortogonais (ou paralelos)

- as transições chegarem a, ou partirem de, subestados de niveis hierárquicos distintos.

Em seguida é efetuada a simulação da transição analisada, desligandose os estados-origem e ligando-se os estados-destino afetados pelas transições habilitadas.

3.4 - Saída $\rightarrow$ o sistema gera o resultado da simulação do diagrama STATECHARTS, mostrando qual a situação atual do mapa de estados resultante. Esse resultado altera a configuração dos estados ligados da EI. 


\subsection{Decisões de Projeto}

cisões:

Para o desenvolvimento da Ferramenta foram tomadas as seguintes de-

- BASE DE DADOS PRÓPRIA - Devido ao problema de eficiência para manipulação dos tipos de dados durante a Simulação, foram desenvolvidas todas as estruturas de dados, bem como as rotinas de gerenciamento das mesmas, ao invés de se utilizar algum sistema de Gerenciamento de Bases de Dados disponível.

- INTERFACE SIMPLIFICADA - Porque não estaria pronto em tempo o EGS (Editor Gráfico de STATECHARTS em desenvolvimento por Batista, em [Bati90]), a primeira versão da Ferramenta, apresentada neste trabalho, foi implementada com uma interface baseada em janelas e utilizando-se o mouse para seleção dos eventos a serem simulados.

- RESTRIÇÕES - Algumas restrições da implementação realizada são comentadas a seguir:

- As ESTRUTURAS DE DADOS referentes aos estados e aos eventos estão implementadas com estruturas associadas de vetores de ponteiros, que atualmente possuem alocação estática, limitadas a certos valores constantes, que podem ser aumentados desde que o software seja recompilado. Atualmente, as CONSTANTES são:

- Nro. máximo de estados $=100$

- Nro. máximo de transições $=100$

- Nro. máximo de eventos $=100$

- Nro. máximo de variáveis $=100$

- Tamanho máximo da Pilha Polonesa $=20$

- Nro. máximo de caracteres na Especificação $=10.000$

- Tamanho máximo dos identificadores de variáveis $=30$

Essa restrição poderá ser eliminada futuramente, sem grandes dificuldades, implementando-se alocação dinâmica para esses vetores e respectivas rotinas de manipulação.

- PASSOS x MICRO-PASSOS: Como não são executadas as Ações, os Micro-Passos não são efetivados, ou seja, a característica de "Broadcasting" da técnica não foi implementada. 
- ORDEM DE EXECUÇÃO DAS TRANSIÇÕES: Todas as transições são efetivadas a cada passo da Simulação, mas existe uma ordem de execução para isso. Teoricamente, segundo Harel, elas deveriam ocorrer simultaneamente. $\mathrm{Na}$ Simulação implementada na ferramenta, atualmente a ordem de efetivação das transições é feita da seguinte forma:

1. tratar as transições relativas aos eventos externos. A ordem para o atendimento das transições paralelas desses eventos externos é a mesma da lista de transições relativas aos eventos (estrutura de dados : TRANS_EV) que foi gerada durante a Análise da Especificação.

2. tratar as transiçôes relativas aos eventos internos, que disparam em função de sua avaliação. Para amenizar essa restrição seria possível estender a implementação para atender às transições:

- por ordem aleatória,

- condicionadas a probabilidades, etc.

A ordem de execução das transições não altera a configuração final do Statechart, a não ser em alguns casos mais sofisticados, envolvendo nãodeterminismo. Harel, em [Hare87b], discute três casos desse tipo, a que ele dá os seguintes nomes:

- não-determinismo estrutural

- não-determinismo causado pela liberdade de escolha das transições dentro do Micro-passo

- não-determinismo causado pela definição de ações conflitantes

Os dois últimos casos não podem ocorrer, usando-se o Simulador, porque os Micro-passos não foram implementados. $O$ não-determinismo estrutural depende da ordem de execução das transições, como por exemplo, na figura 3.22 .

Na versão atual da Ferramenta o não-determinismo estrutural é identificado e emite-se uma mensagem de alerta quando, em casos como o da transição de rótulo "e" na figura 3.22 , a base de dados pode ser levada a uma situação de inconsistência. Dessa forma, a checagem ocorre em tempo de Simulação.

Futuramente, pretende-se investigar outra solução baseada em resultados teóricos e detectar-se a existência de não-determinismo durante a criação da representação interna dos Statecharts. Uma das dificuldades de tal algorítmo é o provável longo tempo de execução, pois precisam ser analisadas todas as possiveis combinações de eventos que podem ocorrer, um a um, dois a dois, etc. 


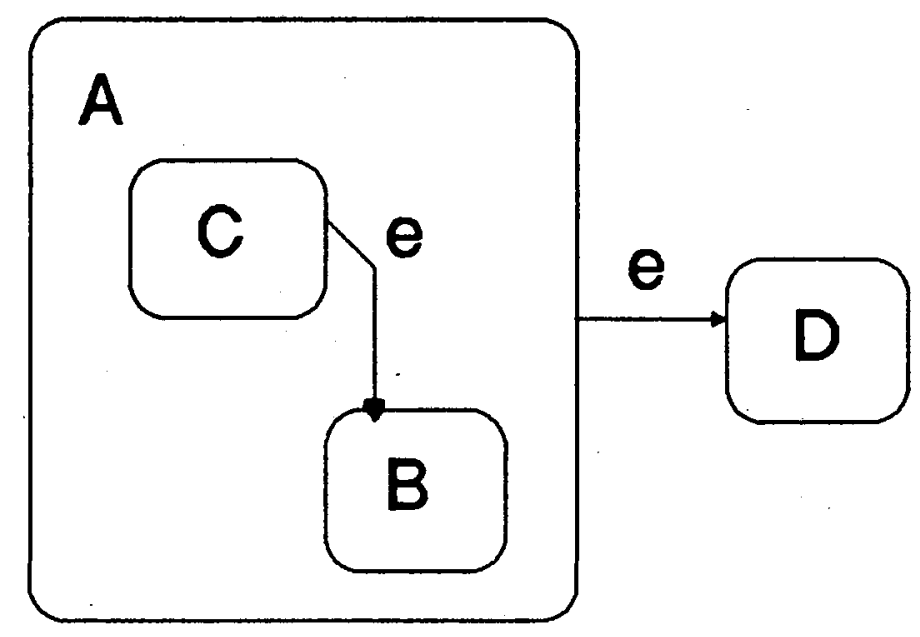

Figura 3.22: Statechart com não-determinismo estrutural

\subsection{Aspectos da Implementação da Ferramen- ta}

O ambiente de programação utilizado foi o de uma WorkStation SUN (SPARC 1) e todos os programas foram escritos em "C", versão de Berkeley, utilizando também o Gerenciador de Janelas OpenWindow e as rotinas do Xview.

O volume de programação da Ferramenta foi o de aproximadamente 6.000 linhas de código fonte para geração da Ferramenta de 80 Kbytes de código executável.

Com relação ao aspecto metodológico do desenvolvimento, os Diagramas de Atividades SADT foram utilizados para organizar e dar uma visão geral das funçôes do sistema. O ANALISADOR, por sua especificidade, foi programado seguindo os métodos convencionais de Análise Descendente Recursiva, utilizando procedimentos recursivos.

Em toda a fase de projeto e programação utilizou-se a idéia de Tipos Abstratos de Dados (TAD).

No capitulo seguinte, que exemplifica a utilização da Ferramenta, são 
apresentados mais detalhes da implementação.

\subsection{Conclusões}

Este capítulo apresentou uma visão geral da sintaxe dos diagramas Statecharts, juntamente com os aspectos principais de sua semântica.

A ferramenta desenvolvida foi apresentada. Para isso, foram listados os requisitos especificados para o desenvolvimento da ferramenta, baseados na definição dos Statecharts. Mostraram-se também a arquitetura da ferramenta e detalhes de seus componentes básicos: a Linguagem de Especificação de STATECHARTS e seu Analisador, a Base de Dados das Especificações e o Simulador.

O Simulador não abrange apenas a execução dos Micro-passos, que embora importantes, serão implementados na próxima versão da ferramenta. Com a versão atual, grande parte dos Statecharts que podem ser desenvolvidos para a especificação de STRs também podem ser simulados pela ferramenta. 


\section{Capítulo 4}

\section{UM EXEMPLO DE USO DA FERRAMENTA}

\subsection{Considerações Iniciais}

Este capítulo ilustra a utilização da Ferramenta, enfatizando alguns dos vários requisitos implementados. Para isso usa-se um exemplo, adaptado de [Hare87b], que apesar de não ser muito complexo abrange os casos principais que se quer demonstrar. Situações mais sofisticadas, explorando os limites da Ferramenta, e casos não cobertos neste capítulo podem ser vistos no Documento de Trabalho [Fort91b].

$\mathrm{Na}$ próxima seção apresenta-se uma breve descrição da Interface da Ferramenta e nas outras duas seções subseqüentes introduz-se o exemplo de um relógio especificado através de um Statechart e da Linguagem de Especificação de Statecharts (seção 4.3) e apresenta-se a simulação de um conjunto representativo de eventos, utilizando-se as próprias saídas do simulador. A essas saídas acrescentam-se comentários apropriados.

\subsection{A Interface da Ferramenta}

A Interface implementada para a Ferramenta utilizou rotinas do Xview e foi também escrita em linguagem $\mathrm{C}$.

$\mathrm{O}$ acesso através da Interface às funções principais do sistema de Si- 
mulação de Especificações STATECHARTS pode ser feito de forma simples através de menus $e$ o acompanhamento dos resultados obtidos dessas duas funções principais, de Análise e Simulação de Especificações de Statecharts, é feito através de duas áreas na tela, permitindo-se boa visualização.

Para a descrịção da Interface, a seguir são listadas suas duas principais fases de acordo com o que poderia ser considerado uma utilização normal, isto é, sem detalhar todos os desvios de uma utilização mais sofisticada ou os desvios de uma utilização inadequada dessa Interface.

Uma janela entitulada "Simulador de Statecharts" é a primeira entrada no sistema, quando da sua chamada. Nesse momento pode ser ativado o menu "pop-up" através do botão de menus do mouse para a escolha de uma das seguintes opções:

- Analisar LES

- Inspecionar

- Simular

- Salvar

- Recuperar

- Terminar

Na figura 4.1 encontra-se esquematizada a seqüência de passos pertencentes à primeira fase de utilização dessa Interface da Ferramenta. Essa primeira fase se refere a carregar em memória uma especificação de Statechart (um diagrama específico) a partir de sua representação na linguagem LES. Para tanto, selecionando- se a primeira opção, com o botão de seleção do mouse, obtém-se uma pequena janela entitulada "Analisar Statecharts", com a mensagem:

Nome da Especificação fonte:

DIR CONTINUE CANCELA

e três botões de seleção: "Continue", "Cancela" e "Diretório Statechart". 
Neste momento existem duas alternativas que o usuário pode utilizar para determinar qual o nome do arquivo em disco em que se encontra gravada a Especificação em LES. A primeira alternativa é a de simplesmente digitar o nome do arquivo que se deseja carregar para Análise, ao lado da mensagem dada.

A segunda alternativa é obtida através do botão de menus do mouse no botão de seleção "Diretório Statechart", que apresenta a lista de nomes de arquivos em disco com extensão ".gra", que foi adotada para todos os arquivos de especificações em LES. Nesse ponto, basta escolher-se qual arquivo (escolha única) será analisado.

A primeira fase da Interface então se faz cumprida e no rodapé da janela aparece o nome do Statechart selecionado. A partir disso, o Statechart selecionado encontra-se carregado em memória na forma do modelo de dados discutido no capítulo anterior, ou seja na forma de Especificação Interna. No caso de existir algum erro na especificação em LES, a Interface notificará o usuário, apresentando, como resultado da análise feita, também o número da linha da especificação fonte onde o erro foi encontrado. Desta maneira o Statechart não pôde ser carregado e o usuário deve retornar ao início dessa fase, após ter corrigido sua especificação fonte.

A segunda fase principal consiste da Simulação desse Statechart selecionado. Para tanto, selecionando-se a opção de "Simular", com o botão de menus do mouse, obtém-se a janela entitulada "Simular Statecharts".

Na figura 4.2 encontra-se esquematizada a janela de Simulação com seus recursos disponíveis. Essa janela se compõe de duas sub-janelas: a superior, que contém os estados ativados e a inferior, que contém os passos da Simulação. Além destas sub-janelas, à direita vê-se um sub-menu dos eventos disponíveis para a simulação.

Essa segunda fase se refere a simular o diagrama Statechart e por isso ela apresenta um menu menor à direita contendo os eventos do Statechart selecionado. Para simular a ocorrência de eventos no mundo real, deve-se selecioná-los através do botão de seleção do mouse nos respectivos eventos do sub-menu e em seguida deve-se apertar o botão de seleção "Disparar". Como conseqüência deste disparo, as duas sub-janelas são preenchidas com informações importantes dos efeitos de Simulação desse disparo.

Na sub-janela superior apresenta-se a configuração dos estados ativados pela(s) transição(ões) ocorrida(s) devido ao disparo do(s) evento(s). Nesta apresentação estão somente os nomes dos estados ativados, de forma tabulada segundo seu nível de Hierarquia de estados no diagrama. 


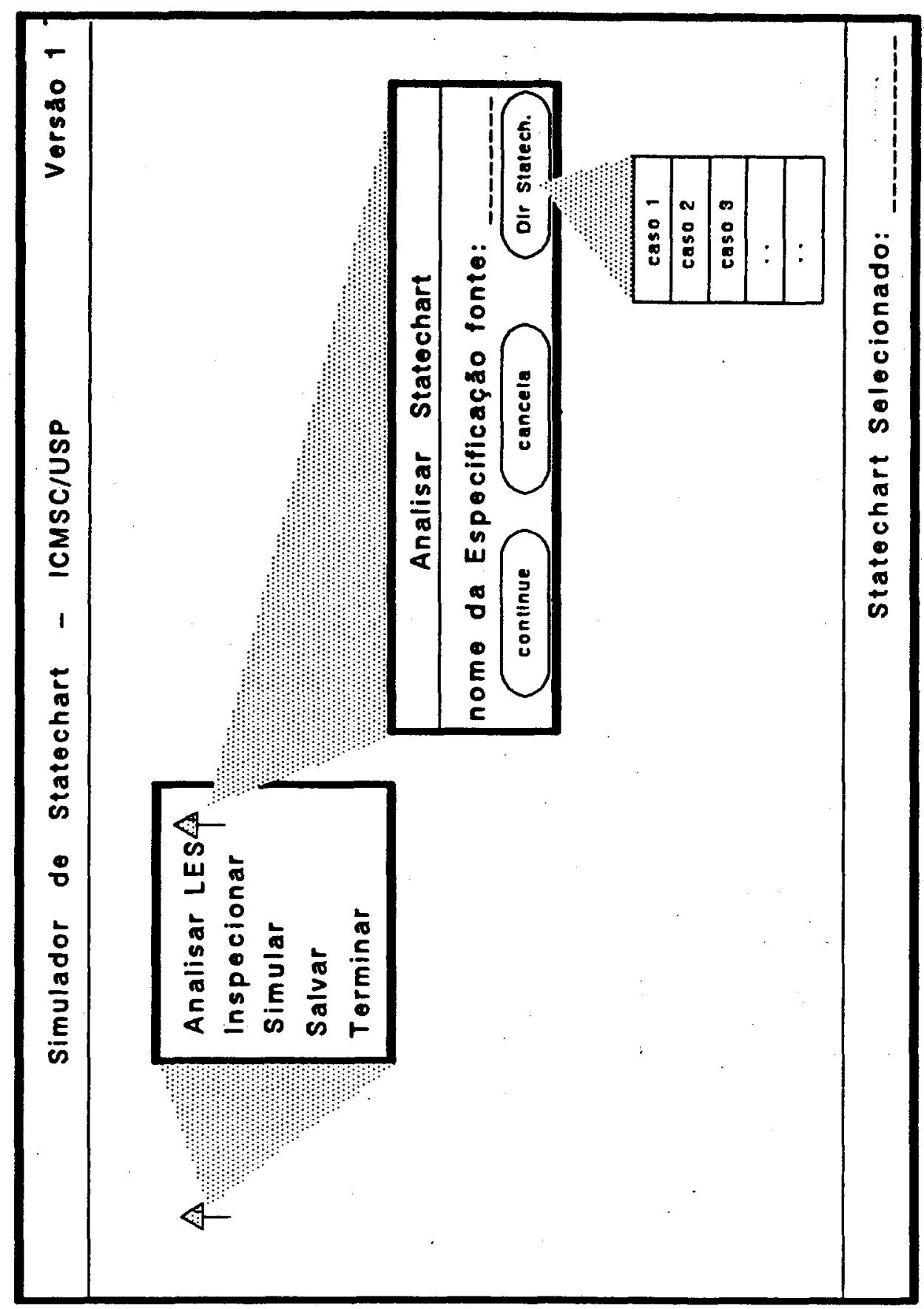

Figura 4.1: Esquema do Menu principal e Seleção da opção ANALISAR da Ferramenta 
$\mathrm{Na}$ sub-janela inferior encontra-se um registro (log) de acompanhamento da Simulação, relacionando cada passo a cada disparo de evento(s) ocorrido(s) e os respectivos efeitos na situação dos estados do sistema especificado, através da lista de nomes de estados "desligados", isto é, os que foram desativados naquele passo, e da lista de estados "ligados", isto é, os que foram ativados naquele passo. botões de seleção :

Nesta fase de Simulação estão disponíveis também as escolhas nos

- Inicializar (default)

- Salvar

- Recuperar

- Terminar

Essas opções podem ser feitas a qualquer instante da Simulação e correspondem a:

- Inicializar por default o Statechart selecionado.

- Salvar o Statechart selecionado, inclusive com os estados ativados atuais, isto é, com a configuração corrente.

- Recuperar um Statechart a partir de sua Especificação Interna, que se encontra armazenada em disco, carregando em memória a sua configuração de estados ativados com que foi armazenado.

- Terminar a execução dessa fase de Simulação, retornando para a janela anterior.

A Interface do sistema permite também situações mais flexíveis de utilização do que a descrita acima. Por exemplo, a de se carregar um Statechart a partir de sua Especificação Interna armazenada em disco. Este é o caso em que o usuário entra para a fase de Simulação sem passar anteriormente pela fase de Análise pois já a possui gravada em memória secundária. A Interface emitirá uma mensagem para que o usuário digite o nome do Statechart que se deseja carregar em memória para que possa então simulá-lo.

Existem também as opções de: 


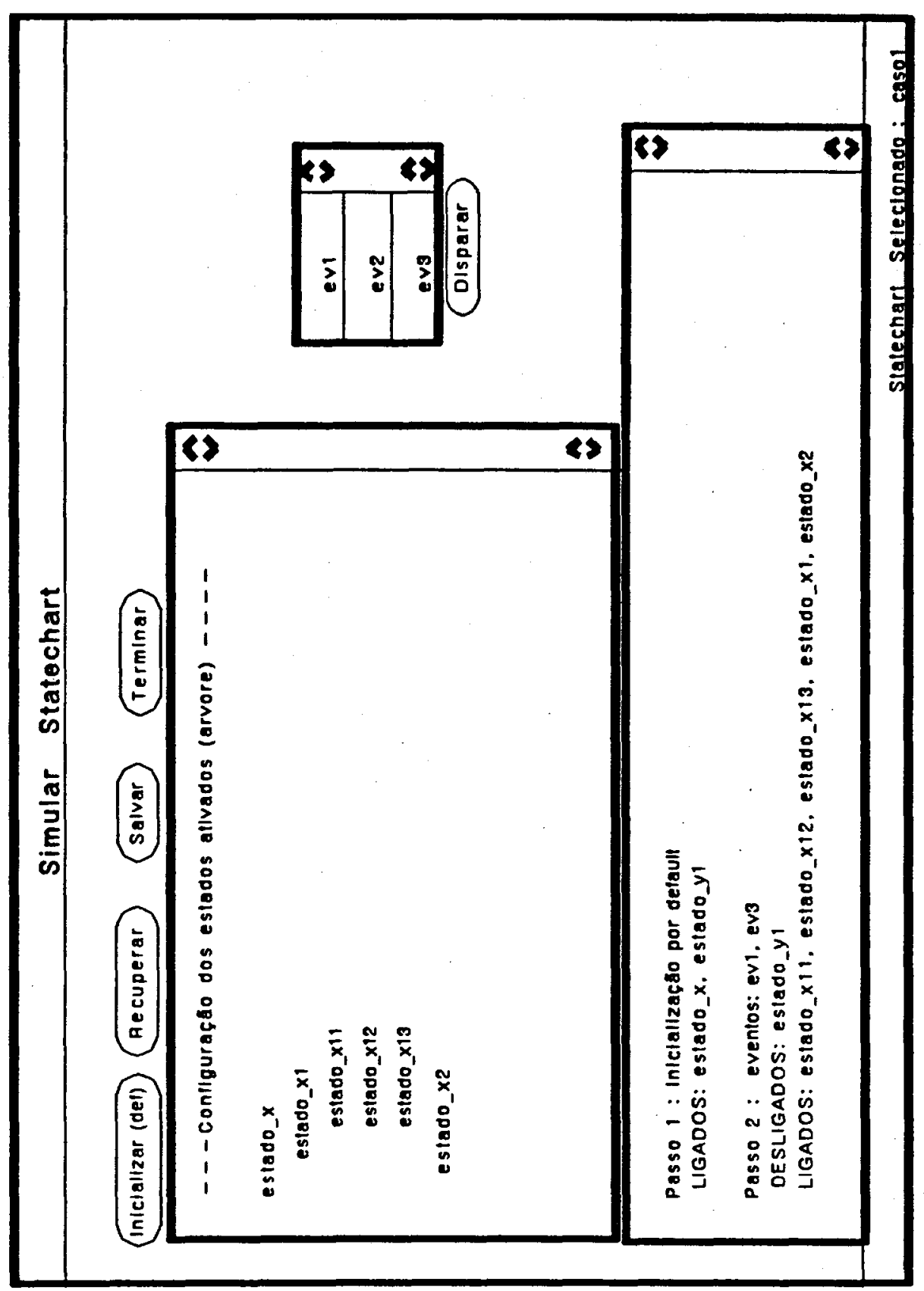

Figura 4.2: Esquema da Simulação de um Statechart com a utilização da Ferramenta 
- "Inspecionar", que ao ser ativada, mostra numa sub-janela todas as estruturas de dados da Especificação Interna carregada em memória.

- "Salvar", que armazena em disco a Especificação Interna que se encontra na memória.

Essas duas op̧̧ões também podem ser escolhidas a qualquer momento, pois a Interface se encarregará de pedir um Statechart, caso já não exista algum carregado em memória.

A figura 4.3 mostra o Diagrama de Estados que especifica parcialmente a Interface da Ferramenta.

\subsection{Exemplo de Especificação em STATECHARTS}

Nesta seção apresenta-se um exemplo de Especificação utilizando-se a técnica STATECHARTS e a sua respectiva representação em LES. O exemplo utilizado é o de um relógio digital simplificado, ligeiramente modificado do exemplo mostrado por Harel, em [Hare87a].

O diagrama mostrando a especificação do relógio-digital-simplificado pode ser visto na figura 4.4 .

Mesmo não sendo de difícil visualização, o exemplo possui também alguns aspectos da técnica STATECHARTS que são interessantes se observar:

- Os cinco subestados paralelos (ortogonais) que ficam ativados quando o sistema entra no estado "LIGADO".

- O evento "B", quando ocorre, pode disparar transições paralelas

- A transição cujo rótulo é do evento "DOIS_MIN" e condição "[in(ACERTAR)]" poderia ser substituída pelo evento interno de TIME_OUT por dois minutos do estado "ACERTAR", implementando-se interrupção utilizando o relógio do computador. O evento de TIME_OUT está previsto pelo Analisador da versão atual da Ferramenta, mas não está implementado na Simulação.

Abaixo encontra-se a especificação em LES referente a esse Statechart:

Estado RELOGIO_SIMPLIFICADO ou

Subestados DESLIGADO def, LIGADO

Estado DESLIGADO atomo 


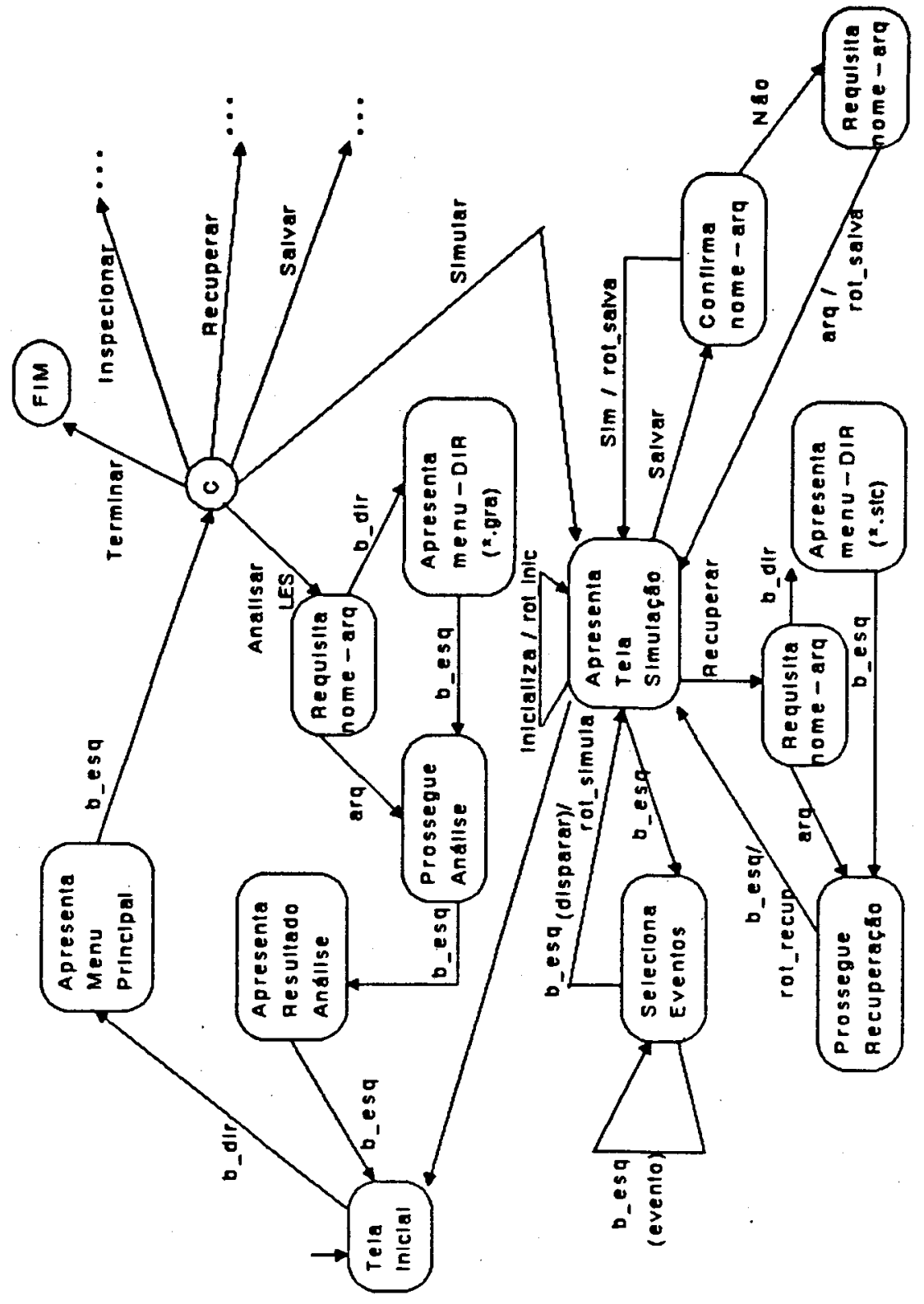

Figura 4.3: Diagrama de Estados da Especificação da Interface da Ferramenta 


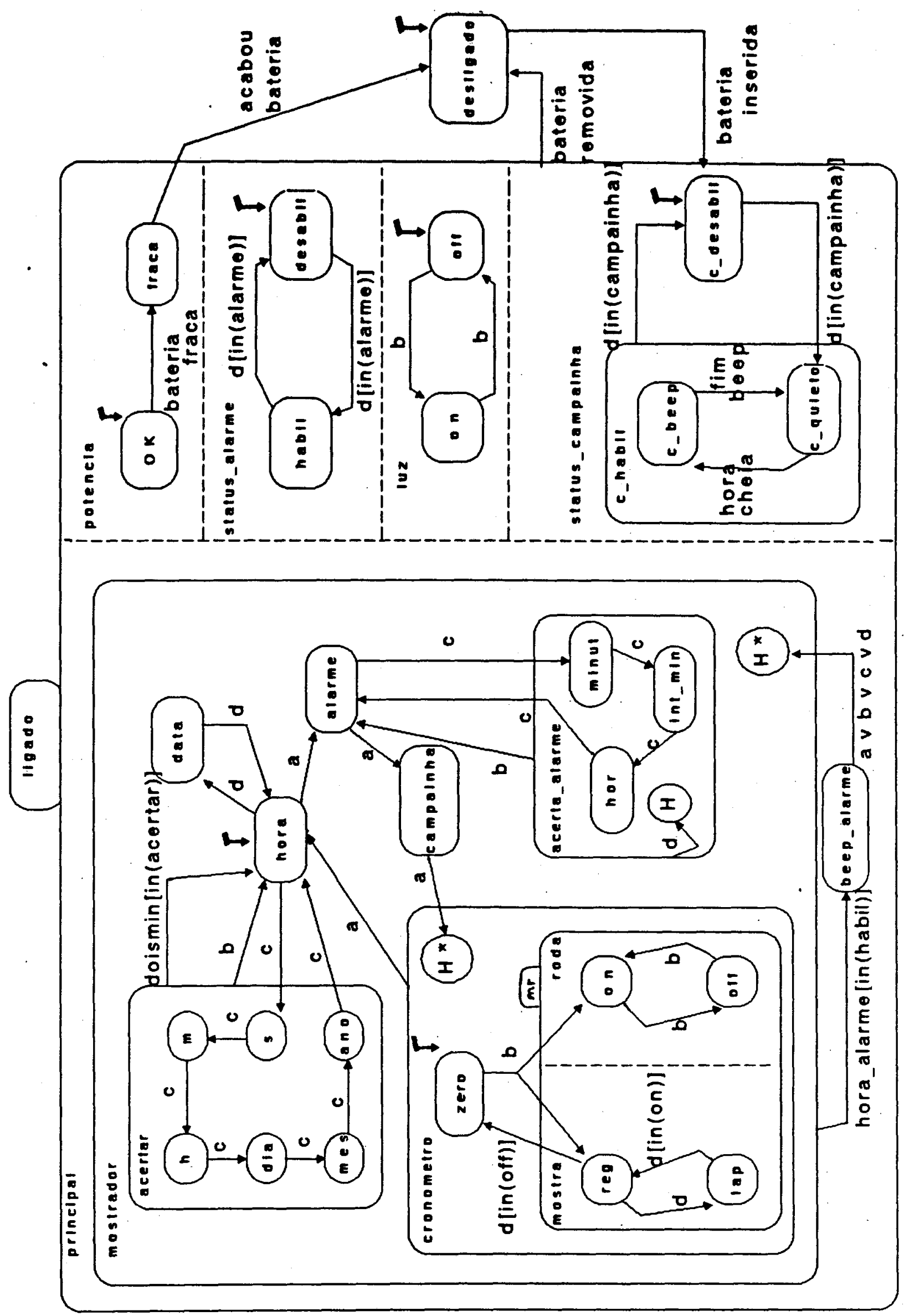

Figura 4.4: Statechart do Relógio Digital Simplificado 
Estado LIGADO e

Subestados PRINCIPAL, POTENCIA, STATUS_ALARME, LUZ, STATUS_CAMPAINHA

Estado STATUS_CAMPAINHA ou

Subestados C_DESABIL def, C_HABIL

Estado C_DESABIL atomo

Estado C_HABIL ou

Subestados C_BEEP, C_QUIETO

Estado C_BEEP atomo

Estado C_QUIETO atomo

Estado LUZ ou

Subestados LUZ.OFF def, LUZ.ON

Estado LUZ.OFF atomo

Estado LUZ.ON atomo

Estado STATUS_ALARME ou

Subestados DESABIL def, HABIL

Estado DESABIL atomo

Estado HABIL atomo

Estado POTENCIA ou

Subestados OK def, FRACA

Estado OK atomo

Estado FRACA atomo

Estado PRINCIPAL ou

Subestados MOSTRADOR def, BEEP_ALARME

Estado BEEP_ALARME atomo

Estado MOSTRADOR ou

Subestados HORA def, DATA, ALARME, CAMPAINHA, ACERTA_ALARME, CRONOMETRO, ACERTAR

Estado HORA atomo

Estado DATA atomo

Estado ALARME atomo

Estado CAMPAINHA atomo

Estado ACERTA_ALARME ou

Subestados MINUT, HOR, INT_MIN

Estado MINUT atomo

Estado HOR atomo 
Estado INT_MIN atomo

Estado CRONOMETRO ou

Subestados ZERO def, MR

Estado ZERO atomo

Estado MR e

Subestados MOSTRA, RODA

Estado MOSTRA ou

Subestados REG, LAP

Estado REG atomo

Estado LAP atomo

Estado RODA ou

Subestados RODA.ON, RODA.OFF

Estado RODA.ON atomo

Estado RODA.OFF atomo

Estado ACERTAR ou

Subestados S, M, H, DIA, MES, ANO

Estado $S$ atomo

Estado $\mathrm{M}$ atomo Estado $\mathrm{H}$ atomo

Estado DIA atomo

Estado MES atomo

Estado ANO atomo ;

Evento BATERIA_INSERIDA Origem DESLIGADO Destino LIGADO Evento BATERIA_REMOVIDA Origem LIGADO Destino DESLIGADO Acao $\{$ clear(LIGADO) $\}$

Evento ACABOU_BATERIA Origem FRACA Destino DESLIGADO

Evento BATERIA_FRACA Origem OK Destino FRACA

Evento D [in (ALARME)] Origem DESABIL Destino HABIL

Evento D [in (ALARME) ] Origem HABIL Destino DESABIL

Evento B Origem LUZ.OFF Destino LUZ.ON

Evento B Origem LUZ.ON Destino LUZ.OFF

Evento D [in (CAMPAINHA) ] Origem C_DESABIL

Destino C_QUIETO

EventoD[in (CAMPAINHA) ] Origem C_HABIL

Destino C_DESABIL

Evento FIM_BEEP Origem C_BEEP Destino C_QUIETO

Evento HORA_CHEIA Origem C_QUIETO Destino C_BEEP

Evento A or B or C or D Origem BEEP_ALARME 
Destino MOSTRADOR / $\mathrm{H}^{*}$

Evento HORA_ALARME [in (HABIL)] Origem MOSTRADOR

Destino BEEP_ALARME

Evento A Origem HORA Destino ALARME

Evento A Origem ALARME Destino CAMPAINHA

Evento A Origem CAMPAINHA Destino CRONOMETRO / ${ }^{*}$

Evento A Origem CRONOMETRO Destino HORA

Evento D Origem HORA Destino DATA

Evento D Origem DATA Destino HORA

Evento C Origem HORA Destino S

Evento C Origem S Destino $M$

Evento C Origem $M$ Destino $H$

Evento C Origem H Destino DIA

Evento C Origem DIA Destino MES

Evento C Origem MES Destino ANO

Evento C Origem ANO Destino HORA

Evento B Origem ACERTAR Destino HORA

Evento DOIS_MIN [ in (ACERTAR)] Origem ACERTAR Destino HORA

Evento C Origem ALARME Destino MINUT

Evento C Origem MINUT Destino INT_MIN

Evento C Origem INT_MIN Destino HOR

Evento C Origem HOR Destino ALARME

Evento B Origem ACERTA_ALARME Destino ALARME

Evento D Origem ACERTA_ALARME Destino ACERTA_ALARME /H

Evento B Origem ZERO Destino RODA.ON, MOSTRA.REG

Evento B Origem RODA.ON Destino RODA.OFF

Evento B Origem RODA.OFF Destino RODA.ON

Evento D Origem LAP Destino REG

Evento D [in (RODA.ON)] Origem REG Destino LAP

Evento D [in (RODA.OFF)] Origem REG Destino ZERO ;

Particularmente, nessa especificação, foi adotado que os nomes dos estados e eventos fornecidos pelo usuário estão escritos em letras maiúsculas. Porém, para a Ferramenta, não existe qualquer tipo de restrição referente à utilização de letras maiúsculas ou minúsculas. 


\subsection{Uma Demonstração de Utilização da Fer- ramenta}

A seguir estão listados e comentados os passos, utilizando- se a Ferramenta, durante a Simulação da Especificação do relógio- digital-simplificado visto na seção anterior. Os trechos abaixo, impressos com letra de impressora comum, são os originais impressos pela Ferramenta.

PASSO (0): Inicializacao por default

Ligados $=$ DESLIGADO

[RELOGIO_SIMPLIFICADO]
[DESLIGADO]

Obs: Este passo (0) de Inicialização por default faz a Busca dos Estados Defaults na Árvore dos subestados, e os "liga" a partir do estado raiz da Árvore, que a partir desse momento fica sempre ativado. No caso da especificação apresentada, o estado raíz é o estado denominado RELOGIO_SIMPLIFICADO.

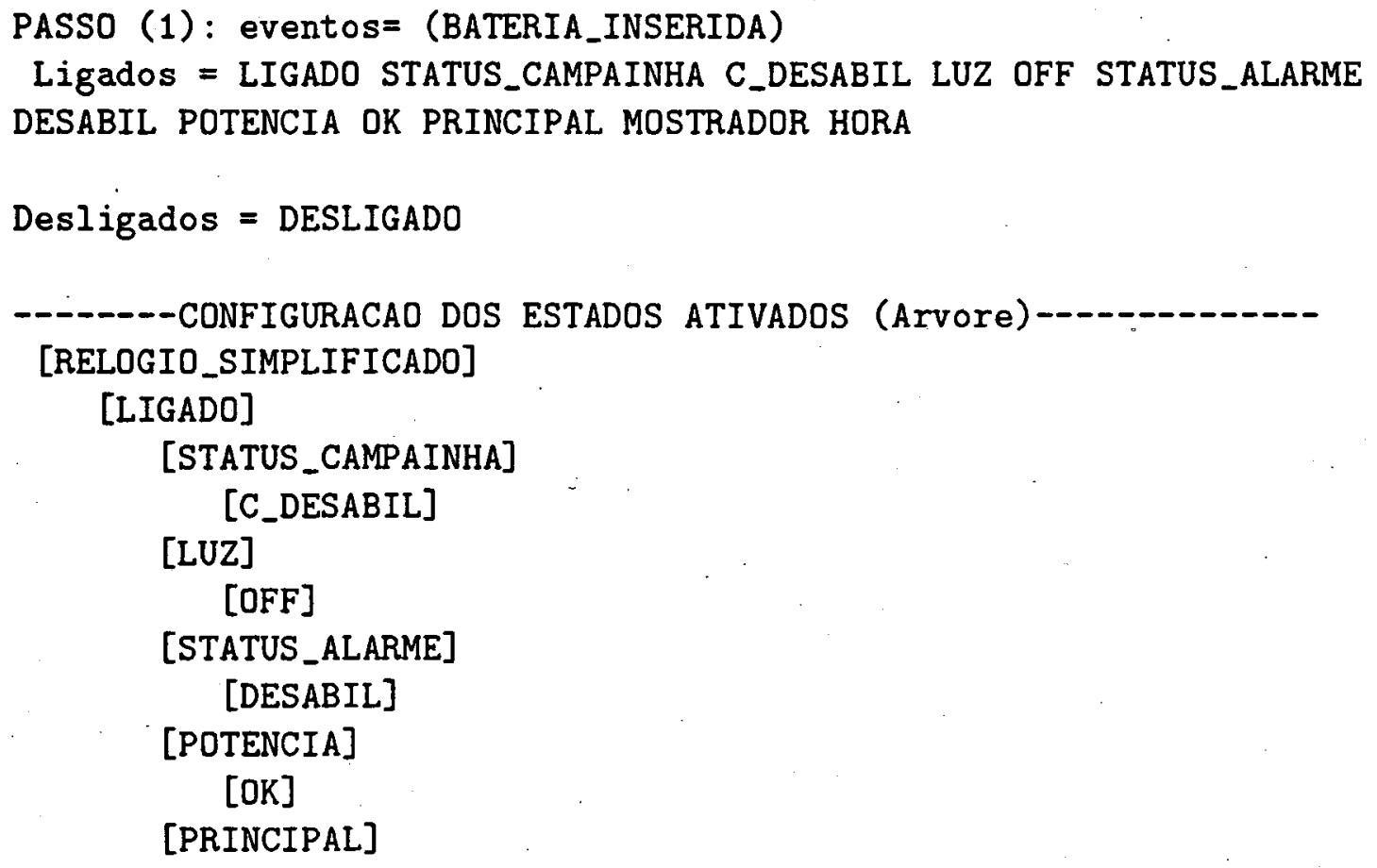


[MOSTRADOR]

[HORA]

Obs: Este passo (1) demonstra os cinco subestados paralelos sendo ativados simultaneamente, pois a transição relacionada ao evento ocorrido possui como estado destino o de nome LIGADO, que por sua vez é um estado do tipo AND e possui os cinco subestados ortogonais como seus filhos.Seguem-se então as ativações dos subestados desses subestados ortogonais, por default.

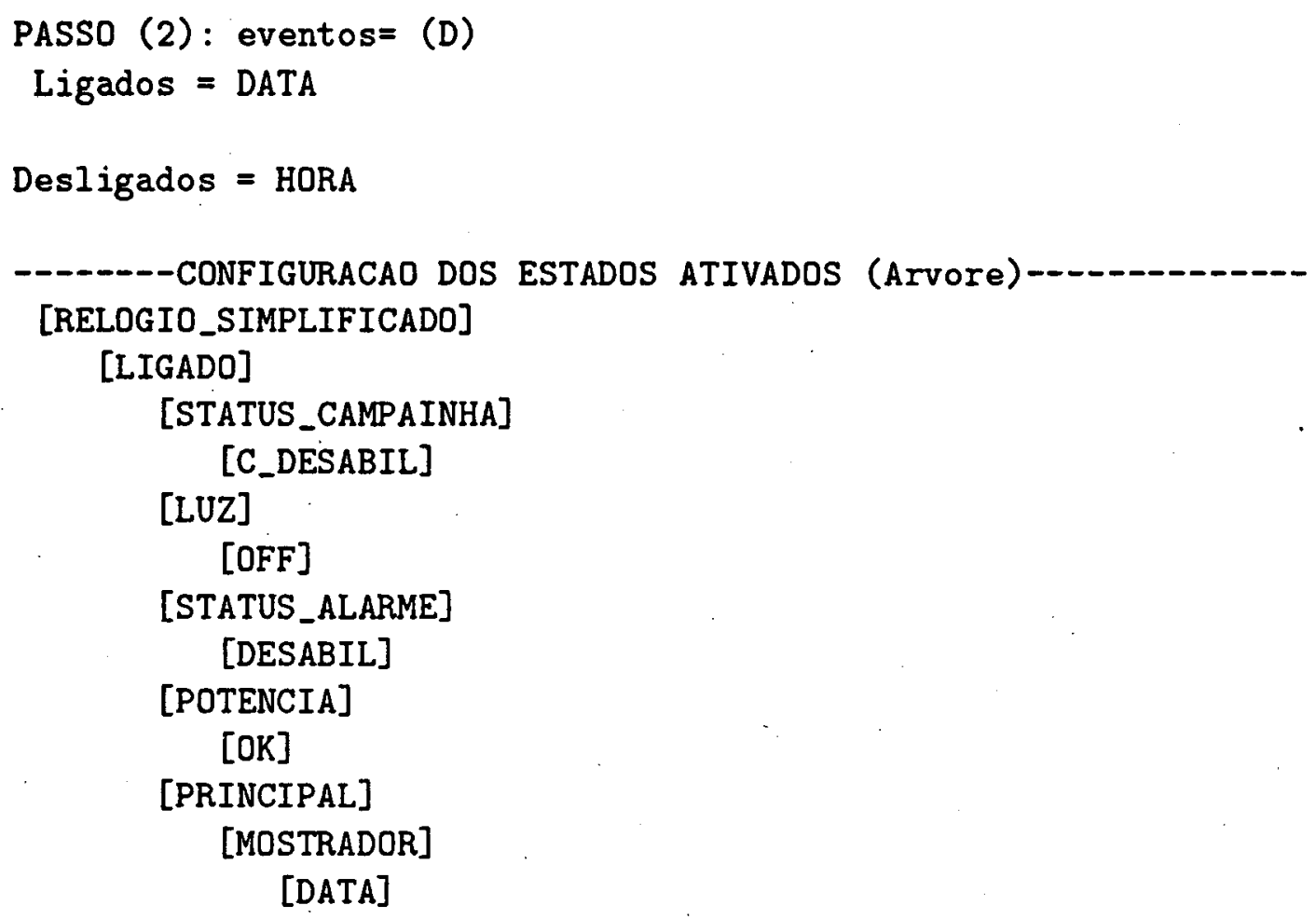

Obs: Neste passo (2) é interessante notar que o disparo do evento D habilitou que três transições simultâneas fossem avaliadas. A transição que ativou o subestado DATA se efetivou. No entanto, as transições:

1. DESABIL $\rightarrow$ HABIL, não se efetivou devido ao sistema não estar com subestado paralelo ALARME ativado no instante em que houve o disparo do evento. 
2. C_DESABIL $\rightarrow$ C_QUIETO, também não se efetivou pois estava condicionada ao sistema estar com o subestado paralelo CAMPAINHA ativado.

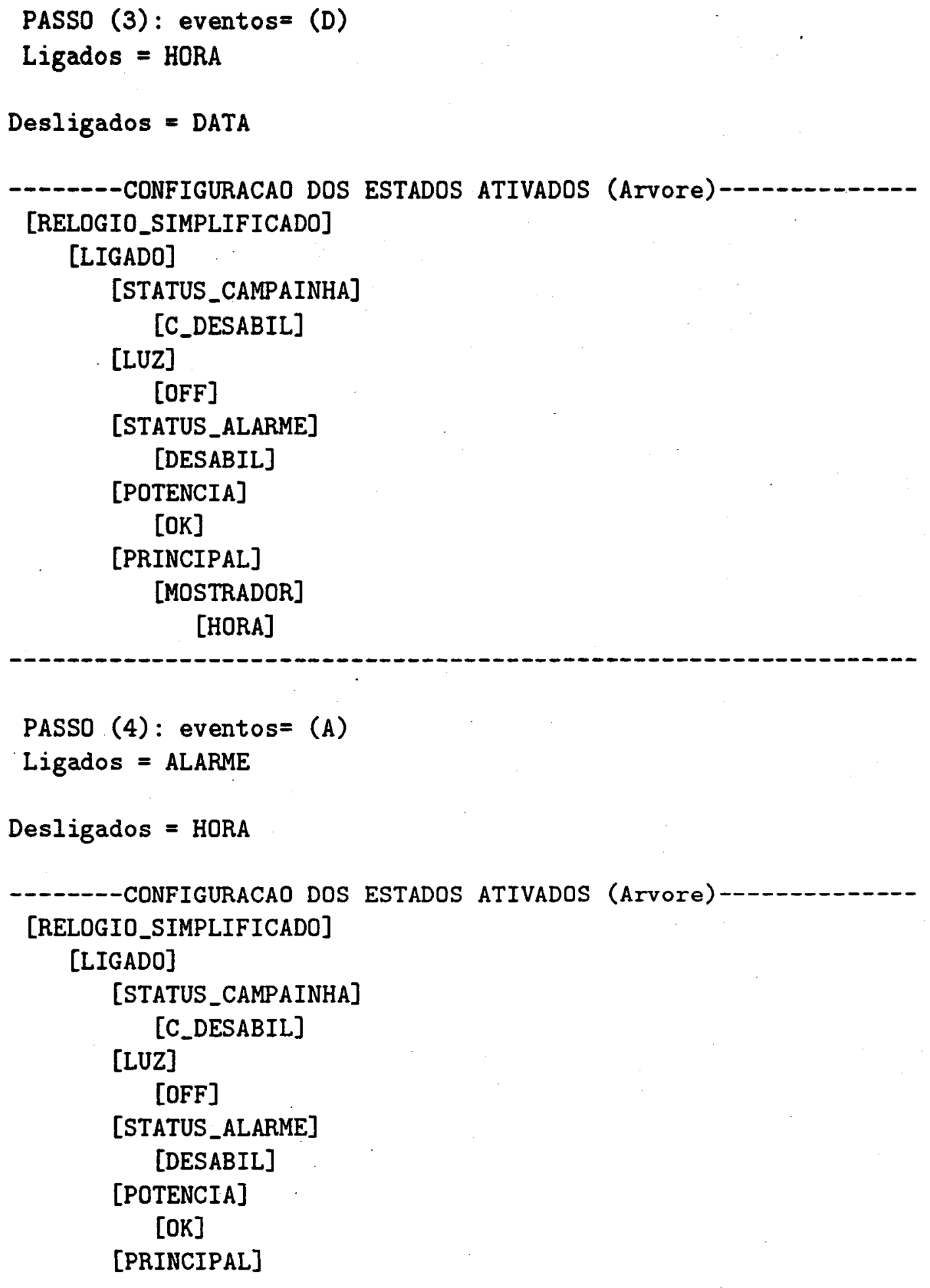


[MOSTRADOR]

[ALARME]

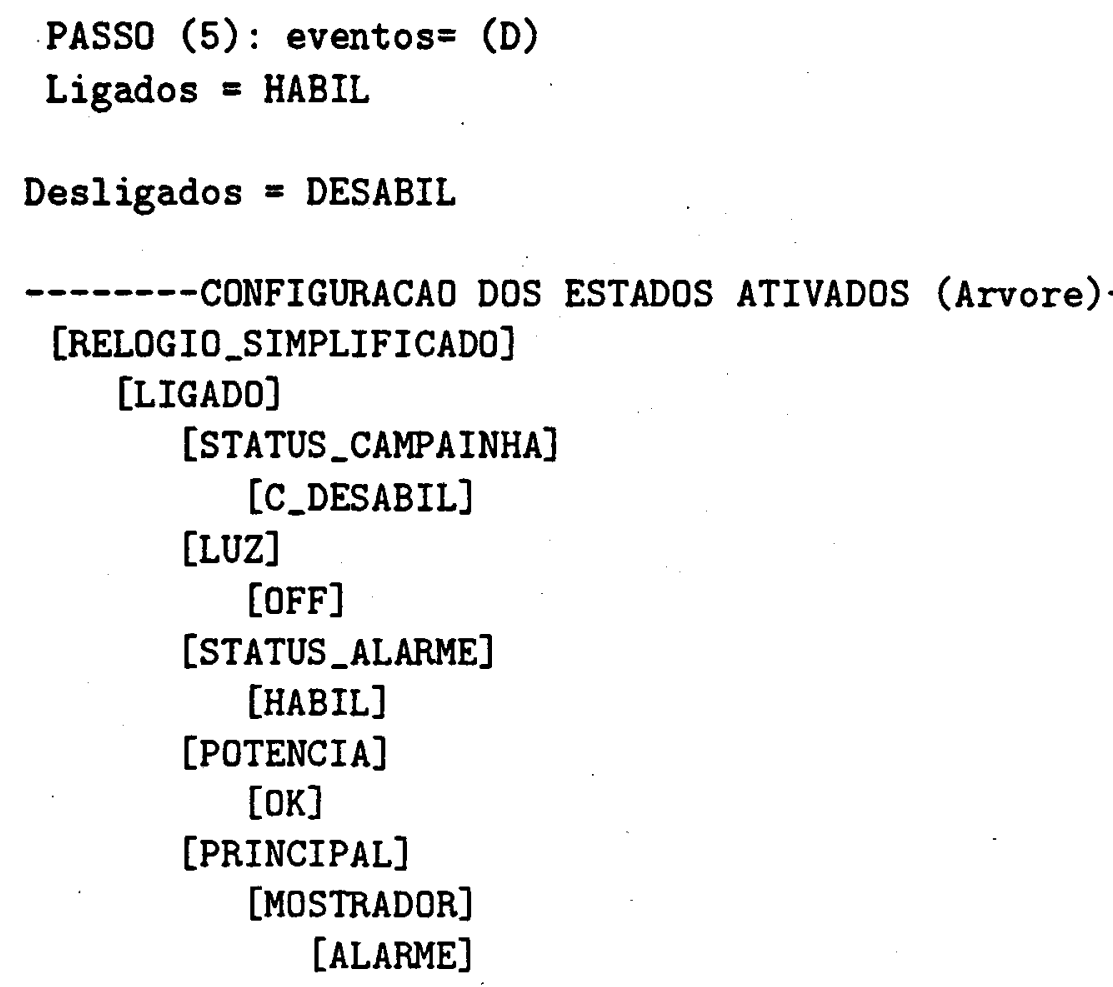

Obs: Este passo (5) ilustra a efetivação da transição sendo avaliada sua expressão condicionante. No caso esta transição foi efetivada (DESABIL $\rightarrow$ HABIL), pois o sistema desta vez estava com o subestado ALARME ativado, em contraste com o passo (2), onde ela também havia sido avaliada.

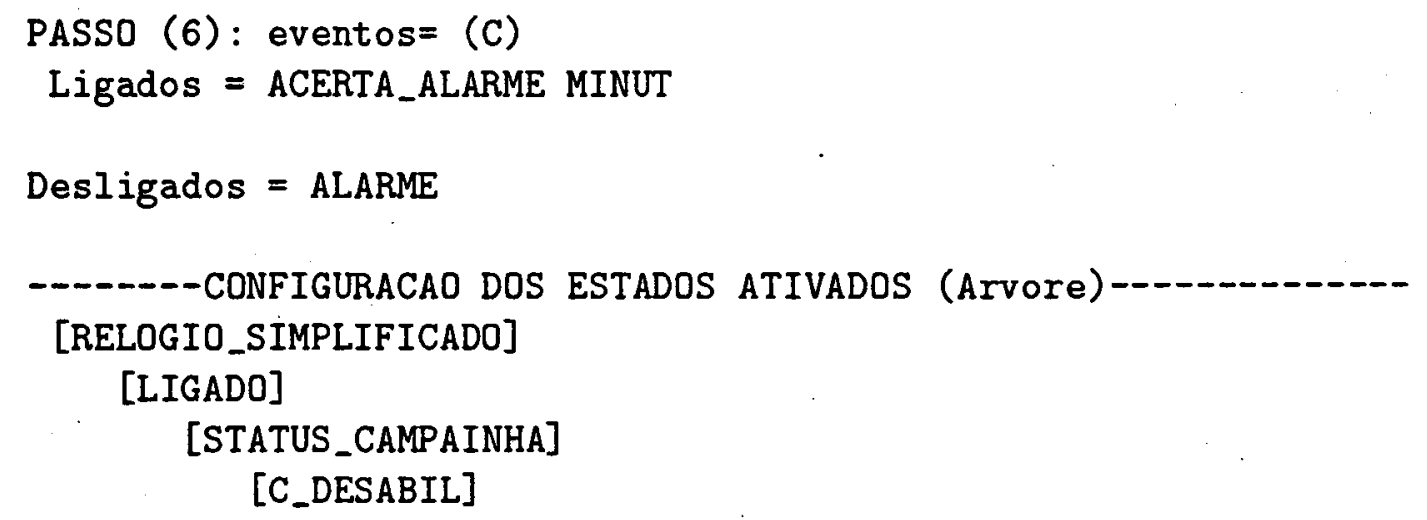


[LUZ]

[OFF]

[STATUS_ALARME]

[HABIL]

[POTENCIA]

[OK]

[PRINCIPAL]

[MDSTRADOR]

[ACERTA_ALARME]

[MINUT]

\author{
PASSO (7): eventos= (HORA_ALARME) \\ Ligados = BEEP_ALARME \\ Desligados $=$ MOSTRADOR ACERTA_ALARME MINUT
}

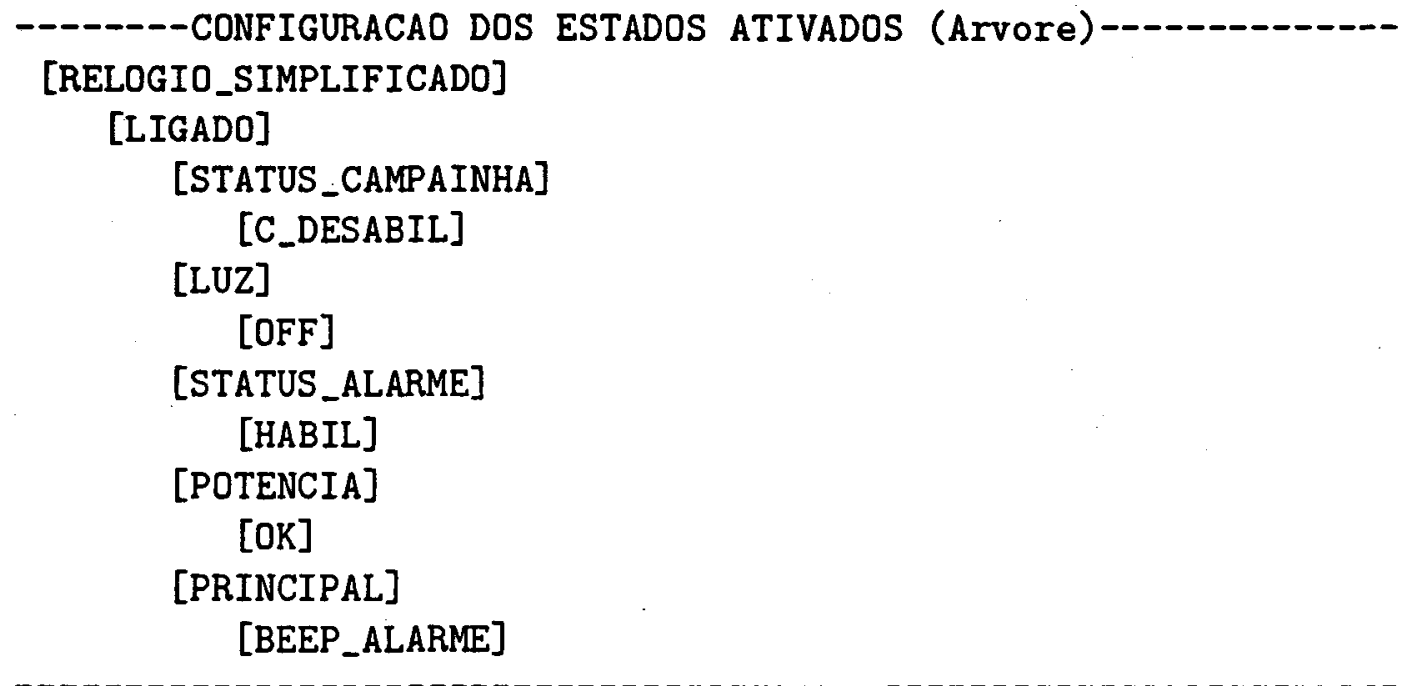

Obs: Este passo (7) ilustra outra situação, em que além do disparo do evento, foi requerida a avaliação de um condicionante para que a transição se efetivasse.

PASSO (8): eventos $=$ (C)

Ligados $=$ MOSTRADOR ACERTA_ALARME MINUT

Desligados $=$ BEEP_ALARME 
CONFIGURACAO DOS ESTADOS ATIVADOS (Arvore)

[RELOGIO_SIMPLIFICADO]

[LIGADO]

[STATUS_CAMPAINHA]

[C_DESABIL]

[LUZ]

[OFF]

[STATUS_ALARME]

[HABIL]

[POTENCIA]

[OK]

[PRINCIPAL]

[MOSTRADOR]

[ACERTA_ALARME]

[MINUT]

Obs: Este passo (8) ilustra a utilização da notação $\mathbf{H}^{*}$ no subestado destino da transição. Portanto, os estados que são "ligados" devido à efetivação desta transição são recuperados do contexto em que da última vez (neste exemplo, a configuração mostrada no passo (6)) o sistema ficou ativado no subestado MOSTRADOR.

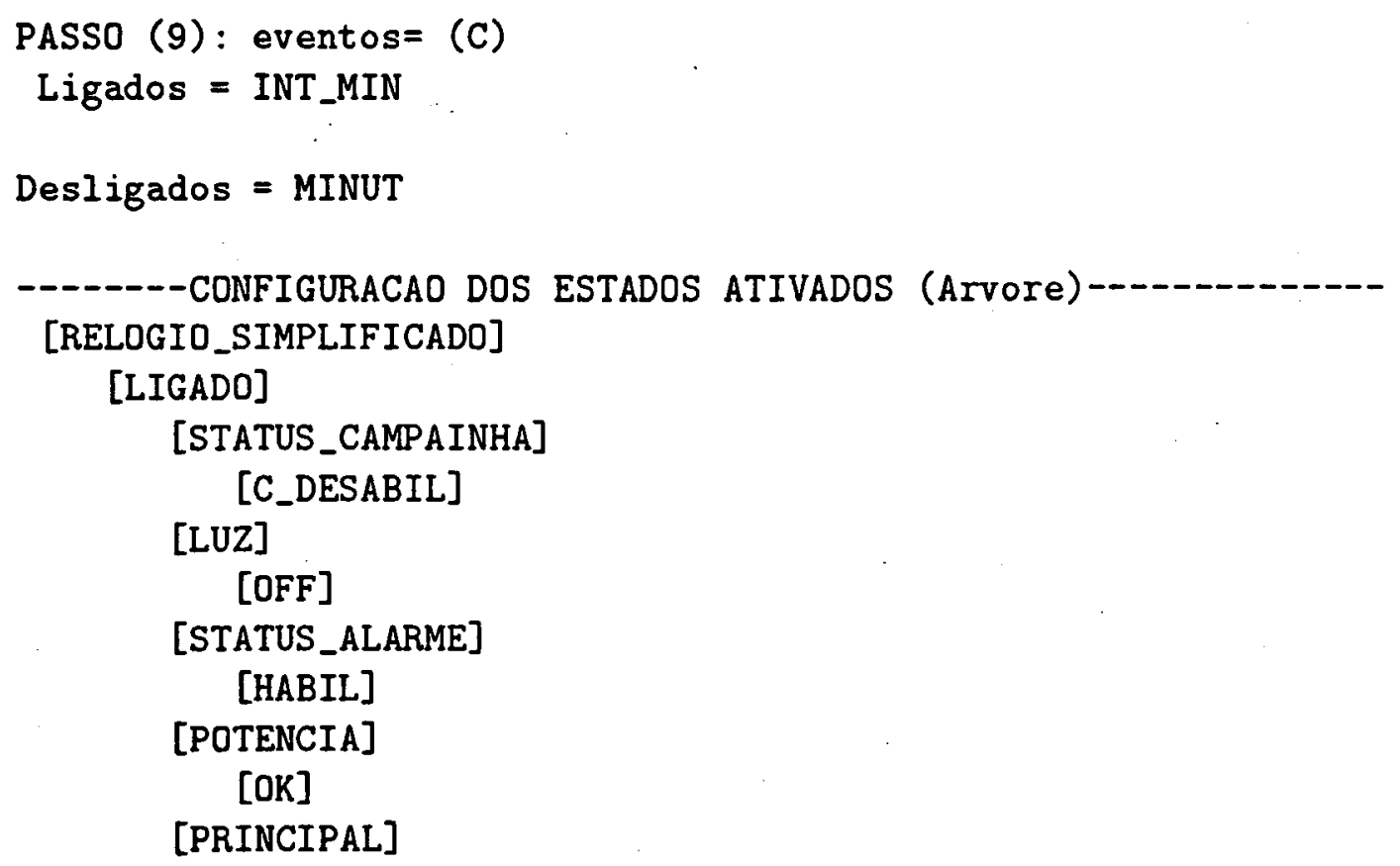




\section{[MOSTRADOR]}

[ACERTA_ALARME]

[INT_MIN]

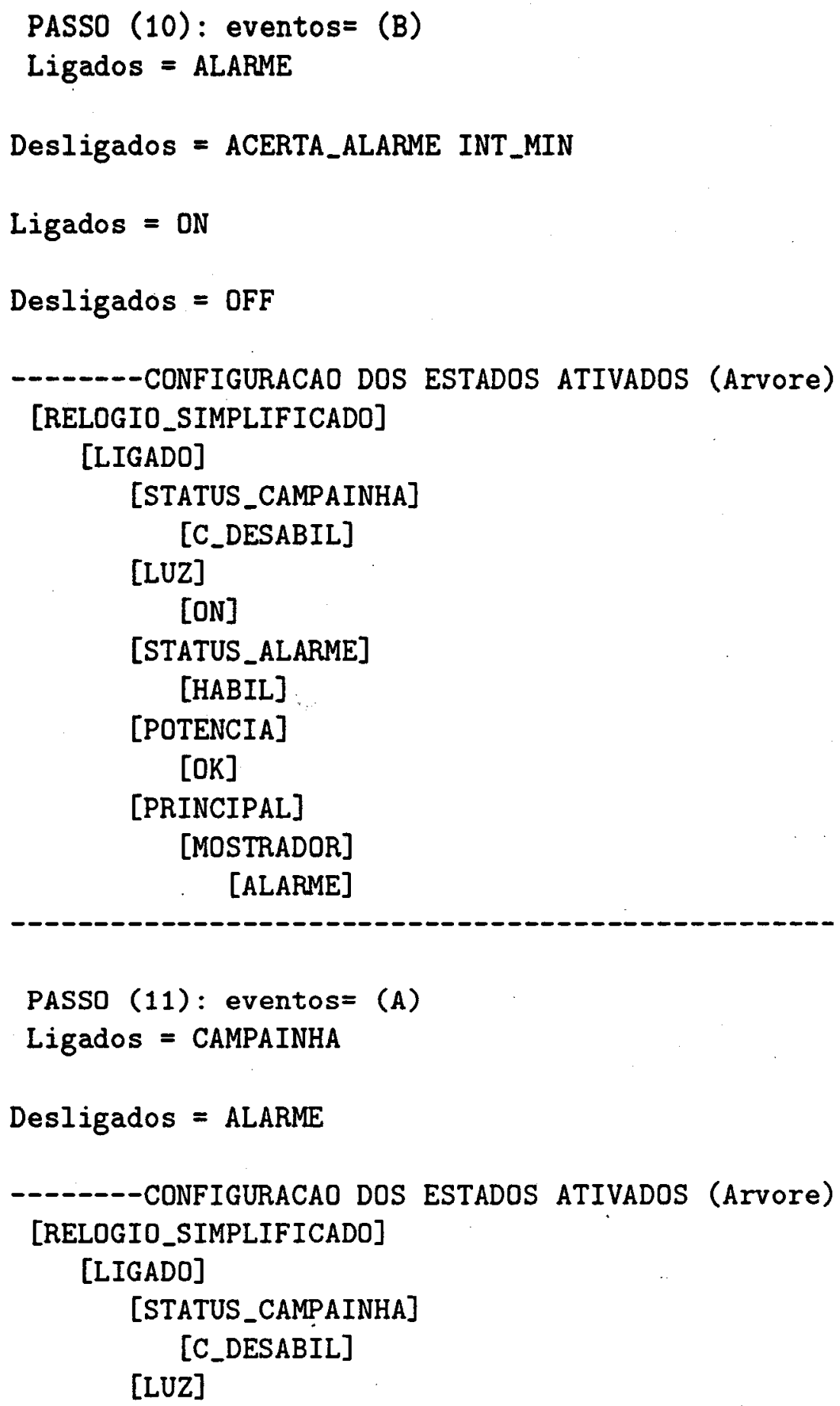


[ON]

[STATUS_ALARME]

[HABIL]

[POTENCIA]

[OK]

[PRINCIPAL]

[MOSTRADOR]

[CAMPAINHA]

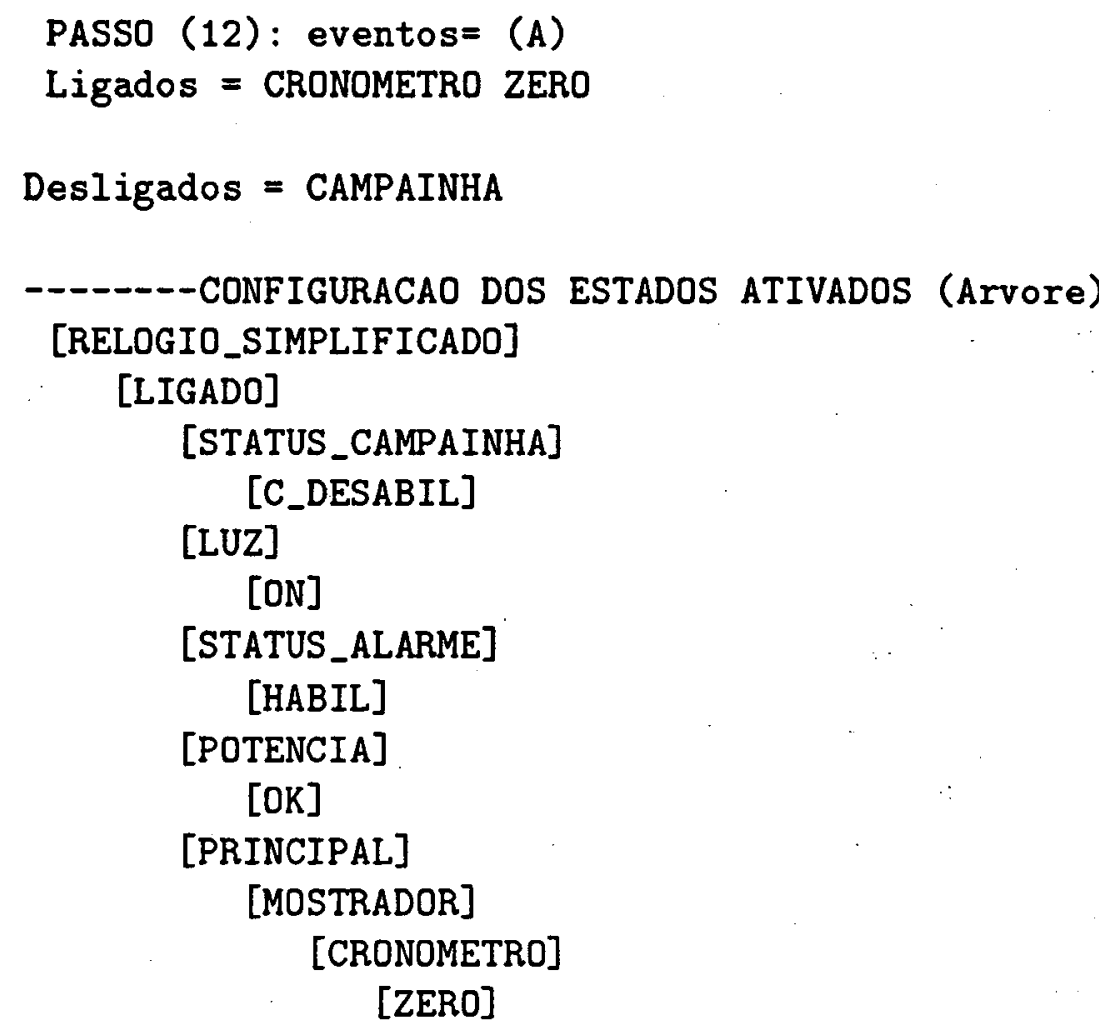

Obs: Este passo (12) também é outro caso utilizando-se a notação $\mathrm{H}^{*}$, porém, possui a particularidade de ser a primeira vez que o sistema ativa o subestado destino da referida transição, ou seja, não existe nenhum contexto a ser recuperado. Portanto, o sistema fica ativado nos subestados destino, por seus defaults.

PASSO (13): eventos $=$ (B)

Ligados = MR RODA MOSTRA REG ON 


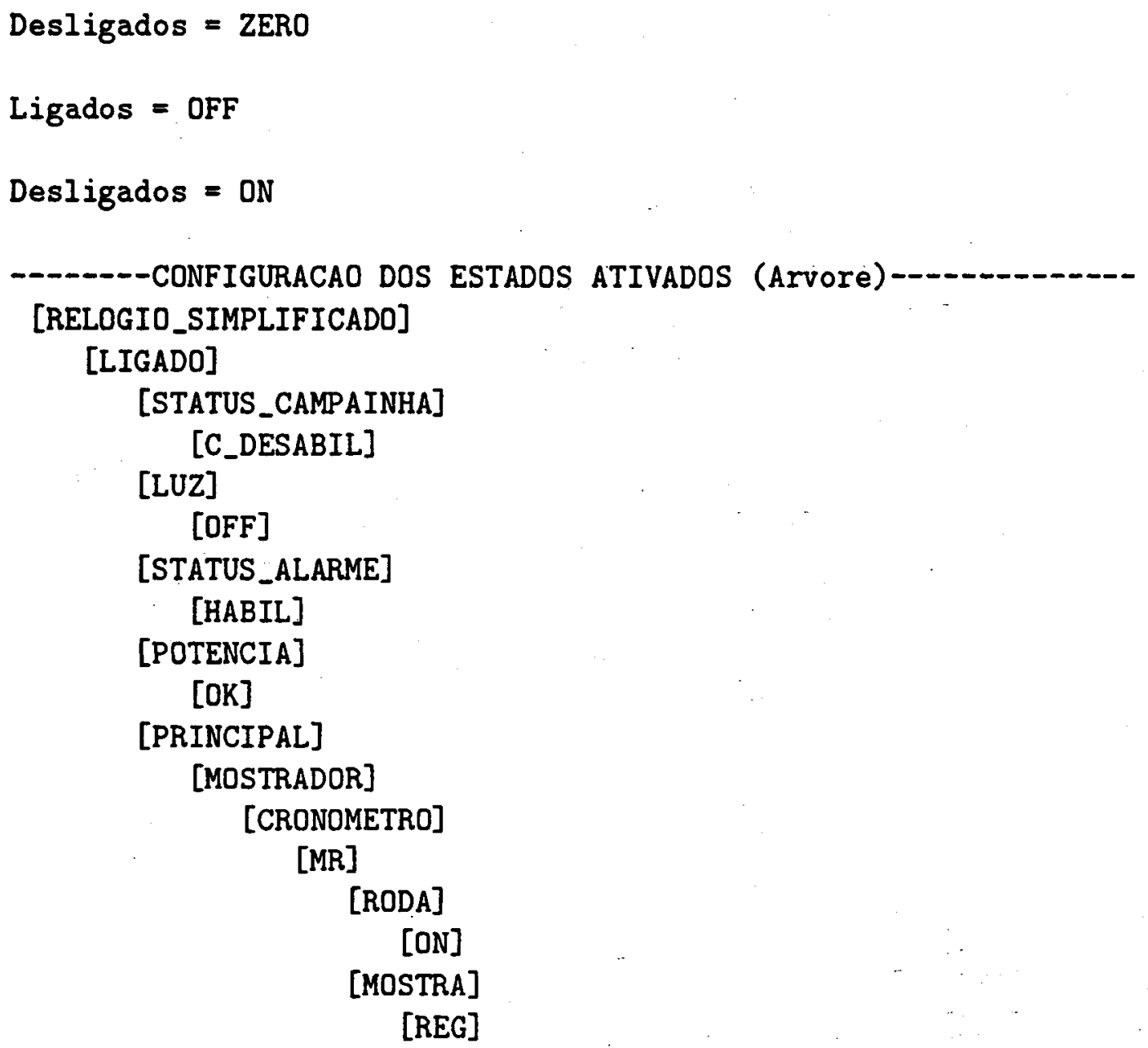

Obs: Este passo (13) ilustra as transições paralelas explícitas pela utilização do arco da transição bifurcado (transições $n \rightarrow m$ ). Estas transições foram denominadas na Base de Dados da Especificação Interna como sub-transições.

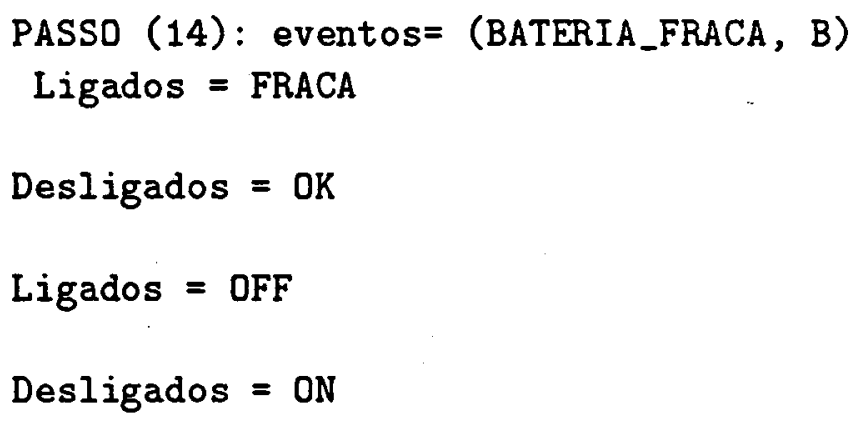




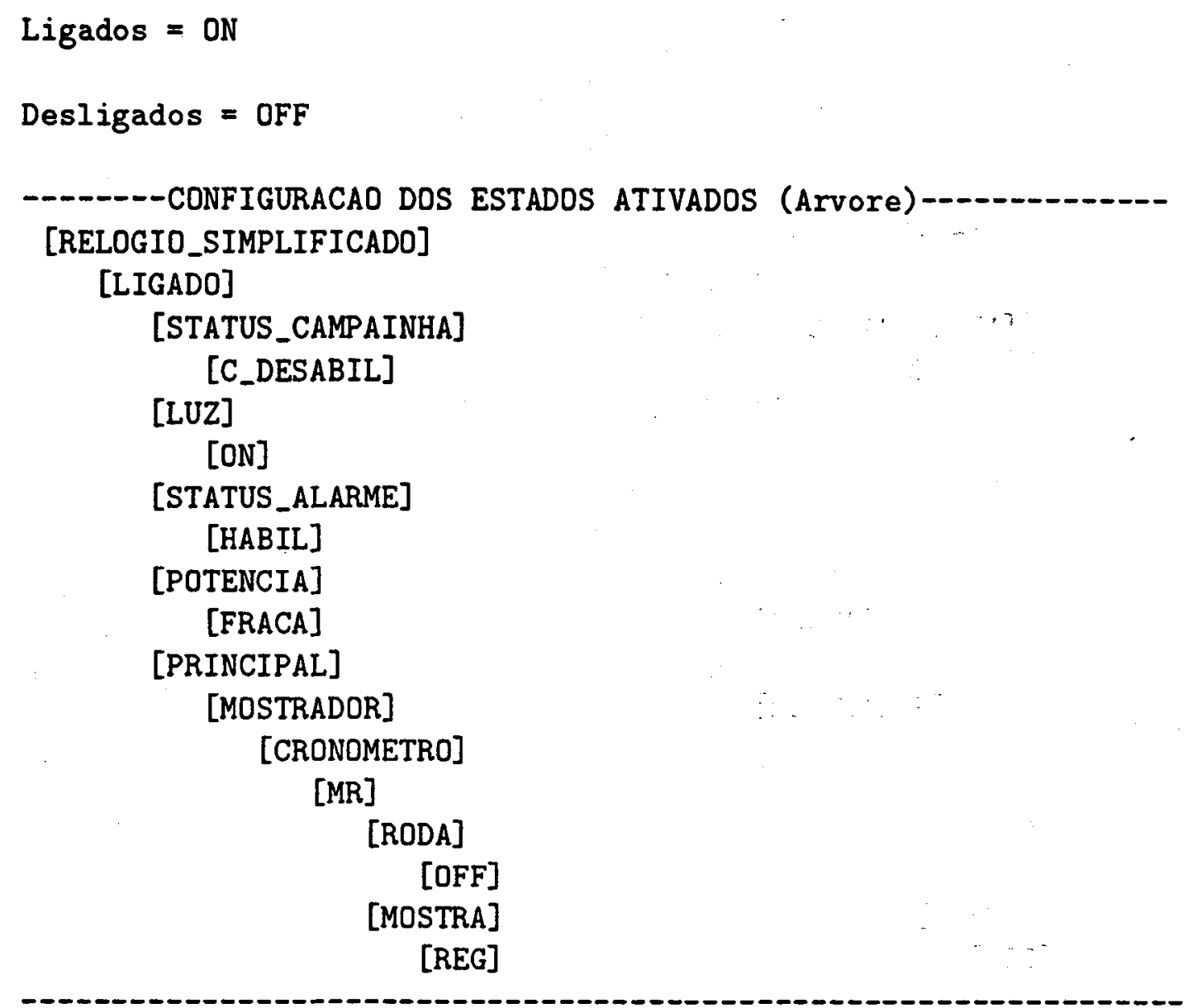

Obs: Neste passo (14) está ilustrado o caso de recepção de mais de um evento ao mesmo tempo. Foram disparados dois eventos simultaneamente: BATERIA_FRACA e B, que resultou na efetivação de três transições paralelas. Isso ocorre seguindo-se as atividades:

1. Buscaram-se todas as transições possiveis, isto é, todas as transições relacionadas aos dois eventos disparados e que tivessem os estados-origem ativados.

2. Foram interpretados os códigos (contidos nas pilhas-polonesas de cada transição) das transições possíveis.

3. Analisaram-se as transições que retornaram satisfatoriamente da interpretação, com relação a afetarem sub-estados de níveis de Hierarquia distintos.

4. Ativaram-se os estados-destino e desativaram-se os estados-origem de cada transição, na ordem em que se encontravam dispostas na Especificação In- 
terna. Este caso mostra também que a ordem dos efeitos das transições paralelas não afeta o resultado da Simulação, a menos nos casos de inconsistência da Base de Dados devido a não-determinismo estrutural.

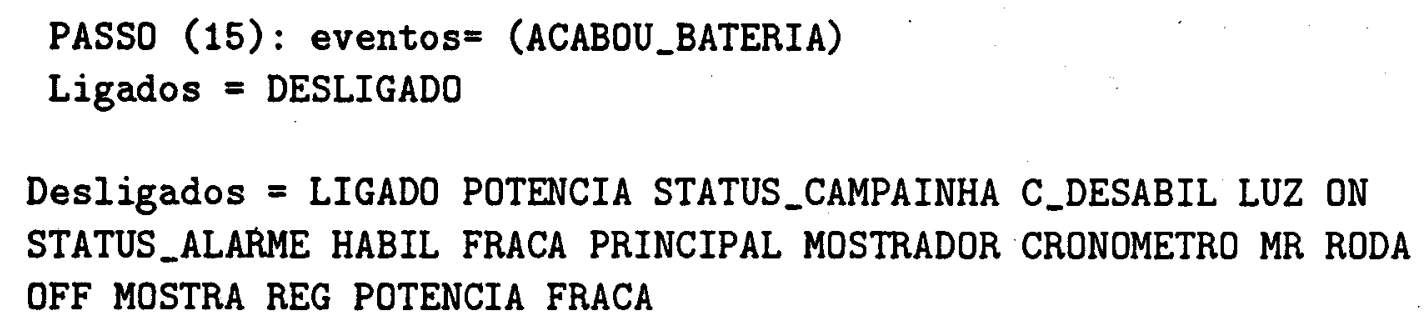

Finalmente, o relógio retornou à situação do início desta demonstração de Simulação: DESLIGADO, devido ao evento ACABOU_BATERIA, mostrando a desativação de todos os subestados até o estado Ancestral Comum entre os subestados origem e destino da transição.

\subsection{Conclusões}

Este capítulo ilustrou com um exemplo a utilização da Ferramenta projetada neste trabalho, com o objetivo de apresentá-la de forma breve. Foram descritas as suas características de comunicação com o usuário e feita uma demonstração comentada do uso da Ferramenta tendo como exemplo a especificação de um relógio digital simplificado.

Para referir-se a exemplos mais exaustivos, com relação à própria notação adotada pela técnica STATECHARTS que a Ferramenta implementou, os casos explorados em [Fort91b] fornecem uma visão mais detalhada dos passos envolvidos na Simulação de Statecharts.

A utilização da ferramenta neste capítulo, aplicando-se em um exemplo não complexo, comprova ainda mais que a técnica STATECHARTS é essencialmente visual e apesar de todo o formalismo lógico pertinente à sua notação, o aspecto gráfico vem completar muito o projeto implementado através da Ferramenta. 
No entanto, o estudo das teorias da semântica e da sintaxe embutidas na técnica STATECHARTS, para a aplicação prática na Ferramenta, foi uma contribuição importante feita durante o desenvolvimento da Ferramenta de Simulação de Especificação em STATECHARTS. A implementação realizada, em sua versão atual, está plenamente capacitada a permitir a simulação de parte substancial dos Statecharts que se pode construir durante a atividade de especificação de sistemas Reativos. 


\section{Capítulo 5}

\section{CONCLUSÕES}

\subsection{Considerações Iniciais}

Neste trabalho apresentou-se, no capítulo 2, uma revisão abrangente de métodos e ferramentas para o desenvolvimento de Sistemas de Tempo-Real, com especial atenção para o problema de especificação e validação do aspecto comportamental desse tipo de sistema.

Essa revisão mostrou que grande parte dos métodos atualmente disponíveis usam alguma forma de diagramas de transição de estado para especificar STRs e que, dentre esses, o tipo de diagrama conhecido como Statechart surgiu recentemente como uma alternativa vantajosa, em comparação com os DTEs convencionais, por ter várias extensões importantes, que facilitam e tornam mais concisas as especificações de problemas complexos. Entretanto, a semântica subjacente a esse tipo de diagrama é muito mais rica e complexa do que os DTEs convencionais.

Assim, foi desenvolvida uma ferramenta para apoio à especificação de STRs através de STATECHARTS, com o objetivo principal de permitir a análise, simulação e depuração da especificação baseada em STATECHARTS. Esse é um ponto de partida muito importante, porque muitas extensões podem ser, a partir de agora, acrescentadas ao ambiente em desenvolvimento no ICMSC-USP, de ferramentas para apoio ao desenvolvimento de Sistemas de Tempo-Real.

A implementação dessa ferramenta exigiu o desenvolvimento de algorítmos complexos e até o momento não discutidos na literatura, envolvendo principalmente: os aspectos de ativar e desativar a hierarquia de estados origem 
e destino de uma transição, respectivamente; gerenciar as transições múltiplas associadas a estados ortogonais; e, gerenciar o mecanismo de transição por história, em todos os seus níveis.

Como parte da ferramenta de simulação, grande esforço foi devotado ao desenvolvimento de um sistema para gerenciar uma base de dados contendo especificações de Statecharts. Dessa forma, a base de dados é independente do simulador e pode ser utilizada por outras ferramentas que se pretende desenvolver. Desenvolveu-se também uma linguagem para especificação de Statecharts e um analisador para aceitá-la e criar as instâncias da base de dados.

\subsection{Avaliação da Ferramenta}

$\mathrm{O}$ reconhecedor da linguagem foi testado exaustivamente e funciona a contento, embora não seja robusto e não se tenha investido muito esforço a nível das mensagens de erro e tentativas de recuperação de erros sintáticos do usuário. Entretanto, o sentimento é de que este reconhecedor servirá apenas em casos especiais de manutenção da base de dados, tão logo o editor gráfico que está sendo desenvolvido por Batista fique pronto [Bati90].

O simulador foi avaliado em aproxidamente uma dezena de casos, testando condições limites do sistema e casos com hierarquia and/or, história, transições múltiplas, etc. O sentimento desta autora é que a distância que o separa entre ser um protótipo para ser considerado um produto acabado não é muito grande e exigiria pouco esforço adicional. Esforço este que deve ser dirigido principalmente ao que se refere à interface e à documentação da Ferramenta para o usuário.

Pretende-se agora avaliar o simulador em problemas reais e em condições práticas de uso. Para isso, aplicações de tempo-real em desenvolvimento dentro da USP, como no Departamento de Engenharia Mecânica da Escola de Engenharia de São Carlos, devem ser especificadas com o apoio da ferramenta. Pretende-se também colocá-la à disposição de outras organizações externas que venham a se interessar.

Esta autora acredita que o Simulador de Especificações possa colaborar para que a técnica Statecharts possa ser, por sua flexibilidade, adaptada e/ou estendida para ser utilizada com outros métodos já existentes, que utilizavam alguma outra forma convencional de diagramas de estado. 


\subsection{Sugestões para futuras pesquisas}

O sistema de gerenciamento da base de dados de Statecharts e o simulador desenvolvidos são o embrião para novas pesquisas (e desenvolvimentos associados), algumas das quais já em andamento.

Em primeiro lugar pretende-se mostrar visualmente a simulação, isto é, os estados ligados e desligados serão enfatizados através de cores e cada passo da simulação será refletido no diagrama através do "apagamento" e "acendimento" de estados na tela. Para isso, um editor gráfico de Statecharts está em desenvolvimento e após o seu término a simulação visual poderá ser implementada.

Uma segunda área de investigação a ser explorada deverá levar a uma extensão do simulador, incluindo a execução, teoricamente fundamentada, dos micro-passos. Isso inclui a execução das ações associadas às transiçôes e o tratamento de forma mais realística de alguns operadores especiais de eventos, como o "time-out", "not-yet", "current", etc.

Uma vez que se tem uma base de dados contendo a especificação interna dos Statecharts, uma área interessante de investigação, tanto no aspecto teórico quanto prático, seria o estudo de verificações de propriedades dos Statecharts e a implementação de programas que realizem essa verificação na base de dados. Como exemplo de algumas propriedades podem-se citar: ausência de impasses ("deadlocks"), alcançabilidade dos estados, caminhos no diagrama, diversos tipos de consistência do diagrama, deteç̧ão de não-determinismos estruturais, etc.

Cresce também o interesse no uso de STATECHARTS para especificação de diálogos homem-máquina e a utilização dessa técnica em Sistemas de Gerenciamento de Interface do Usuário (SGIU). O núcleo do simulador poderia ser usado com um sistema desse tipo para controlar o aspecto dinâmico do diálogo, em parceria com outros componentes do SGIU.

Finalmente, algumas extensões de pequeno porte podem contribuir para enriquecer o simulador desenvolvido, oferecendo mais opções aos usuários, como por exemplo: relatórios diversos sobre o conteúdo da base de dados, introdução de parâmetros para especificar preferências, como listar ou não os estados na lista de história, armazenar num arquivo de registro ("log") os passos da simulação, etc. 


\section{Bibliografia}

[Alfo77] ALFORD,M. - A Requirements engineering methodology for real-time processing requirements. IEEE Trans. Softw. Eng., SE3(1): 60-69, 1977.

[Alle83] ALLEN,J.F. - Maintaining knowledge about temporal intervals. CACM, 26(11): 832-843, 1983.

[Allw81] ALLWORTH,S.T. Introduction to real-time software design. London, Macmillan, 1981.

[Ambl77] AMBLER,A.L.; GOOD,D.I.; BROWNE,J.C.; BURGER,W.F.; COHEN,R.M.; HOCH,C.G.; WELLS,R.E. - GYPSY: a language for specification and implementation of verifiable programs. IN Proceedings of the ACM Conference on language design for reliable software. SIGPLAN Notices, 12(3):1-10, 1977.

[Andr83] ANDREWS,G.R.; SCHNEIDER,F.B. - Concepts and notations for concurrent programming. Computing Surveys, 15(1): 3-43, 1983.

[Balz81] BALZER,R. - Transformational implementation: en example. IEEE Trans. Softw. Eng., SE7(1): 3-14, 1981.

[Bati90] BATISTA,J.E.S. - Um Editor Gráfico para Statecharts. Minidissertação apresentada ao ICMSC-USP, visando ao exame de qualificação para o Mestrado, 1990.

[Benn90] - BENNET,S.; VIRK,G.S. Computer control of Real-time Processes. London, Peter Peregrinus Ltd., 1990. 305p.

[Berr84] BERRY,G.; COSSERAT,L. - The ESTEREL synchronous programming language and its mathematical semantics. IN Seminar on concurrency. Berlin,LNCS 197: 389-448, Springer-Verlag, 1984. 
[Blum88] BLUMOFE,R.; HECHT,A. - Executing real-time structured analysis specifications. ACM SIGSOFT, 13(3): 32-40, 1988.

[Bruy88] BRUYN,W.; JENSEN,R.; KESKAR,D.; WARD,P. - ESML: An extended systems modeling language based on the data flow diagram. $A C M$ SIGSOFT, 13(1): 58-67,1988.

[Came86] CAMERON,J.R. - An overview of JSD. IEEE Trans. Softw. Eng., SE12(2): 222-240, 1986.

[Camp77] CAMPOS,I.M.; ESTRIN,G. - Concurrent software system design supported by SARA at the age of one. IN Proceedings of the Third International Conference on Software Engineering. IEEE: 230-242, 1977.

[Cunh89] CUNHA,P.R.F.; MOURA,M.T.S. - Representação gráfica para LOTOS. IN III Simpósio Brasileiro de Engenharia de Software. Recife-PE, 1989.

[Davi88] DAVIS,A.M. - A comparison of techniques for the specification of external system behavior. CACM, 31(9): 1098-1115, 1988.

[Estr79] ESTRIN,G.; RAZOUK,R.R.; VERNON,M. - Evaluation methods in SARA - the graph model simulator. IN Proceedings of the 1979 Conference on simulation, measurement and modeling of computer systems. Association for Computing Machinery, 1979.

[Fort91a] FORTES,R.P.M.; MASIERO,P.C. - Uma Linguagem para Especificação de Statecharts e seu Analisador. Documento de Trabalho, Cód. ME91/01, ICMSC-USP, 1991.

[Fort91b] FORTES,R.P.M.; MASIERO,P.C. - Demontração do Sistema de Simulação de Especificação de Statecharts em alguns Casos Críticos. Documento de Trabalho, Cód. ME-91/02, ICMSC-USP, 1991.

[Free83] FREEMAN,P. - Fundamentals of design. IN Tutorial on Sofware design techniques. Fourth edition, New York, IEEE: 2-22, 1983.

[Goma84] GOMAA,H. - A software design method for real-time systems. CACM, 27(9): 938-949, 1984.

[Hami76] HAMILTON,M.; ZELDIN,S. - Higher Order Software - a methodology for defining software. IEEE Trans. Softw. Eng., SE2(1): 9-32, 1976.

[Hare87a] HAREL,D. - STATECHARTS: a visual formalism for complex systems. Science of Comp. Programming, 8: 231-274, 1987. 
[Hare87b] HAREL,D. - STATECHARTS: on the formal semantics of Statecharts. IN Proceedings of the 2nd IEEE Symposium on Logic in Computer Science. Ithaca, New York, 1987.

[Hare88a] HAREL,D. et al - STATEMATE: a working environment for the development of complex reactive systems. IN Proceedings of the Tenth International Conference on Software Engineering. (Singapore,April), Washington D.C., IEEE, 1988.

[Hare88b] HAREL,D. - On visual formalisms. CACM, 31(5): 514-530, 1988.

[Hat184] HATLEY,D.J. - The use of structured methods in development of largesoftware avionics systems. IN Proceedings of the AIAA/IEEE 6th Digital Avionics Systems Conference (Baltimore, MD) Washington D.C., IEEE , 1984.

[Heni80] HENINGER,K. - Specifying software requirements for complex systems: new techniques and their application. IEEE Trans. Softw. Eng., $\operatorname{SE6}(1): 2-13,1980$.

[Hoar78] HOARE,C.A.R. - Communicating sequential processes. CACM, 21(8): 666-677, 1978.

[Jaco83] JACOB,R.J.K. - Using formal specifications in the design of a humancomputer interface. CACM, 26(4): 259-264, 1978.

[Masi89] MASIERO,P.C. Uma visão geral do método JSD. São Carlos, ICMSC/USP, 1989. (Notas didáticas ICMSC/USP, 3).

[Mell83] MELLICHAMP,D.A. Real-Time Computing with applications to data acquisition and control.California, Van Nostrand Reinhold, 1983.

[Mell85] MELLOR,S.; WARD,P.T. Structured development for real-time systems. New Jersey, Prentice-Hall, 1985.

[Mend88] MENDES,S.B.T.; AGUIAR,T.C. Métodos para especificação de sistemas. Curitiba, III EBAI, 1988.

[Miln80] MILNER,R. A calculus of communicating systems. LNCS 92, SpringerVerlag, 1980.

[Mosz84] MOSZKOWSKI,B. - Executing temporal logic programs. IN Seminar on concurrency. Berlin,LNCS 197: 111-130, Springer-Verlag, 1984. 
[Pari83] PARIKH,G.; ZVEGINTZOV,N. - Understanding software. IN Tutorial on Sofware Maintenance. IEEE Computer Society, New York, IEEE: 61-63, 1983.

[Pete77] PETERSON,J. - Petri-nets. ACM Comput. Surv.,9 (3): 223-252, 1977.

[Pres87] PRESSMAN,R.S. Software engineering: A practioner's approach. Singapore, McGraw-Hill, 1987.

[Quir85] QUIRK,W.J. Verification and validation of real-time software. New York, Springer-Verlag, 1985.

[Ross77a] ROSS,D.T. - Structured analysis (SA): a language for communicating ideas. IEEE Trans. Softw. Eng., SE3(1): 16-34, 1977.

[Ross77b] ROSS,D.T.; SCHOMAN,K.E. - Structured analysis for requirements definition. IEEE Trans. Softw. Eng., SE3(1): 69-84, 1977.

[Saff75] SAFFER,S.I.; MISHELEVICH,D.J. - A definition of real-time computing. $C A C M, 18(9)$ : 544-545, 1975.

[Simp79] SIMPSON,H.R.; JACKSON,K.L. - Process synchronisation in MASCOT. The Computer J., 22(4): 332-345, 1979.

[Ward86] WARD,P.T. - The transformation schema: an extension of the data flow diagram to represent control and timing. IEEE Trans. Softw. Eng., SE12(2): 198-210, 1986.

[Whit85] WHITE,S.M.; LAVI,J.Z. - Embedded computer system requirements (REQECS) Workshop. IEEE Comp., 18(4): 67-70, 1985.

[Whit87] WHITE,S.M. - A pragmatic formal method for computer system definition. New York, Polytechnic University, Ph.D. Thesis, 1987.

[Zave82] ZAVE,P. - An operational approach to requirements specification for embedded systems. IEEE Trans. Softw. Eng., SE8(3): 250-269, 1982.

[Zave85] ZAVE,P. - A distributed alternative to finite-state-machine specifications. ACM Trans. Program. Languages Systems, 7(1): 10-36, 1985. 


\section{Apêndice A}

\section{Gramática da Linguagem de Especificação de Statecharts (LES)}

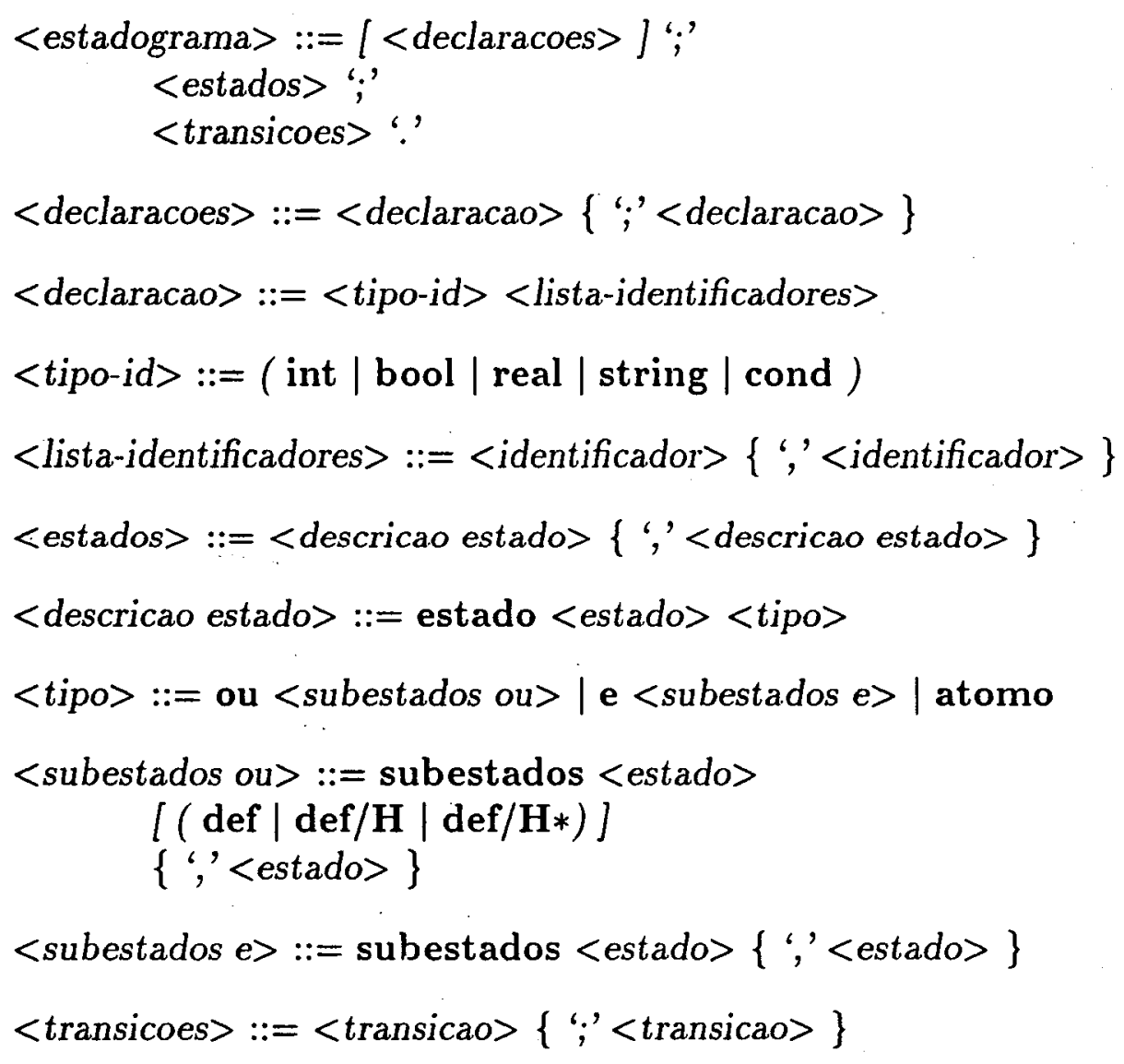




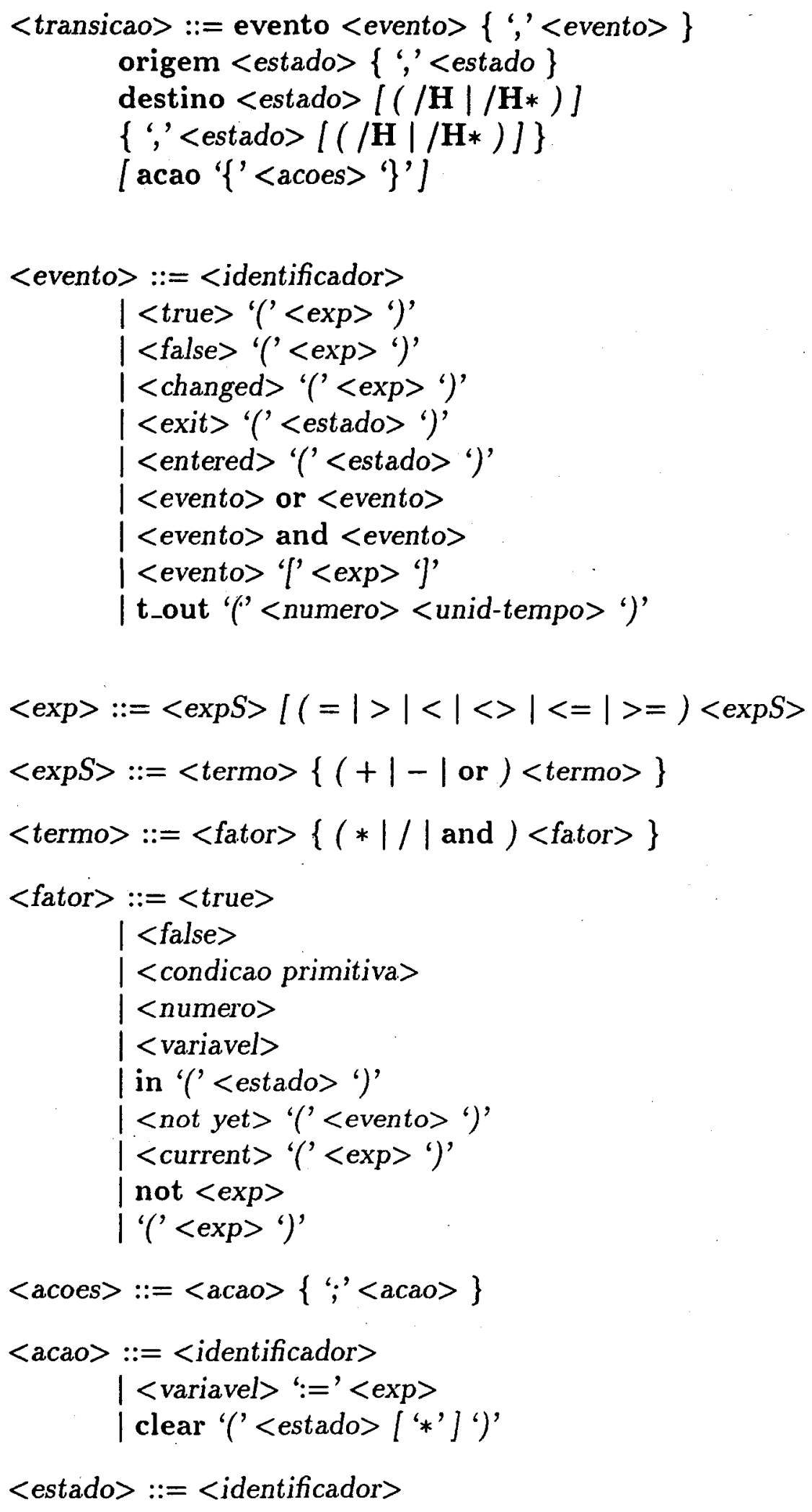




$$
\begin{aligned}
& \text { | <identificador>'.'<identificador > } \\
& <\text { variavel }>:=<\text { identificador }> \\
& <\text { true }>::=([\mathbf{t T}][\mathbf{r R}][\mathbf{u U}][\mathrm{eE}] \mid \mathrm{tr}) \\
& <\text { false }>:=([\mathrm{fF}][\mathrm{aA}][\mathbf{L}][\mathrm{sS}][\mathrm{eE}] \mid \mathrm{fs}) \\
& <\text { changed }>::=(\text { changed } \mid \text { ch }) \\
& <\text { exit }>:=(\text { exit } \mid \text { ex }) \\
& \text { <entered }>:=(\text { entered } \mid \text { en }) \\
& <\text { not yet }>::=(\text { not_yet } \mid \text { ny }) \\
& <\text { current }>::=\text { ( current } \mid \text { cr }) \\
& <\text { identificador }>::=[\mathbf{a}-\mathbf{z A}-\mathbf{Z}] \\
& {[\mathbf{a}-\mathbf{z A}-\mathbf{Z} 0-9] \text { * }} \\
& <\text { numero }>::=[0-9]+ \\
& \text { <unid-tempo }>:=(\operatorname{seg}|\min | \mathbf{h r})
\end{aligned}
$$




\section{Apêndice B}

\section{Tipos de dados das Estruturas Internas da Especificação em STATECHARTS}
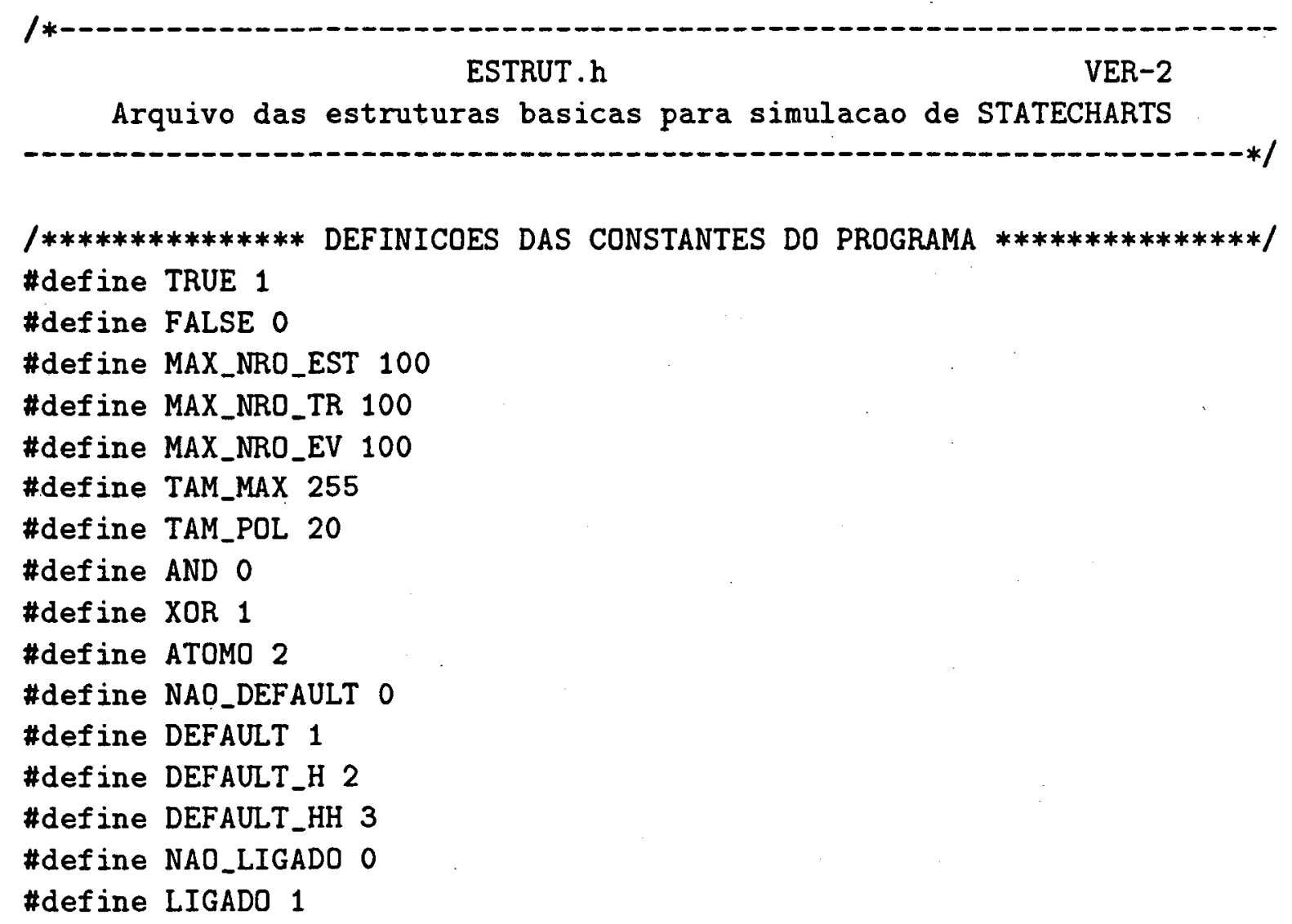


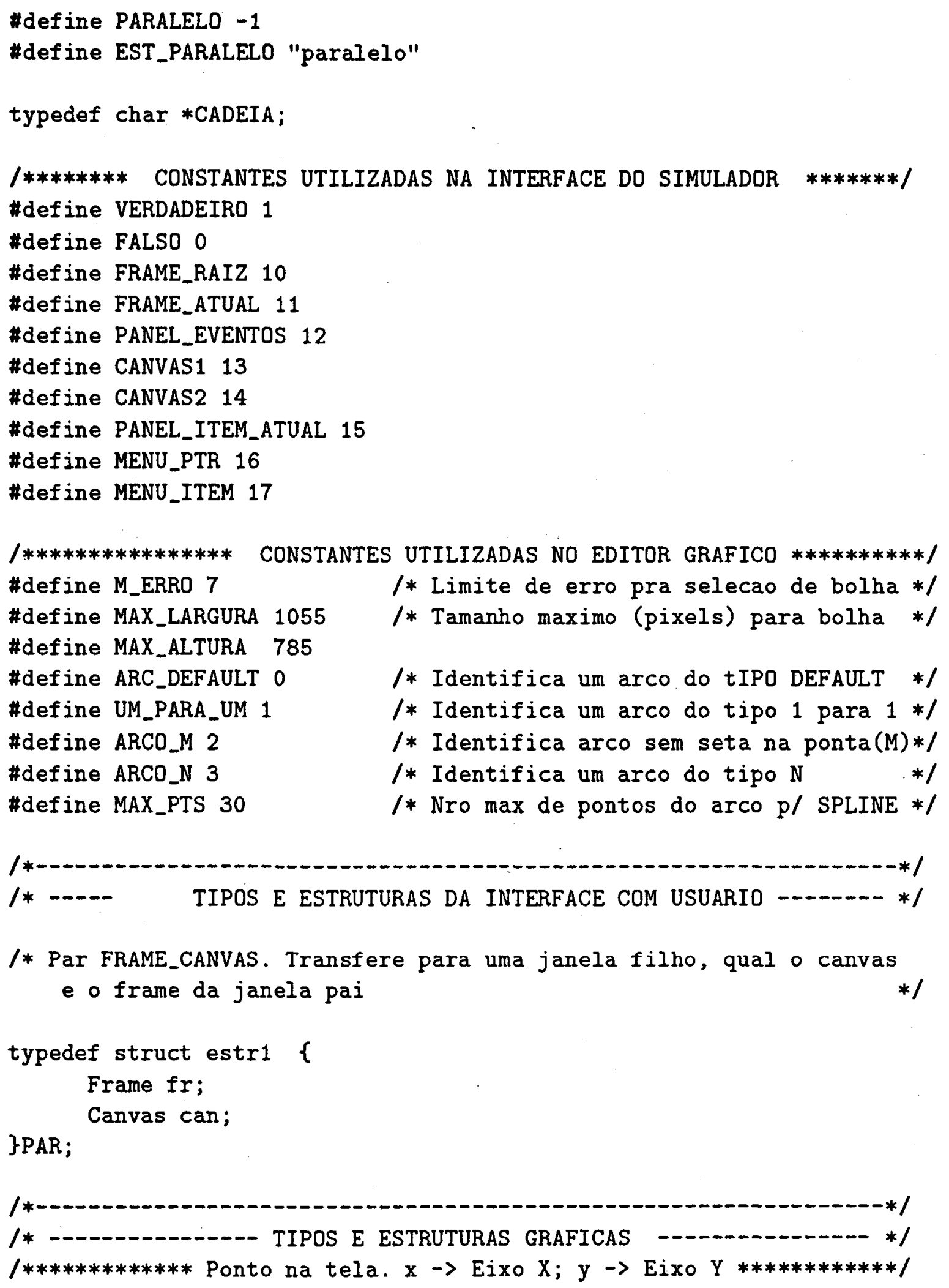


typedef struct coorde \{

int $x, y$;

\}COORDENADA;

/******** COORD. $(x, y)$ REAL. Para tracar arco $c /$ SPLINE $* * * * * * * * * * /$ typedef struct tipo_ponto \{

float $x$;

float $y$;

\}COORD_REAL;

/****** INF. p/ Armazenar uma curva e traca-la c/ SPLINE ********/

typedef struct tipo_curva \{

int ordem;

int nro_pontos;

COORD_REAL malha[MAX_PTS];

\}TIPO_CURVA ;

$/ * * * * * * * * * * * * * * * * * * *$ Estrut. de um ARCD ************************/ typedef struct arco \{

TIPO_CURVA arc; $/ *$ 0s pts. que geram o arco */

COORDENADA hist, $/ *$ posicao da historia(Se existir)*/ pos_rot; $/ *$ Posicao do rotulo(nomeo) */

char rotulo[40]; $/ *$ Nome do arco $* /$

\}ARCO; int valor_hist; /* Tipo da historia(H,H*, " ") */

$/ * * * * * * * * * * * *$ declaracao da estrutura RETANGULO $* * * * * * * * * * * * * * * * /$ typedef struct list \{

COORDENADA c1, /* Ponto inicial do poligono */

c2; /* Ponto final do poligono */

\}RET ;

struct list *prox;

/************ declaracao da estrutura GRAF *********************/ typedef struct graf \{ int $x, \quad / *$ Coord. do canto superior esquerdo */

$\mathrm{y}$,

$x_{\text {_larg, }} / *$ Coord. do canto inferior direito da bolha */ y_alt,

x_nome, /* Coord. posicao inicial de escrita do nome */

$y$ _nome; 
\}GRAF;

ARCO arc_hist; I* Se houver historia, armazenar arco */

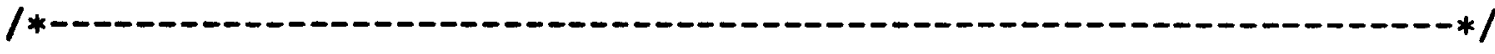

/* -

/*************** declaracao da estrutura TAB-EST $* * * * * * * * * * * * * * * * * * * *$ / typedef struct tab \{

CADEIA nome_est;

1* Nome do estado

$* 1$

int ind_sub_est;

/* Indice do subest $\mathrm{p} /$ este no $*$ /

int tipo;

1* Tipo (e/ou/atomo) $(0 / 1 / 2) * /$

int defo;

$1 * \operatorname{def} / \mathrm{nao}=(1 / 0), \operatorname{defH} / \operatorname{defH} *=(2 / 3) * /$

int nivel;

1* altura-arvore (raiz $=0$ )

int lig;

$1 *$ indica "ligado" (1/0)

int ult_lig;

/* indica hist "ligado"

struct tab *pai ;

/* pont. para o pai

struct tab *prim_filho; /* pont. para $\circ 10$. filho

struct tab *prox_irmao; /* pont. para prox irmao

struct tab *ant_irmao

/* pont. para irmao ant.

GRAF gf;

int sentinela;

1* Sub tipo das inf. graficas

$1 *$ alerta $=1234$

\}NO_ESTADO;

NO_ESTADO *subest[MAX_NRO_EST]; /* vetor ponts $\mathrm{p} /$ sub-estados */

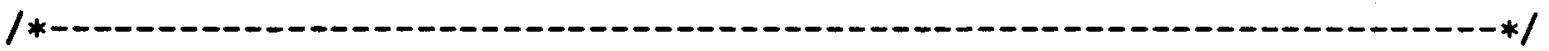

/*** Estr. temporaria que guarda os sub arcos tracados que depois serao guardados nas sub transicoes(Usado em arcos M pa N) $* * * *$ /

typedef struct lista_estados \{

NO_ESTADO *bolha;

/* pont. para a bolha corresp. */

struct lista_estados *prox; /* pont. para prox. no da lista */ ARCO arco;

1* Inf. Graficas do sub arco

JLISTA_ESTADOS;

/*--------

/*************** declaracao da estrutura da Pilha Polonesa $* * * * * * * * * * * l$ typedef struct polon \{

int tipo_item;

int ind_item;

\}PILHA_POL[TAM_POL];
/* tipo do item a ser avaliado */

$/ *$ indice do item $* /$ 


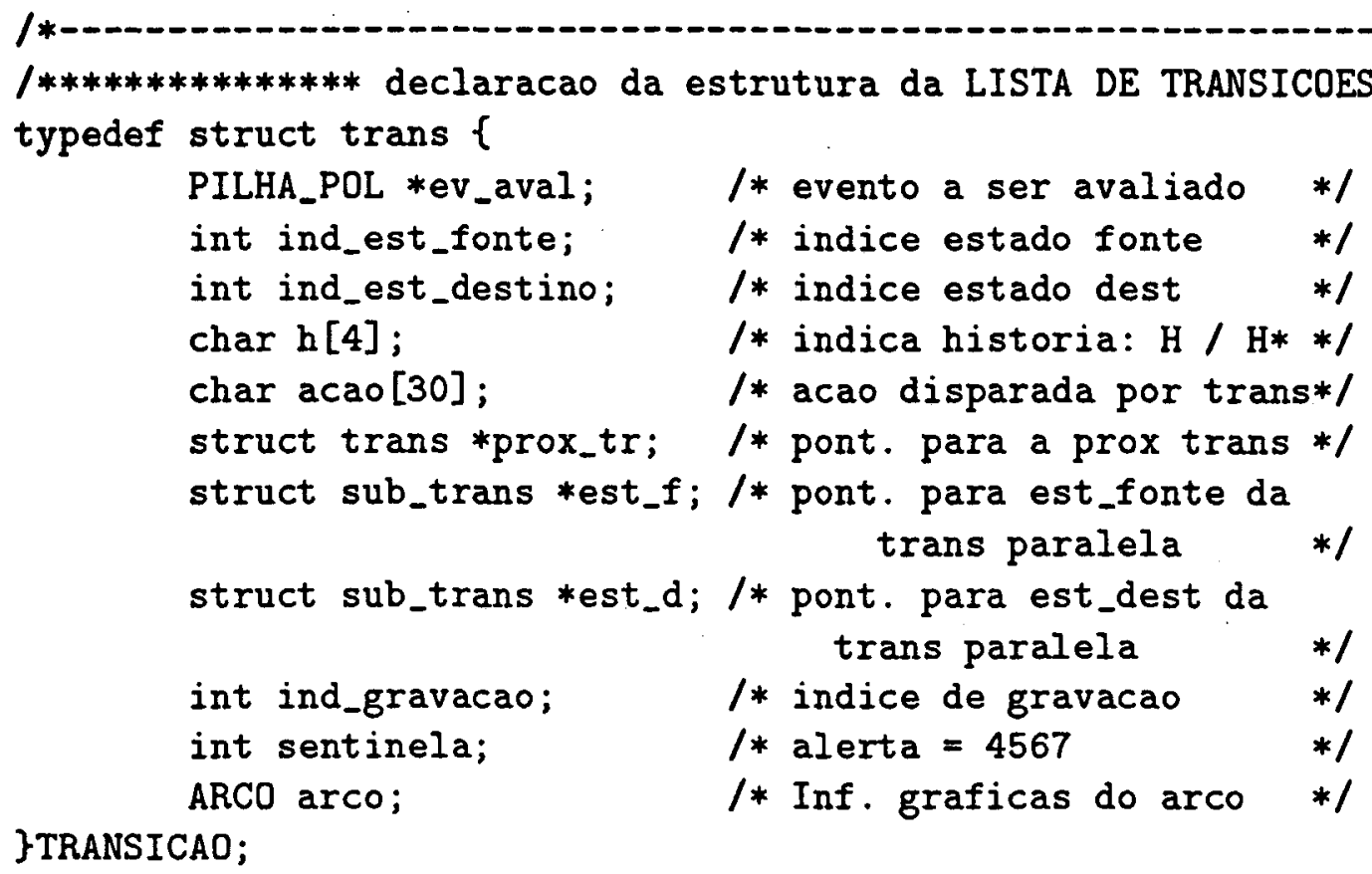

TRANSICAO *tr_ok[MAX_NRO_TR]; /* vetor de ponts. p/ trans habilit */

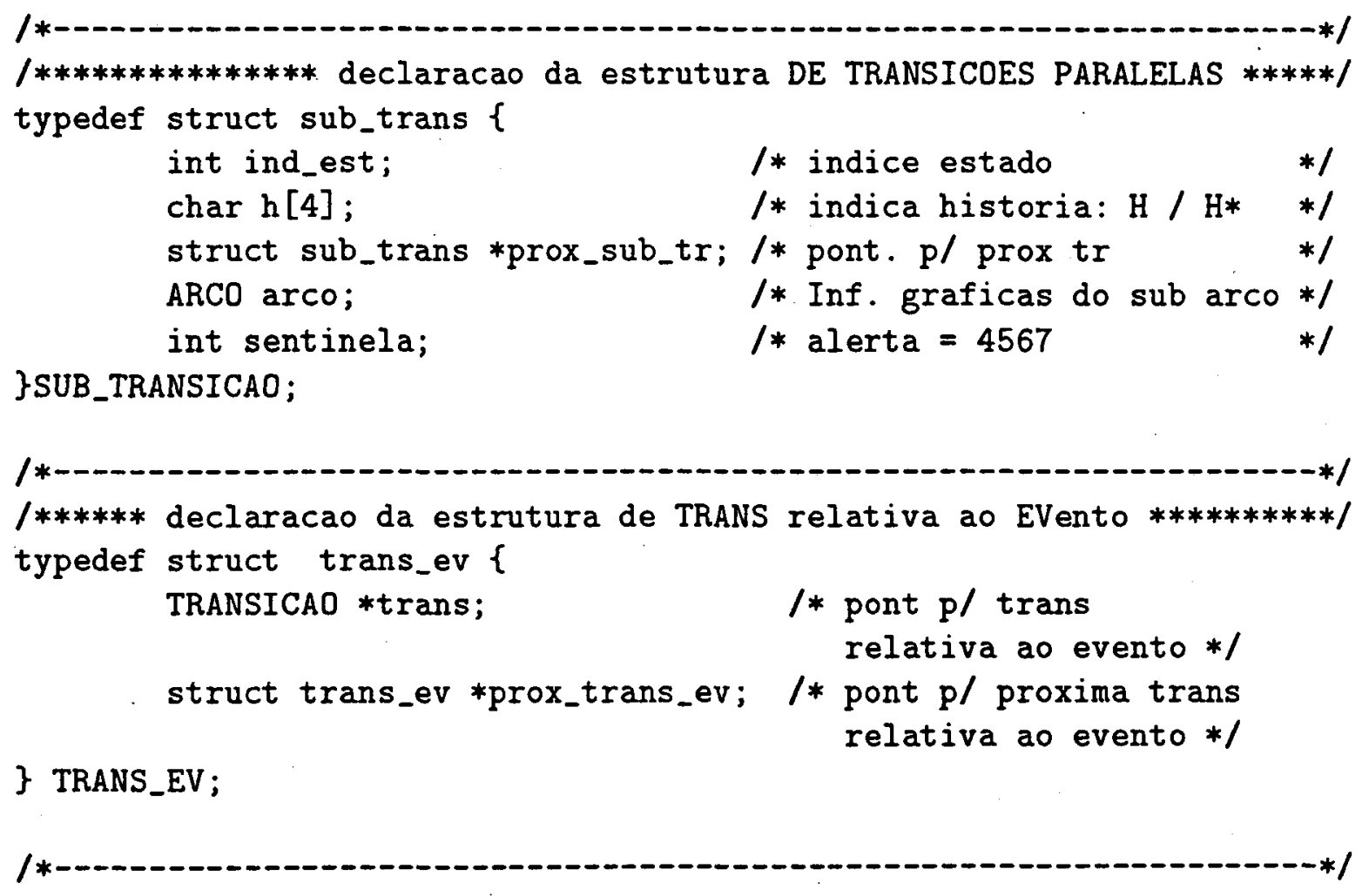


/********** declaracao da estrutura de TAB-EV typedef struct evento \{

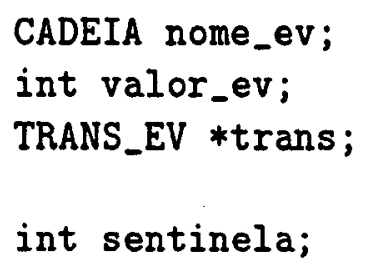

int sentinela;

\}NO_EVENTO;

NO_EVENTO *event [MAX_NRO_EV]; /* vetor de ponts. p/ eventos STTCHART */

/*-----

/******** declaracao estruturas LISTA de caminho de estados $* * * * * * * * * * /$ typedef struct lista_est \{

$$
\begin{array}{ll}
\text { NO_ESTADO *ptr_est; } & / * \text { ptr para estado } * / \\
\text { struct lista_est *prox_lista; } & / * \text { ptr p/ prox est } * /
\end{array}
$$

\}LISTA_EST;

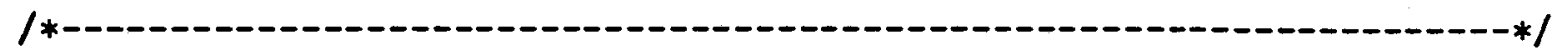

/**** declaracao estrutura dos estados sintaticamente declarados $* * * * * /$ typedef struct st \{

$\begin{array}{lll}\text { CADEIA n_st; } & \text { /* nome estado } & * / \\ \text { CADEIA n_pai; } & / * \text { nome estado-pai } & * / \\ \text { int tipo; } & \text { /* tipo do estado } & * / \\ \text { int defo; } & / * \text { default } & * / \\ \text { char marca; } & / * \text { marca para montar a arvEOU } * /\end{array}$

\}ST;

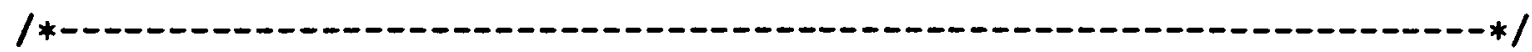

/**** declaracao estrutura TABELA de Estados Temporaria (TET)

para a analise semantica para criacao da arvore EOU ***********/

ST *subst [100]; /* tabela intermediaria de subestados criada na analise sintatica $* /$

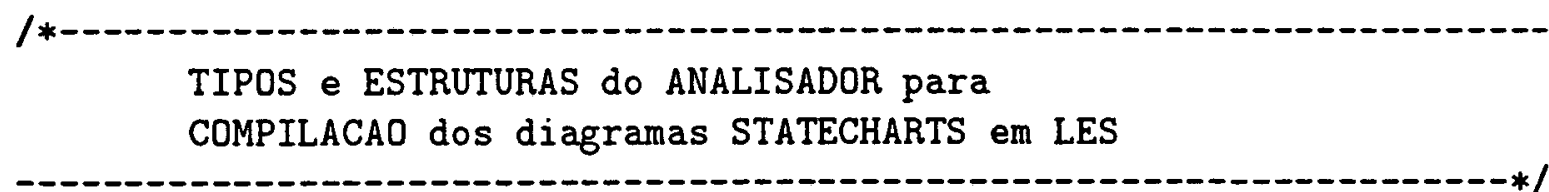

/************ DEFINICOES DAS CONSTANTES PARA COMPILACAO DA LES $* * * * * * * /$ 
\#define TAM_CHARTS 10000

\#define TAM_TAB_VARS 100

\#define IDENTIFICADOR 0

\#define NUMERO 1

\#define TIPO 2

\#define ERRO 999

\#define TEMP 1000

enum operadores $\{$ ATRIB $=10$,

GE, GT,
LE, LT,
EQ, NE $\} ;$

enum simb_espec $\{$ PT_VIRGULA $=20$, VIRGULA, ABRE_CHAVES, FECHA_CHAVES, ABRE_PARENTS, FECHA_PARENTS, MAIS, MENOS,

MULTIPLICA, DIVIDE,

ABRE_COLCHETES, FECHA_COLCHETES, PONTO $=32\}$;

enum pal_chaves $\{$ ESTADO $=50$, SUBESTADO_DU, SUBESTADO_ATOMO,

DEF,

DEF_HH,

EVENTO,

DRIGEM,

$\mathrm{H}$,

$\mathrm{TR}$,

NOT,

OP_OR,

TIMEOUT,

NOT_YET,

ENTERED,

EXIT,

CURRENT,

INT,

REAL,

COND,

SEG,

SUBESTADOS, SUBESTADO_E,

DEF_H,

DESTINO,

$\mathrm{HH}$,

FS,

ACAO,

OP_AND,

IN,

CHANGED,

CLEAR,

BOOL,

STRING,

MINUTO, 
HORAS,

enum tipos_aval
FIM \};

OPERADOR, OP_TIME,

EXPRESSAO \};

struct var_type \{

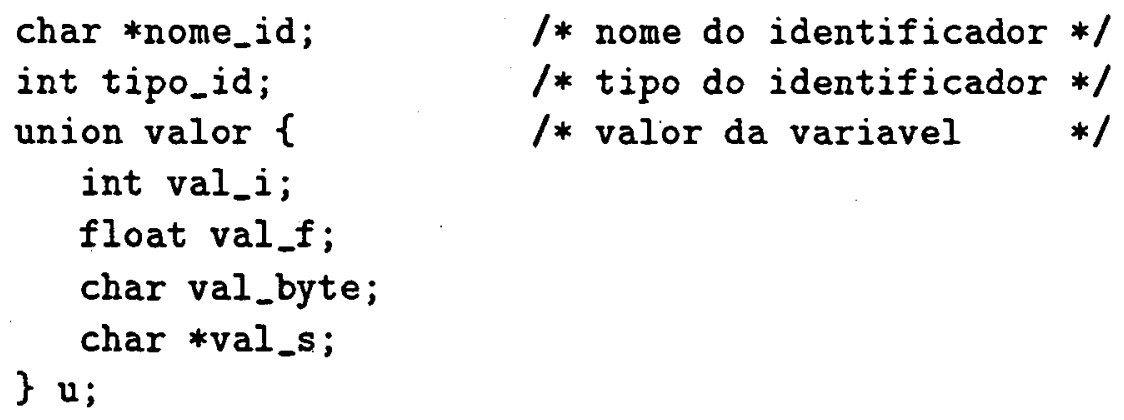




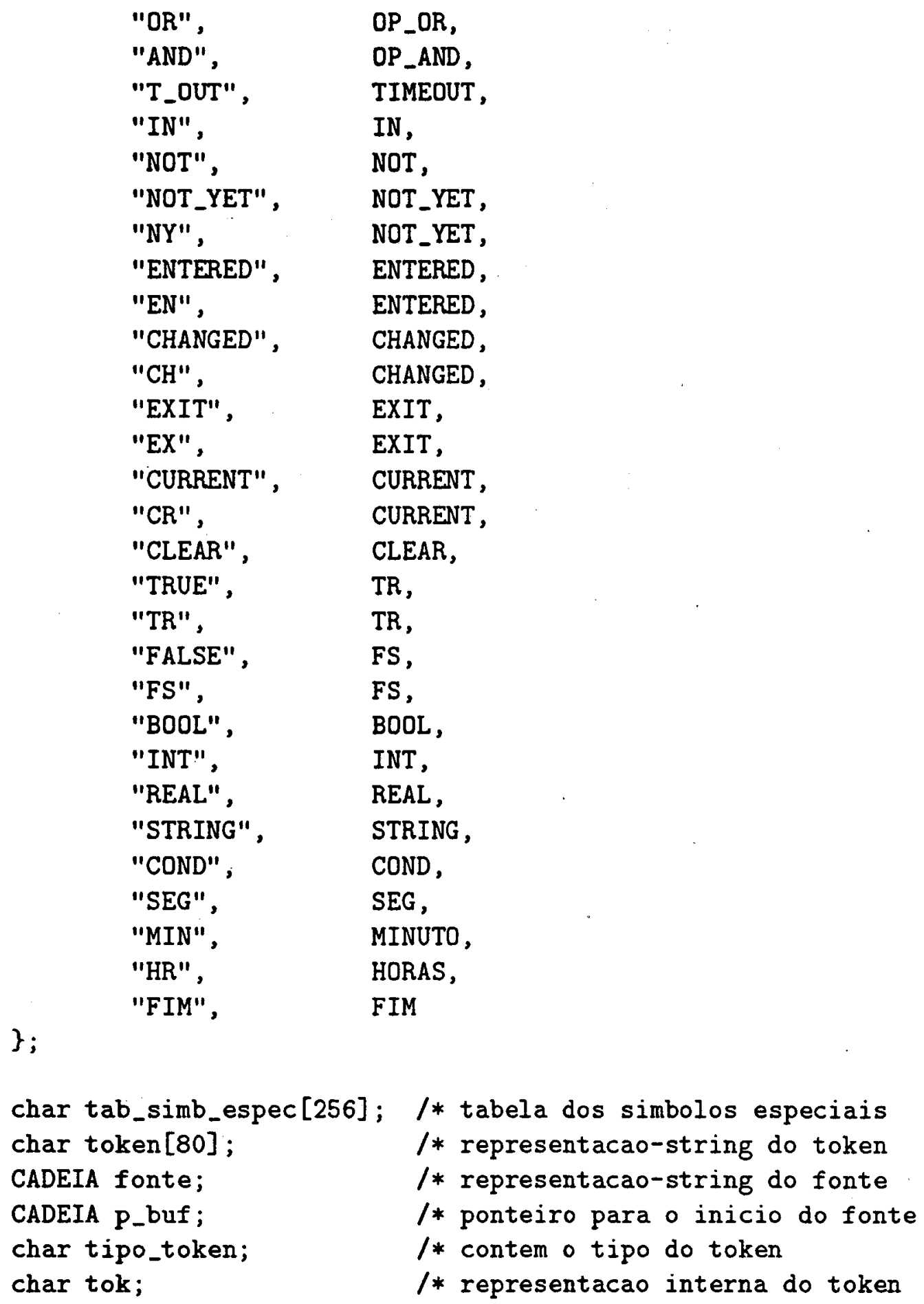


/*********** registro a ser gravado para TABELA DE ESTADOS ***********/ typedef struct regis_estado \{

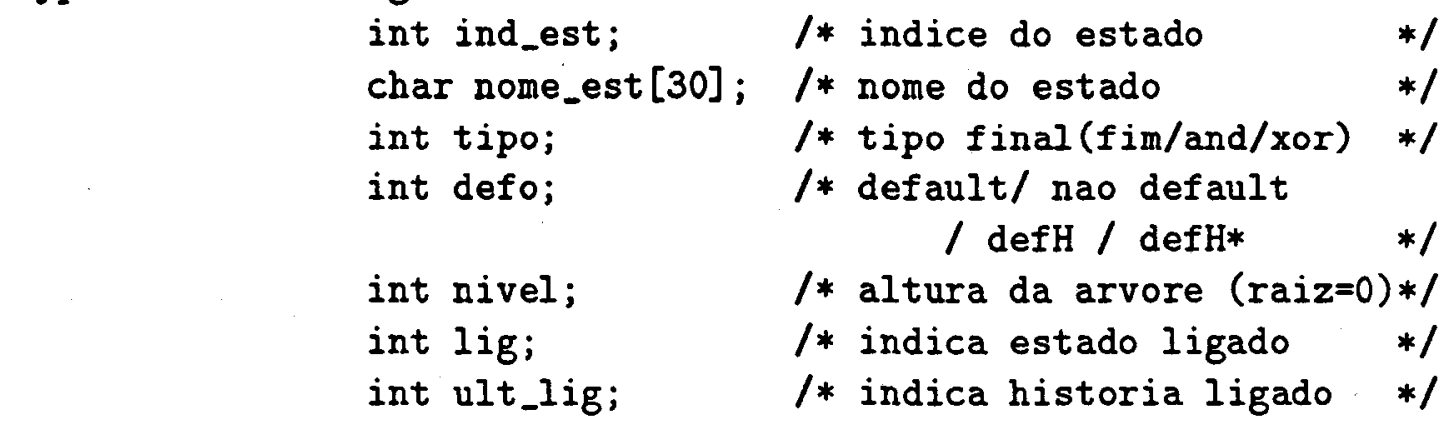

\}REGISTRD_EST;

/*-1

/***** registro a ser gravado para TABELA DE EVENTOS $* * * * * * * * * * * * * * * * * /$ typedef struct regis_ev \{

$\begin{array}{lll}\text { int ind_ev; } & / * \text { indice do evento } & * / \\ \text { char nome_ev[30]; } & / * \text { nome do evento } & * / \\ \text { int qtdd_trans; } & / * \text { qt. trans relativas ao evento } * /\end{array}$

\}REGISTRO_EV;

/*-

/** registro a ser gravado para TABELA DE TRANSICOES *****************/ typedef struct regis_tr \{

$\begin{array}{lll}\text { int ind_tr; } & / * \text { indice da transicao } & * / \\ \text { int qt_pol; } & / * \text { quantas linhas-pol } & * / \\ \text { int ind_estf; } & / * \text { ind do estado-fonte } & * / \\ \text { int ind_estd; } & / * \text { ind do estado-dest } & * / \\ \text { char h[4]; } & / * \text { historia: H / H* } & * / \\ \text { char acao[30]; } & / * \text { acao disparada por trans } & * / \\ \text { int nro_sub_tr_f; } & / * \text { nro de est_fontes paralelos } \\ \text { int nro_sub_tr_d; } & \text { na sub_trans nro de est_dest paralelos } \\ & \text { na sub_trans }\end{array}$

\}REGISTRO_TR;

/*---0---

/**registro a ser gravado p/ as TABELAS DE SUB-TRANSICOES ************/ typedef struct regis_sub_tr \{

char ind_est;

/* indice do estado

char $h[4]$;

/* historia: H / H* 
JREGISTRO_SUB_TR;

|*--

/*** registro a ser gravado para as tabelas PILHAS-POLONESAS *********/ typedef struct regis_polon \{

\}REGISTRO_POL; int tipo_item; $/ *$ tipo do item a ser avaliado $* /$ int ind_item; $/ *$ indice do item $* /$

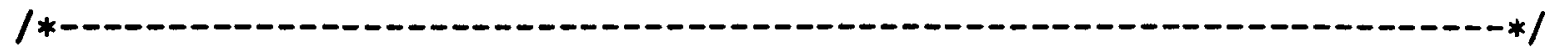

/****** registro a ser gravado para as TRANS_EVENTOS $* * * * * * * * * * * * * * * * * /$ typedef struct regis_trans_ev \{ int ind_ev; $/ *$ indice do evento $* /$ int ind_tr; $\quad / *$ indice da transicao */

\}REGISTRO_TRANS_EV;

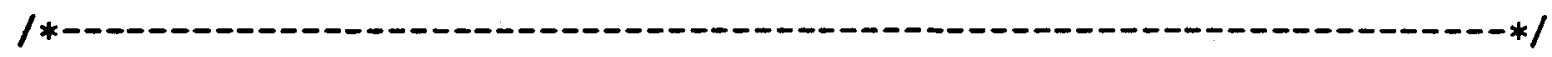
$/ * * * * * *$ registro a ser gravado para a TABELA DE VARIAVEIS $* * * * * * * * * * * /$ typedef struct regis_vars \{

int ind_var;

/* indice da variavel */

int tipo_var;

/* tipo da variavel */

union \{

int valor_i;

float valor_f;

char valor_byte;

char *valor_s;

\} u;

/* valor da variavel */

char nome_var[30];

/* nome da variavel */

\}REGISTRO_VARS; 
